\title{
Using Growth Curve Modeling to Describe Differential Patterns of Change in College Level Student Academic Achievement across Four Years Based on Degree Attainment and Mathematics Remediation
}

Zornitsa Georgieva

Follow this and additional works at: https://researchrepository.wvu.edu/etd

\section{Recommended Citation}

Georgieva, Zornitsa, "Using Growth Curve Modeling to Describe Differential Patterns of Change in College Level Student Academic Achievement across Four Years Based on Degree Attainment and Mathematics Remediation" (2015). Graduate Theses, Dissertations, and Problem Reports. 5662.

https://researchrepository.wvu.edu/etd/5662

This Dissertation is protected by copyright and/or related rights. It has been brought to you by the The Research Repository @ WVU with permission from the rights-holder(s). You are free to use this Dissertation in any way that is permitted by the copyright and related rights legislation that applies to your use. For other uses you must obtain permission from the rights-holder(s) directly, unless additional rights are indicated by a Creative Commons license in the record and/ or on the work itself. This Dissertation has been accepted for inclusion in WVU Graduate Theses, Dissertations, and Problem Reports collection by an authorized administrator of The Research Repository @ WVU.

For more information, please contact researchrepository@mail.wvu.edu. 
Using Growth Curve Modeling to Describe Differential Patterns of Change in College Level Student Academic Achievement across Four Years Based on Degree Attainment and Mathematics Remediation

\author{
Zornitsa Georgieva \\ Dissertation submitted \\ to the College of Education and Human Services \\ at West Virginia University \\ in partial fulfillment of the requirements for the degree of \\ Doctor of Philosophy in \\ Education/Learning, Instructional Design and Technology \\ Reagan Curtis, Ph.D., Chair \\ Marjie Flanigan, Ed.D., Committee Member \\ Karen Rambo-Hernandez, Ph.D., Committee Member \\ Neal Shambaugh, Ph.D., Committee Member \\ Sam Stack, Ph.D., Committee Member
}

Department of Learning Sciences and Human Development

Morgantown, West Virginia

2015

Keywords: undergraduate education, degree completion, academic performance, mathematics remediation

\author{
Copyright 2015 Zornitsa Georgieva
}




\begin{abstract}
Using Growth Curve Modeling to Describe Differential Patterns of Change in College Level Student Academic Achievement across Four Years Based on Degree Attainment and Mathematics Remediation
\end{abstract}

\begin{abstract}
Zornitsa Georgieva
There is a focus on increasing the number of college degrees on national and state levels and a move toward performance-based funding for institutions of higher education. With these shifts, institutions need to study not only student persistence but student progression toward degree completion as well. This institutional case study of a single liberal arts four-year institution utilized academic momentum theory to examine college student academic performance trajectories across four years. Academic momentum theory poses that student initial academic progress defines a trajectory of subsequent progress and degree completion. Growth curve modeling was used to examine changes in student performance over time. Three research questions were investigated. The first research question addressed the initial level of student performance and growth trajectory between the first and eighth semester of enrollment. The second research question examined if the academic performance growth differed for students who graduated versus those who did not. The third research question investigated if successful mathematics remediation and graduation were significantly associated with student academic performance growth. The results revealed that students experience initial decline in academic momentum followed up by a recovery during the second and third year of enrollment and eventual growth in performance. Those who completed degrees at the institution showed a pattern of initial loss of academic momentum but regaining of momentum by the junior year. In comparison, those who did not complete a degree showed a consistent decline in academic performance across all semesters. The trajectory of those who were successfully remediated and completed a degree mimicked that of their college ready peers, even though they had lower initial GPA. The second and third year of college enrollment emerged as potential intervention points for boosting academic momentum and promoting student success. Further examinations are necessary to determine what events take place during the second and third year and influence the differential patterns of student performance. In addition, future investigations should study any gender differences in the performance trajectories.
\end{abstract}




\section{Table of Contents}

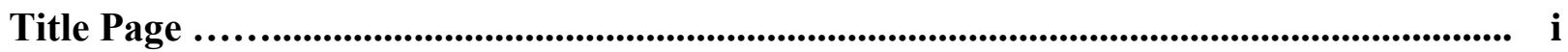

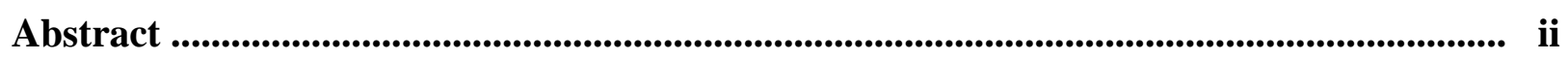

Table of Content .............................................................................................................................. iii

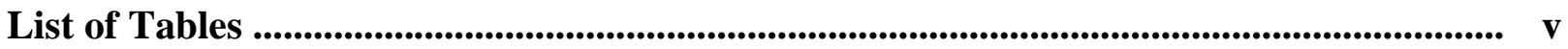

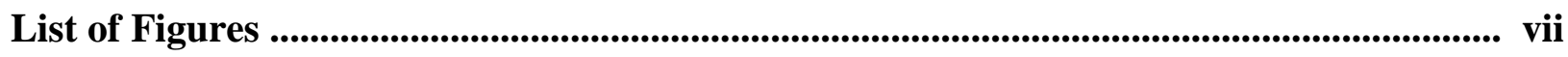

Chapter 1: Introduction ......................................................................................................... 1

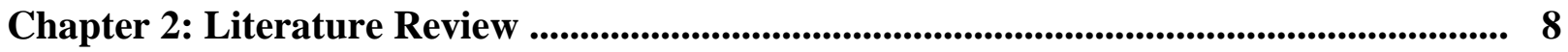

Theory of Academic Momentum ............................................................................ 9

A Shift in Examination From first Years to Later College Career .................................... 11

Secondary Education Performance and Experiences and Their Impact on Higher

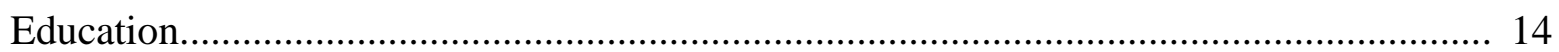

Post-Secondary Performance across College Career .................................................. 22

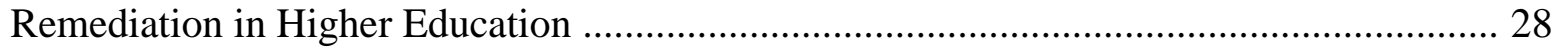

Institution-Centered Examinations in Higher Education .......................................... 33

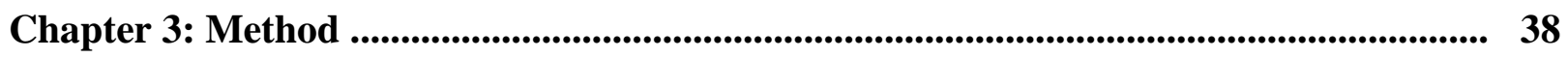

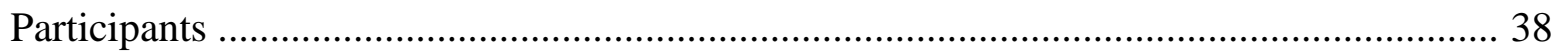

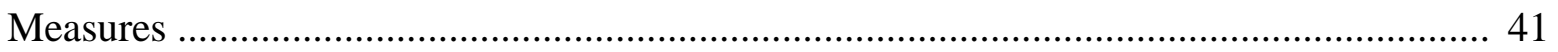

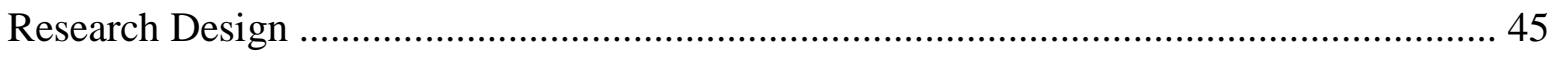

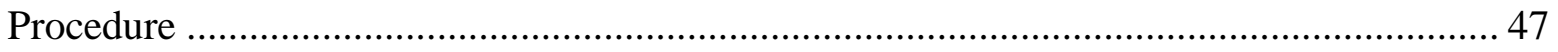

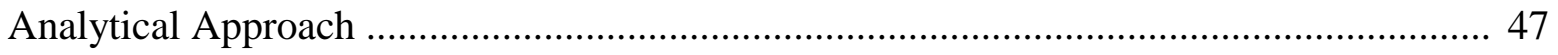

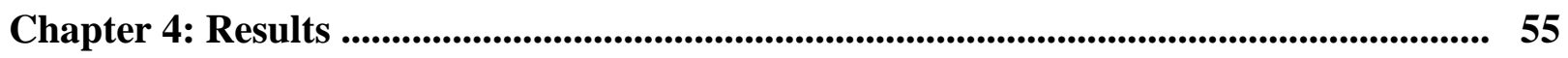

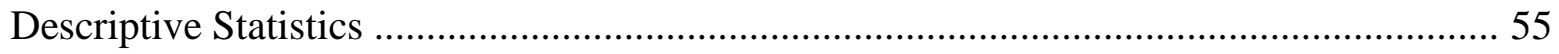

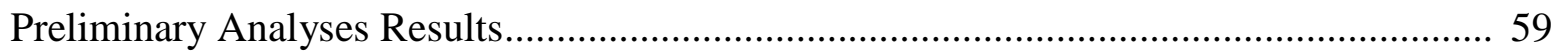

RQ1: What is the average initial level of academic performance and growth trajectory of all students from the first through the eighth semester of enrollment? .............................. 61

RQ2: Does academic performance growth differ for college students who graduate versus

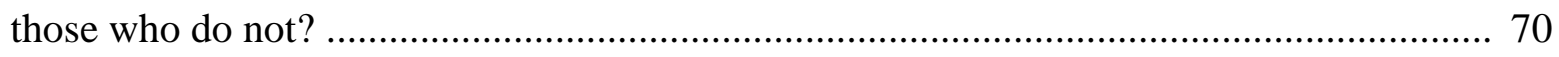

RQ3: Is successful mathematics remediation and graduation status significantly associated with student academic performance growth? ........................................................... 75 
Chapter 5: Discussion ................................................................................................................. 87

Initial Level and Changes in Academic Performance ............................................... 87

Beyond the First Year in College ...................................................................... 89

Differences in Growth Trajectories Based on Graduation .......................................... 93

Differences in Growth Trajectories Based on Graduation and Remediation .................... 96

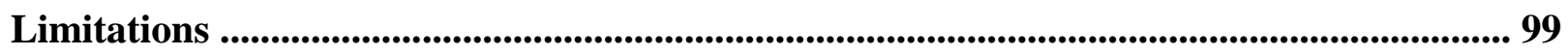

Data and Methodological Considerations ............................................................. 99

Academic Momentum Theory Considerations ........................................................ 101

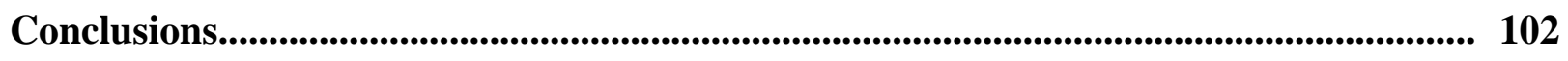

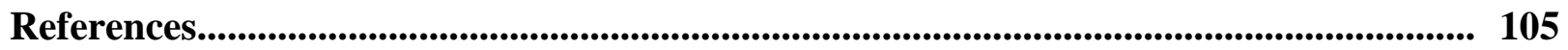

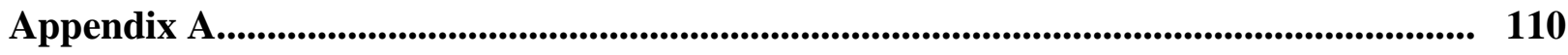

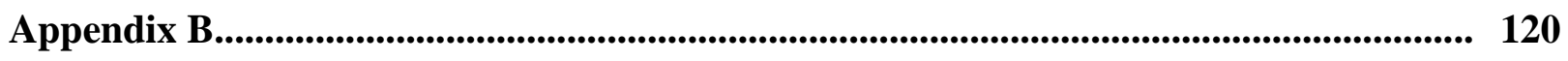

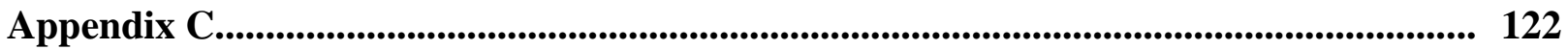




\section{List of Tables}

\begin{tabular}{clr}
\hline Table & \multicolumn{1}{c}{ Name } & Page \\
\hline 3.1 & Sample Sizes for Each Cohort Included in the Analyses & 39 \\
3.2 & Ethnic Distribution of the Sample & 40 \\
3.3 & Sample Descriptive Statistics for ACT Scores, SAT Scores, and High School & 41 \\
& GPA
\end{tabular}

3.4 Sample Descriptive Statistics for Cumulative College GPA and Cumulative Earned Hours

3.5 Cumulative College GPA Mean and Standard Deviation for Non-Graduates and Graduates

3.6 Cumulative College GPA Mean and Standard Deviation for Students Not Successful at Remediation, Successful at Remediation, and College Ready

3.7 Proportion of Missing Data for Each Semester 48

3.8 Test for Normal Distribution of GPA for Each Semester 49

4.1 Descriptive Statistics, Skew, and Kurtosis for Student GPA for Semesters 1 through 8 for the Overall Sample

4.2 Means and Standard Deviations for Student GPA for Semesters 1 through $8 \quad 57$ Based on Graduation Status

4.3 Means and Standard Deviations for Student GPA for Semesters 1 through $8 \quad 58$ Based on Mathematics Remediation Status

4.4 Pairwise Correlations across Semester GPA 59

4.5 Parameter Estimate for Two-Level Growth Curve Models of College GPA 62

4.6 GPA Means and Standard Deviations for Each Semester across the Four 65 Cohorts 
4.7 Fixed Effects for the Hierarchical Model with Cohort Effects 67

4.8 Random Effects for the Hierarchical Model with Cohort Effects 68

4.9 Fixed Effects for the Hierarchical Model with Cohort Effects 69

4.10 Random Effects for the Hierarchical Model with Cohort Effects 70

4.11 Fixed Effects for the Hierarchical Model Based on Student Graduation 73

4.12 Random Effects for the Hierarchical Model Based on Student Graduation 74

4.13 Means and Standard Deviations of Student GPAs from Semester 1 through 76

Semester 4 Based on Successful Mathematics Remediation and Graduation

Status

4.14 Fixed Effects for the Hierarchical Model Based on Student Graduation and 78

Successful Remediation in Comparison to Unsuccessful Remediation

4.15 Random Effects for the Hierarchical Model Based on Student Graduation and 79

Successful Remediation in Comparison to Unsuccessful Remediation

4.16 Means and Standard Deviations of Student GPAs from Semester 1 through 81

Semester 8 Based on Successful Mathematics Remediation and No

Remediation and Graduation Status

4.17 Fixed Effects for the Hierarchical Model Based on Student Graduation and $\quad 82$

Successful Remediation in Comparison to No Remediation

4.18 Random Effects for the Hierarchical Model Based on Student Graduation and

Successful Remediation in Comparison to No Remediation 


\section{Lists of Figures}

\begin{tabular}{|c|c|c|}
\hline Figure & Name & Page \\
\hline 2.1 & $\begin{array}{l}\text { Associations across variables examined in the past literature and relations to be } \\
\text { investigated in the current study. }\end{array}$ & 35 \\
\hline 3.1 & $\begin{array}{l}\text { Two-level model for student academic achievement with graduation and remediation } \\
\text { predictors }\end{array}$ & 51 \\
\hline 4.1 & $\begin{array}{l}\text { Average student academic performance across semesters for students included in the } \\
\text { analyses and students excluded in the analyses. }\end{array}$ & 56 \\
\hline 4.2 & Depiction of linear and nonlinear trajectories across eight semesters & 61 \\
\hline 4.3 & Mean GPA for each semester from semester 1 through semester 8 for Cohort 1 & 63 \\
\hline 4.4 & Mean GPA for each semester from semester 1 through semester 8 for Cohort 2 & 64 \\
\hline 4.5 & Mean GPA for each semester from semester 1 through semester 8 for Cohort 3 & 64 \\
\hline 4.6 & Mean GPA for each semester from semester 1 through semester 8 for Cohort 4 & 65 \\
\hline 4.7 & $\begin{array}{l}\text { Model of GPA growth for graduates and non-graduates between semester } 1 \text { and } \\
\text { semester } 8 \text { of enrollment }\end{array}$ & 74 \\
\hline 4.8 & $\begin{array}{l}\text { Model of GPA growth for graduates and non-graduates and those successful at } \\
\text { remediation and those who were not successful between semester } 1 \text { and semester } 4\end{array}$ & 80 \\
\hline 4.9 & $\begin{array}{l}\text { Model of GPA growth for graduates and non-graduates and those successful at } \\
\text { remediation and those who did not require remediation between semester } 1 \text { and } \\
\text { semester } 8\end{array}$ & 86 \\
\hline
\end{tabular}




\section{Chapter 1}

\section{Introduction}

While college attendance has increased over past decades, no significant increase has been observed in the proportion of the general population with college degrees (Barton, 2002; Horn, Berger, \& Carroll, 2004). A question arises because of this growth in college-going rates with no related increase in degree recipients: What happens during college that inhibits students' chances of degree completion? In college retention and graduation literature, academic performance emerges as a consistent factor associated with college persistence and degree completion (e.g., DeBerard, Spielmans, \& Julka, 2004; Murtaugh, Burns, \& Schuster, 1999). Therefore, examining student academic performance progression though college may provide insight into how academic performance changes over time. Such examination may reveal if college graduates tend to exhibit different academic development trajectories in comparison to those who leave college without a degree, thus providing new and valuable information for institutions to revise their "at-risk" student policies and provide better support for students on their path to degree completion.

Efforts to increase rates of college attendance and degree completion have been a major focus during the past two decades. Some improvement in college going rates is evident. The National Center for Educational Statistics (2014) reports that in 2012 about $66 \%$ of all high school completers (regular high school graduates and GED recipients) enrolled in 2-year or 4year institutions during the fall immediately after high school completion. This is a six percent increase from the 1990's. Although a greater proportion of this increase is driven by enrollment in two-year institutions which grew from $20-25 \%$ in 1990 s to $21-29 \%$ in 2012 , a large percentage 
of the college- going population still enrolls in four-year institutions. About $40 \%$ of high school graduates opt to enroll in four-year colleges and universities.

Trends differ based on student gender, ethnicity/race, and income levels (Horn et al., 2004). For example, female students currently go to college at a higher rate than males. The proportion of males enrolling in two-year institutions is increasing while the population of males enrolled in four-year institutions decreased in the last decade. Similarly, more females choose the two-year track while the number of female students enrolling in four-year institutions increased only slightly in comparison to the early 2000's. Students of all income levels seem to attend college at a higher rate even though the growth in the low income student population is much faster in comparison to those in middle and high income brackets (Horn et al., 2004; NCES, 2014). Trends seem to differentiate in terms of ethnicity as well. The proportion of white students going to college remains relatively stable but the proportion of college-goers from other ethnic groups is increasing.

There are a number of factors that impact changes in college going trends. These factors are interrelated and they all contribute to the greater number of students entering postsecondary education. The first factor associated with higher college going rates is the number of high school graduates. Stillwell and Sable (2013) report that high school graduation rates are currently at their highest in the last three decades. While this is true when examining the nationwide trends, some states (e.g., Iowa, Maine, and West Virginia) show a decrease in the number of traditional high school graduates (NCES, 2012). Because the majority of college goers are traditional age high school graduates, secondary education graduation rates provide the main "supply" of potential students to higher education. 
Greater access to higher education also impacts the number of students attending college (U. S. Department of Education, 2009). In the first part of the twentieth century, college was reserved only for the social elite. After World War II, the creation of the G.I. Bill allowed many students to enter college, who historically did not have access to higher education. In addition, greater opportunities for educational attainment has been emphasized through legislation like the War on Poverty in the 1960's and the creation of federal programs (e.g., TRIO), which provide services to students from disadvantaged backgrounds to progress through the educational pipeline. Today more than ever before, the existence of greater access is evident in the number of first generation college students who enter higher education institutions (NCES, 2014).

Accessibility is one aspect of higher education but affordability is what some claim really counts for the average college student (Bettinger, 2004). For example, the G.I. Bill not only provided the opportunity for many to attend college but also the funding to do so. The process of applying and receiving federal financial aid was streamlined in 2009 to promote college going, especially for low and middle-income students (U.S. Department of Education, 2009). Affordability was addressed by increasing the amount of federal grants for those who qualify (e.g., Pell Grant) and eligibility for other financial resources like educational loans becoming more immediate. Thus, students today can estimate instantaneously, whether they are eligible for enough financial aid to cover the cost of college. While the absolute amounts of student aid and available funds for distribution have increased, there is debate whether this increase is comparable to increases in cost (Barton, 2002).

These and other policies and regulations ensure that students have greater access to higher education and funds necessary for this education. Higher education policies are often driven by national and state initiatives to increase college going rates and the number of college 
graduates. For example, the state of West Virginia has set a goal of 40,000 college degrees (associate and bachelor) by 2025 (Higher Education Policy Commission, 2009). On a national level, current policies and efforts emphasize college completion in addition to college attendance (Horn et al., 2004; U.S. Department of Education, 2009).

While changes in college going rates are observed, it is important to also consider changes in college persistence and degree completion. After all, access does not automatically guarantee a degree for those who enter postsecondary education. The overall persistence rates are on the rise (Horn et al., 2004). However, differences across student subpopulations do exist. For example, females persist and graduate at a higher rate than males, as do non-minority students in comparison to ethnic minorities (Ross et al., 2012).

Capturing college attendance, retention, and graduation trends are results from an increased emphasis on institutional accountability in higher education. In the 1970s and 1980s, institutions began collecting and reporting student academic performance data in a systematic manner for accountability purposes (Ewell, 2008). In 2006, the Voluntary System of Accountability (VSA) was developed by the National Association of State Universities and Land-Grant Colleges (NASULGC) and the American Association of State Colleges and Universities (AASCU). Common metrics for graduation and retention rate statistics were included as a part of this system.

Historic trends of persistence and degree completion paint a different picture than the optimism streaming from improved higher education enrollment. Students persist at a higher rate but also tend to stay longer in school than they once did. Horn et al. (2004) found that students were more likely to be enrolled in higher education five years after their initial enrollment. While this does not necessarily represent continuous enrollment, many students do take longer than four 
years to complete a degree. Further, no significant increase in the proportion earning college degrees has been recorded (Barton, 2002). Even though graduation rates vary somewhat across different types of institutions, a quick examination of the last decade shows that the change in graduation rates is small. For all students, about 35\% who started at 4-year institutions and $46 \%$ of those who initially enrolled in 2-year institutions have exited higher education by year 6 of their enrollment-without completing any type of a degree or a certificate (Radford, Berkner, Wheeless, \& Shepherd, 2010). Ross et al. (2012) report that about 58\% of students who start at a 4-year institution as full time students complete a degree by their 6th year in the higher education system. The graduation rates numbers have stagnated since the 1970s (Barton, 2002).

The economic aspect of the issue is also a consideration for institutions of higher education. More states are moving toward performance-based funding. Along with accountability, performance metrics, including student progress indicators and graduate rates are tied to institutional funding (Alexander, 2000; Friedel, Thornton, D'Amico, \& Katsinas, 2013). This a shift from the input-based system to outcome-based approaches (Alexander, 2000). As performance-based funding gets adopted by more states, institutions will feel the extra pressure to ensure that they receive adequate funding to provide services (Friedel et al., 2013). Considering the already decreasing federal funding for public two-year and four-year institutions over the past decade, receiving sufficient funding will be a matter of survival especially for smaller and less selective institutions (National Center for Educational Statistics, 2013). Institutions will need to be more effective in serving students and supporting their progression to ensure they receive funding.

Another aspect of the higher education access and completion debate is the issue of remediation. Even though remediation dates back to the 1600s (Spann \& McCrimmon, 1993), a 
number of states (e.g., Connecticut, New York) have introduced policies that place restrictions on remedial coursework offerings in higher education institutions (Bastedo \& Gumport, 2003; Fain, 2012). A dilemma arises. On one hand, there is a greater push to eliminate remediation from four-year institutions while on the other hand a significant portion of students need remediation (Merisotis \& Phipps, 2000). As a result, about $80 \%$ of public four-year institutions and almost $100 \%$ of public two-year institutions currently offer remedial level courses (Parsad \& Greene, 2003). Students who needs remediation are quite diverse and include students from suburban areas (38\%), rural areas (40\%), and urban high schools (52\%), with $52 \%$ of students coming from the lowest quartiles of SES but also $24 \%$ representing the highest quartile (Attewell, Lavin, Domina, \& Levey, 2006). There are considerations for possible impacts on student access and stratification as a result of restrictions in remediation (Bastedo \& Gumport, 2003). The question to be investigated revolves around remediation's role and impact, if any, on degree attainment.

Adelman (1999) emphasized that degree completion is what counts for college administrators and policy makers, but most of all for students. Persistence without a degree is not beneficial because higher education persistence does not automatically correspond to degree completion. In addition, public use of institutional graduation rates is increasing. These rates are often utilized as measures of accountability and institutions themselves are being held responsible for degree completion and degree completion in a timely manner (Adelman, 1999).

Because of the discrepancy between growth in the number of students who enter higher education and growth in completion rates (Barton 2002), it becomes critical to examine what happens in higher education between student entry and student exit. Such examination is especially essential for those who persist but do not graduate. Even though graduation rates are 
often examined within six year timeframes, Horn et al. (2004) found that the percentage of students who actually graduate past the fourth year markedly declines relative to the those who complete their degree within four years. This is another reason to look closely at the longitudinal development of college student careers to identify critical time points and potential intervention foci to further facilitate college graduation. After all, as Barton (2002) points out, "a considerable resource available to increase the rate of college graduation lies in the large group of young people who start college but do not finish" (p. 11). Therefore, the research questions addressed in this dissertation are:

1. What is the average initial level of academic performance and growth trajectory of all students from the first through the eighth semester of enrollment?

2. Does academic performance growth differ for college students who graduate versus those who do not?

3. Is successful mathematics remediation and graduation status significantly associated with student academic performance growth?

a) Does initial level of academic achievement and performance growth differ for students who were successfully remediated in comparison to those who were not, taking into account if they attained a degree or not?

b) Does initial level of academic achievement and performance growth differ for students who were successfully remediated in comparison to those who did not need remediation, taking into account if they attained a degree or not? 


\section{Chapter 2}

\section{Literature Review}

Two large bodies of literature that inform research on college success are considered in the current examination: secondary academic achievement and postsecondary academic performance. On the high school level, researchers have utilized indicators of academic performance including high school GPA, high school ranking, and standardized test scores like ACT or SAT, for the prediction of college success (e.g., Bean, 1985; Fletcher \& Tienda, 2009). Recently, other relevant factors (high school curriculum and advanced placement coursework) also have been considered as contributors to performance measures and their associations with college success (e.g., Adelman, 1999; Geiser \& Santelices, 2004). In addition to secondary education metrics, examinations of early college GPA and college credits accumulation also contribute to the field of college success research. Consideration of both secondary and postsecondary educational experiences is expected because student education is a continuum. Students transition into postsecondary education by bringing their pre-college knowledge, skills, and experiences. Because of this growth nature of education, researchers are moving away from a static examination of college success and toward longitudinal investigations to capture changes that occur over time.

Two theories commonly employed in higher education retention examination are the causal model of student attrition (Bean, 1980) and Tinto's dropout model (Tinto, 1975). Both models examined student success in terms of continuous student enrollment and looked at factors impacting dropout decisions. Bean (1980) identified institutional level factors (e.g., institutional quality, housing), student background characteristics (e.g., SES, hometown size), and the results of interactions between those (e.g. performance, satisfaction, institutional commitment) as areas 
impacting student decision to remain enrolled. Similarly, Tinto (1975) acknowledged those factors but framed their impact in terms of student integration (social and academic).

Furthermore, Tinto emphasized the longitudinal nature of the dropout phenomenon and viewed it as "a longitudinal process of interactions between the individual and the academic and social systems of the college" (p. 94) but he did not examine how that process changed over time. Another aspect which was not explicitly addressed in these two theories was degree completion. Retention is necessary for degree completion. However, longer college enrollment does not always reflect degree attainment. A third theory, academic momentum, encompasses both the longitudinal and degree completion aspects of student success (Adelman, 1999, 2006; Attewell, Heil, \& Reisel, 2012). This dissertation draws on the theory of academic momentum to better understand college student development.

\section{Theory of Academic Momentum}

The theory of academic momentum examines student progression longitudinally and focuses on student completion (Adelman, 1999, 2006; Attewell, et al., 2012). Specific to undergraduate education, academic momentum emphasizes three aspects. Firstly, initial student academic course load and student progress define a trajectory that influences subsequent progress and ultimately degree completion. The second aspect is that academic momentum is strongly associated with degree completion even after variability due to student demographic and socioeconomic characteristics and pre-college achievement and preparation are accounted for. The third aspect is that student participation in specific academic activities (e.g., taking summer courses) and student patterns of enrollment (e.g., continuous enrollment versus stopping out) influence academic momentum and degree completion. 
Similar to momentum in physics, where momentum is defined as the tendency of an object in motion to continue moving, academic momentum focuses on the speed of student progression through college and continuity of college enrollment. High academic momentum is associated with relatively heavy course load, high performance, and continuous enrollment while lower momentum may be associated with any of the following: taking fewer credits, including being a part-time student; experiencing low academic performance; or discontinuing one's enrollment in the educational pipeline, even temporarily. Because of the way momentum is defined, natural variability in momentum across college student careers is expected. However, any significant loss in momentum, especially early in college, is associated with reduced chance of graduation (Attewell et al., 2012).

Even though this theory focuses on bachelor degree completion, the initiation of academic momentum is associated with secondary education. In his initial examination, Adelman (1999) found that the two most important predictors in 4-year college completion were academic resources and continuous enrollment. Academic resources encompass academic content and performance achieved in secondary education. Adelman found that test scores, class rank, and high school GPA were relatively weak predictors relevant to academic momentum. However, high school curriculum, and particularly curriculum intensity and quality, are what made the difference for degree completion. In addition, Adelman determined that trend in college grades was one of the predictors with the highest odds ratios relative to degree attainment.

Under academic momentum theory, student demographic profile has limited impact on student progression toward degree completion. While much literature exists around sociodemographic characteristics of students relative to their college education, Adelman (1999) found that once past the first year in college, student SES was only a very modest predictor of 
degree completion. He discovered that students from low SES who experienced high intensity and quality high school curriculum have higher degree completion rates than those coming from high SES backgrounds with relatively poor high school curriculum. This finding is a possible indicator that any interventions designed to impact academic momentum do not need to target specific student subpopulations but rather should be implemented across all students regardless of their socio-demographic characteristics.

Specific academic activities and enrollment patterns also are an integral part of the academic momentum concept. For example, taking summer courses can have a positive impact on student academic momentum while discontinuing school enrollment (e.g., taking a break after high school and delaying one's enrollment in college) slows momentum. Adelman (1999) found that students who enter postsecondary education immediately after high school graduation complete bachelor degrees at a higher rate than all other students. Not only continuous enrollment in the postsecondary system, but continuous enrollment throughout the educational pipeline is associated with maintaining high academic momentum and therefore degree attainment.

\section{A Shift in Examination from First Years to Later College Career}

Historically, the first year in college has been found critical for student college careers and particularly for student retention (Tinto, 1996, 1999). The freshman year in college has been deemed critical for a number of reasons. First, when considering retention, college students leave at higher rates during or immediately after their first year in college (Horn \& Carroll, 1998). Mortenson (2005) reported that about $30 \%$ of students leave during or after their first year in college. First years are a transitional period when students adjust to the new rules and requirements of higher education. While transitional periods exist between any two consecutive schooling levels, for example from elementary to middle school (e.g., Cauley, \& Jovanovich, 
2006) or from middle school to high school (e.g., Bottoms, 2002; Cauley \& Jovanovich, 2007), the transition to college has been examined in greater depth.

Because of research pointing toward the importance of the first year in college, numerous interventions have been designed to address transition to higher education. The main idea of these interventions is that targeting the specific challenges associated with the transition may better facilitate the adjustment of students to the new college environment (Goodman \& Pascarella, 2005). One of the most common support mechanisms is first-year seminar (Pascarella \& Terenzini, 2005). According to Pascarella and Terenzini (2005), as much as $95 \%$ of all fouryear institutions in the US offer some type of freshman seminar course. Even though they vary widely across institutions, these and similar programs focus on promoting student success, including success in gateway courses and psychological adjustment for new academic expectations (Chemers, Hu, \& Garcia, 2001; Kuh, Cruce, Shoup, Kinzie, \& Gonyea, 2008; Tinto, 1996). In their synthesis of significant research on first-year retention, Pascarella and Terenzini found that first year seminars tend to be effective in increasing student retention from first to second year in college. Still, many of these examinations focused exclusively on the events in the first year and few include focus on students' second year in college or beyond (e.g., Kuh et al., 2008).

Examining the post-freshmen years is an understudied need in the field of for postsecondary educators. Practitioners recognize that the first year, while critical, is not the only time of risk when students leave the educational pipeline. Cheng, Ickes, and Verholfstadt (2012) examined change in student GPA over three semesters as a gauge of college success. Pascarella and Terenzini (2005) found some evidence that first-year seminar participants were more likely to graduate within four years in addition to other positive impacts (e.g., higher grades), thus 
extending common freshman experience course examination beyond the first year in a more longitudinal approach. Lord, Bjerregaard, and Hartman (2013) omitted the examination of the first years of postsecondary education and focused on later college student careers when students tend to enroll in upper level courses. Others have focused on students in later phases (third year) as a more accurate picture of students' academic success (e.g., Allen, Robbins, Casillas, \& Oh, 2008).

In addition to shifting research focus to later phases of students' college careers, educational researchers began studying higher education issues over longer periods of time. Bean (1985) considered drop-out across different classes (freshman, sophomore, juniors, and seniors) rather than just first year. Ishitani (2003) provided more evidence that even though there is a decrease in chances for dropping out in the third and fourth year in college, persistence is still an issue. Even though longitudinal examinations of college students were conducted in the 1980s (e.g., Bean, 1985), only recently have they become more common (e.g., Ishitani, 2003; Tumen, Shulruf, \& Hattie, 2008).

As a result of current examinations focusing beyond first year, researchers have become aware of multiple critical periods for college success, each with unique challenges and opportunities. A significant proportion of students persist past their sophomore year but still fail to graduate (Radford et al., 2010). Therefore, as the question expands from persistence-only to persistence and graduation, longitudinal designs become of "critical importance" (Goodman \& Pascarella, 2006, p.28). Nora, Barlow, and Crisp (2005) argue for in-depth longitudinal data exploration. That necessity is driven by the trend where a number of students remain enrolled in college in their third, fourth, and fifth year of studies but still fail to successfully complete a degree. Therefore, as Ishitani (2003) calls for longitudinal examinations, he points out that in 
order to better understand student success, it is important to examine "risk periods and knowing the risk over time" (p.447).

\section{Secondary Education Performance and Experiences and Their Impact on Higher}

\section{Education}

If education is considered a continuum of student progress from high school to college, it is plausible to assume that secondary education has an impact on postsecondary education. Academic momentum theory acknowledges the importance of students' high school experiences and preparation for gaining high initial momentum in college. High school performance, captured as high school grade point average or class ranking, is often a criteria for college admission but also has been examined as a predictor for college performance and college completion (e.g., Bean, 1985; Martin, Wilson, Liem, \& Ginns, 2013; Tumen et al., 2008). There are five main aspects of secondary education most commonly examined in relation to postsecondary performance, persistence, and graduation. These include high school grade point average, high school rank, high school curriculum, advanced placement or other college

preparatory coursework, and college admissions tests (e.g., SAT, ACT). Even though it could be argued that college admission tests are not necessarily related to high school preparation, because many students complete those during their junior and senior year of high school, this performance indicator will be reviewed here as a secondary education metric.

High school grade point average. Almost three decades ago, Bean (1985) found that high school GPA and high school performance was the best predictor of college GPA for each class standing, including freshman, sophomore, junior, and senior. Even though Bean focused on white students who enrolled full time, there is evidence that high school GPA is a significant predictor of college GPA in the examination of other student subgroups. For instance, in a 
longitudinal analysis of Latina/o college students, Bordes-Edgar, Arredonso, Kurpius, and Rund (2011) found that high school GPA was the most powerful predictor when considering cumulative GPA 4.5 years after college entrance. In their examination, high school GPA alone accounted for $16.2 \%$ of the variance in final college GPA. These findings are somewhat inconsistent with other examinations, which concluded that high school GPA shows association only with early college performance. For example, Martin et al. (2013) found that high school achievement was a significance predictor for academic achievement during the first and second year of college but its impact diminished over time. Similarly, Noble and Sawyer (2002) determined that high school GPA was a better predictor than ACT scores but only for 2.00, 2.50, and 3.00 levels of first-year college GPA. The greater predictive power of high school GPA over SAT in relation to first-year college GPA was confirmed by Zwick and Scklar (2005) as well, even though they determined that there was a differential predictive accuracy across ethnic groups.

In addition to association between high school GPA and college GPA, there is a body of literature that examines the predictive power of secondary level achievement in relation to postsecondary education persistence and degree attainment. High school grade point average was a significant predictor for persistence (Wintre \& Bowers, 2007). Tumen et al. (2008) found that previous achievement on a secondary level was significant for on-time completion but not for completion beyond the on-time cut off. Bordes-Edgar et al. (2011) examined college graduates and non-graduates from the same cohort and determined that those who graduated had higher high school GPA. High school GPA was also found a significant predictor for college completion as examined by Zwick and Sklar (2005) but only for white English-speaking students. 
Even though high school GPA is commonly utilized in the college admissions process and many researchers include it in their college success models, there are certain limitations of utilizing high school GPA as a predictor. High school GPA is inherently biased as it does not account for differences in high school curricula including rigor or difficulty of coursework. In addition, grade inflation and inconsistent grading practices across various teachers, schools, and school districts may be responsible for inconsistent and perhaps inaccurate estimation of high school impact on numerous college measures. Thus, researchers often look for alternatives to high school GPA to estimate student prior-to-college learning and achievement.

High school rank. Apart from high school GPA, many utilize high school ranks as a measure of prior academic achievement. One perceived advantage of high school ranks is that they could be considered a norm-referenced measure where students are compared to their classmates and for that reason high school ranking could be a more accurate indicator of precollege achievement than high school GPA. Similarly to high school GPA examinations, those who examine high school rank focus on various metrics relative to college progression including freshman to sophomore year persistence (e.g., Cabrera, Nora, \& Castaneda, 1992; Kahn \& Nauta, 2001), later years' persistence (e.g., Fletcher \& Tienda, 2009), and college GPA (e.g., McKenzie \& Gow, 2004).

When focusing on college performance, McKenzie and Gow (2004) found that higher high school ranks were associated significantly with higher achievement during the first and second semesters in college. These findings were confirmed by Fletcher and Tienda (2009) who examined high school ranking rather than high school GPA and found significant association with college GPA and college persistence as measured between the fourth and fifth semester. Persistence from freshman to sophomore year was also significantly predicted by high school 
rank according to Kahn and Nauta (2001). However, Cabrera et al. (1992) found that high school ranking was not significantly related to actual persistence. A number of other factors included in their model (e.g., college performance, intention to persist) showed much stronger relations than high school ranking.

High school curriculum. Adelman (1999) claimed that neither high school rank nor high school GPA weighted most heavily in preparation for college degree completion. His argument was focused on high school curriculum as central for college preparation. His examination focused on the quality and intensity of high school curriculum and determined that higher quality and intensity was associated with more positive consequences in terms of performance, persistence, and bachelor degree attainment than any other secondary education performance indicator. In his later examination (Adelman, 2006), he concluded that high school curriculum was the sole most important factor for providing the greatest initial academic momentum toward degree completion. He further determined that the highest level of mathematics completed in high school was the key for student progression.

Mathematics was another variable of interest in the examination conducted by Horn, Kojaku, and Carroll (2001). They looked at high school curriculum and its relation to a number of college-related variables. In their examination, they identified three levels of curriculum based on rigor: core curriculum and below, mid-level, and rigorous high school curriculum. The rigorous curriculum included an additional year of mathematics (including pre-calculus or higher), three years of foreign language, and at least one advanced placement course. The rigorous curriculum was associated with higher persistence three years after initial college attendance, lower levels of transferring from the initial institution attended, and higher first year and overall GPA. 
However, Adelman (2006) provided a warning for examining high school curriculum as a measure of prior achievement, claiming that while examining curriculum provides a better picture of student preparation, the issue of rigorous and high level course availability and access should be considered. For example, not all high schools possess the resources and offer upperlevel courses for students. In addition, the requirements relevant to coursework in high school vary vastly and even if schools offer such courses, there is the question of whether students will choose to or will be advised to take them.

College admission tests: SAT and ACT. Another way to avoid the biases inherent to high school GPA is to examine aptitude tests such as the SAT and ACT and their relations to college-level metrics. Even though some two-year institutions do not require SAT or ACT for admission, the majority of students entering four-year institutions are required to complete them. Institutions utilize the scoring of these instruments because of their consistency; the tests provide a viable base for comparison across students or across groups of students.

However, the current literature does not provide consistent evidence of the relation between SAT/ACT and college success. For example, Bordes-Edgar et al. (2011) noticed that even though the difference was not significant, students who were still enrolled in college during their fifth year had lower SAT scores than those who had dropped out. Their initial hypothesis that SAT and ACT would predict subsequent college GPA was not supported. Contrarily, college entrance exams were found as significant predictors in other examinations. For example, Zwick and Sklar (2005) found that after taking high school GPA into account, SAT scores were a significant predictor for college graduation for white and Hispanic English speaking students.

Fletcher and Tienda (2009) found significant associations between student SAT and ACT scores and first semester college GPA, as well as their persistence from second to third year in 
college. Others found that ACT scores could be utilized as an effective predictor for college GPA but these investigations were limited to end of first year cumulative GPA (Gifford, BricenoPerriott, \& Mianzo, 2006; Nora \& Cabrera, 1996). Even though test scores were found to be predictive of college GPA, Nora and Cabrera (1996) found that they did not have any significant effect on decisions related to withdrawal from college. In other words, persistence and academic performance in college may be driven by different factors. Similarly, ACT was not significantly related to first semester persistence (Kahn \& Nauta, 2001). The predictive power of SAT was weakened by the variability explained by high school curriculum (Horn et al., 2001). Kahn and Nauta (2001) warned that pre-college characteristics and college first semester data may not be sufficient to identify students at risk of dropping out. Similarly to other authors, they call for longitudinal examination to gain a better idea of those indicators associated with noncompletion.

Advanced placement and dual enrollment courses. Established in 1955, Advanced Placement (AP) courses were originally designed to provide high school students with an opportunity to take college-level courses and earn college credit while still in high school (Commission on the Future of the Advanced Placement Program, 2001). Because of AP design and intended purpose, it is natural to examine how taking and performing in AP classes may be related to college success (e.g., Dougherty, Mellor, \& Jian, 2006; Geiser \& Santelices, 2004; Klopfenstein \& Thomas, 2009). Furthermore, studies examining high school curriculum and its effect on college performance suggested that AP coursework was an integral part of rigorous curricula and thus could be linked to success in college (Adelman, 1999; Horn et al., 2001). Dougherty et al. (2006) pointed out that taking and passing AP coursework may demonstrate 
ability to be successful at college level work and for this reason there were expectations that AP coursework should be predictive of college performance.

Another trend in secondary education also contributes to the increased interest in examining AP coursework. While initially few students took such courses, there was a significant increase in the number of students and the number of AP exams taken during the 1980s and 1990s (Commission on the Future of the Advanced Placement Program, 2001). With the higher proportion of students gaining exposure and taking such courses, it is vital to examine the strength of the association between AP coursework and college metrics. The majority of examinations relative to AP coursework focus on two specific aspects: enrolling in AP courses without consideration for students taking or passing the AP exam and the actual AP exam score. The AP exam is not a requirement and some students opt out of taking it. Others who are interested in receiving college credit take AP exams and receive a test score. The interest of which one, AP enrollment or AP test performance, is worthwhile investigating comes from the differential impact found of these two measures.

In line with previously examined indicators, the focus here is on student persistence and student performance (as measured by grades) in college. Enrolling in AP courses by itself was very weakly associated with first and second year college persistence and was not predictive of college GPA after controlling for high school GPA, parental education, and SAT scores (Geiser \& Santelices, 2004). However, when in the same examination the performance on AP examination and not only the number of AP credits students take was examined, a strong association between AP examination score and college performance was found. This finding was not consistent with other examinations. For example, when specific academic areas are considered (e.g., mathematics, science, English, history), taking AP courses had no significant 
impact on first semester GPA (Klopfenstein \& Thomas, 2006). Sadler and Tai (2007) also examined area specific AP coursework and found that even though significant, the positive association between AP score and college performance in the same area was marginal and it did not approach a meaningful size (e.g., a letter grade change in a college-level course). They found that high AP scoring students did not achieve high performance in college level courses.

The association between AP coursework and student progression in college is also supported in the literature. Taking AP courses was associated with students attending postsecondary education at higher rates, but more importantly it was more strongly related to degree completion (Adelman, 1999). In his later examination, Adelman (2006) focused on dual enrollment courses, which are an alternative to advanced placement. He calculated that completing at least six credits in dual enrollment coursework helps students gain academic momentum. He further claimed that students who complete 12 credits maintained high momentum. Adelman focused on the completion of those courses and earning the credit rather than the specific score students received. In other examinations, students who took and passed the AP exam were found to graduate at higher rates in comparison to those who did not take AP courses or only took AP courses but did not take the exam or did not pass it (Dougherty et al., 2006). This association held consistently across ethnic groups and across income levels.

The body of research focused on AP poses certain limitations. Dougherty et al. (2006) emphasized that in order to study the true impact of AP, experimental designs with random assignments were necessary. Those, however, are not very feasible in educational settings and researchers often rely on correlational associations to examine any possible impacts. Another consideration in AP research is that students self-select to enroll in AP and to take AP exams. Thus, AP participation may be associated with other variables (e.g., motivation, academic self- 
efficacy) that are more directly related to college success than the AP coursework. Further, Geiser and Santelices (2004) bring the question of access and the inequality students experience when it comes to AP. Similar to high quality high school curriculum, AP offerings are limited in certain areas or schools and not available for some students. Socioeconomic and demographic differences may be contributing factors to who enrolls and is successful in AP, and such factors may have a far-reaching impact well into postsecondary education (Geiser \& Santelices, 2004).

\section{Post-Secondary Performance across College Career}

Apart from pre-college performance and various forms of achievement, student academic success has been examined in college as well. On average, it takes more than four years for students to complete a bachelor's degree if they are continuously enrolled (Adelman, 1999), and during that time many experiences may alter a student's path to graduation. Earlier works focus on student persistence and academic performance, most often as captured by their college GPA (e.g., Kahn \& Nauta, 2001; Nora \& Cabrera, 1996). However, recently there are shifts to examine various other college-level metrics and their relation to graduation (e.g., Adelman, 1999, 2006; Attewell et al., 2012).

Focus on credit accumulation in college. A more unorthodox approach was proposed originally by Adelman $(1999,2006)$ and more recently Attewell et al. (2012). They examined college student progression in terms of credits completed and accumulated over semesters. One underlying supposition here is that students who accumulate more credits persist through college at higher rates and progress closer to degree completion.

Attewell et al. (2012) examined student progression through the lens of successful completion of coursework without consideration for how well they performed. They claimed an academic momentum theory approach because the number of credits students completed was one 
component of gaining and maintaining high momentum (Adelman 1999, 2006). Course load was found to have a significant impact on student trajectory and graduation (Attewell et al., 2012). Students who accumulated more credits over time were more likely to graduate while students who enrolled as part time students or took 12 or less credits during their first semester had significantly lower degree completion rates compared to their full time peers. This held true even after controlling for SES and high school preparation, which have been found to impact student decision to enroll full time or part time (Chen, 2007).

The gap between part-time and full-time student graduation rates within 8.5 years of initial enrollment was between 4.6 and 7 percent and a negative association was found between dropping to part-time status at any time and degree completion (Adelman, 2006). Because the distinction between part-time and full-time students in terms of credit hours may be a matter of a single credit hour (students with 11 credits are considered part-time students while those with 12 credits are counted as full-time students), it may be more practical to talk about the number of hours associated with high academic momentum. Adelman (1999) determined that students completing less than 20 credits during their first year in college were less likely to complete a degree. One limitation of the 1999 examination by Adelman was that he focused on the first year in college and did not account for any summer coursework that might contribute to credit accumulation. In fact in his later examination, he concluded that earning four credits or more during summer semesters was positively associated with degree completion.

First semester high and low credit loads do not have uniform impact across student subgroups. Differential impacts have been found based on student gender, SES, and high school preparation (Attewell et al., 2012). Even though none of these reached statistical significance, the direction of the association may provide insight to how heavy and low credit hour loads impact 
student progression. Females benefitted from attempting more credits their first semester, while this effect for males was slightly negative. Those with lower SES who took more credits also benefited relative in terms of graduation. However, this trend was reversed for those with higher SES. Students with both less and more rigorous high school preparation saw positive impact of taking higher credit loads during their first semester even though the observed benefit was larger for those coming with less rigorous preparation. Because of these inconsistencies, it is difficult to gauge if larger credit loads are beneficial overall.

The above examinations investigated number of credits students completed during the first and second semester with the presumption that higher number of credits would be indicative of higher academic momentum and ultimately graduation (Attewell et al., 2012). One limitation of such an approach is the fact that based on federal regulations relative to satisfactory academic progress, higher education institutions may enforce policies that restrict the number of credits students can enroll in a given semester (Satisfactory Academic Progress Policy, 2009). Students who do not meet Satisfactory Academic Progress may be limited to enrolling in only up to 12 credit hours, which may be considered lower academic momentum. Further, Attewell et al. (2012) found little evidence that those who took heavy course loads (18 credits or more) in their first semester benefited in the long-run. Another consideration for studies examining credit load is the recent trend for students to repeat courses to improve their grade. Adelman (1999) reported that there was an increase in the number of students who repeated courses from $4 \%$ to $7 \%$ between 1970s and 1980s. Because of these limitations, student performance rather than course load may be a more appropriate metric to examine across college student careers.

Focus on initial college performance. College performance is probably one of the most investigated factors in higher education literature. It has been related to college retention (e.g., 
Bean, 1985), subsequent college performance (e.g., Martin et al., 2013), and degree attainment (e.g., Adelman, 1999). From an academic momentum perspective, performance is most often captured by student grades and is another essential factor to student college progression. There are a number of different pathways through which college grades may support or inhibit student progress toward completion of a degree. If students do not perform well, they may be in danger of academic dismissal. In addition, grades and maintaining a certain grade point average may be a requirement for receiving financial aid. Past literature has examined the strong association between financial aid and persistence (Bettinger, 2004). Achieving certain grade point average in overall coursework or a subset of coursework may be a requirement for acceptance in some academic programs as well as for graduating. These suggest that college grades are indeed an important factor when degree attainment is investigated.

The role of college GPA and persistence is evident in past literature. Bean (1985) studied college GPA as a predictor for college dropout. He expected that grades would have an impact on college student dropout early in college. He also hypothesized that grades would show an increase later in student career as a result of greater student commitment, which develops the longer students stay in school. Even though there was indeed a decrease in student dropout in later college years, Bean found that college GPA was not significantly related to dropping out. Earlier grades did have a greater influence on freshman and sophomore decision to leave the institution but not past those first two years. For freshman-to-sophomore persistence, Kahn and Nauta (2001) also identified first semester GPA as the primary predictor after controlling for precollege characteristics. Additionally, first semester GPA was positively related to student persistence but only for minority students (Nora \& Cabrera, 1996). Stinebrickner and Stinebrickner (2009) provided one possible explanation for the relation between grades and 
persistence. They claimed that upon entering college, students tend to overestimate their own abilities and discount the possibility of bad performance. They found this to be a factor in decision to drop out of college for students who experienced very low performance and the greatest discrepancy between expected and actual performance.

Persistence is not the only college-level measure with which first and second semester GPA is associated. Martin et al. (2013) utilized the academic momentum framework and determined that ongoing achievement did significantly predict subsequent achievement during the first four semesters in college. Similarly, first semester GPA was significantly correlated with second semester GPA in an examination conducted by McKenzie and Gow (2004). Even though first and second semester performance is more commonly examined, later college performance has been studied. Lord et al. (2013) examined the relation between gains in GPA and student graduation, persistence, and dropping out for students enrolled in upper division coursework. They concluded that higher academic gains were associated with dropping out rather than with persistence and graduation. The authors provided one potential explanation for this counter intuitive phenomenon. Considering the ceiling effect of GPA, students who already performed well did not have a lot of room to improve. On the other hand, lower achievers might have experienced greater absolute growth but that growth was not sufficient to maintain high momentum.

Later college performance as examined by Lord et al. (2013) has stemmed a new line of research. Today researchers begin to explore later college careers when students enter their junior or senior status because this period bears some distinct differences from first and second year. Students are more likely to have declared a major by this time and majoring in a specific field is arguably related to higher interest and student inclinations that they possess the skills to 
be successful (Bolvin, Fountain, \& Baylis, 2000). Along with that, upper level coursework is reported to be more difficult and more challenging for students (Carlan \& Byxbe 2000). According to Allen et al. (2008), this latter point provides a more accurate picture of student academic level. Lord et al. found that intervention specific to upper level students did have a small but significant positive effect on on-time graduation and suggested that there were benefits to offering academic support in upper level coursework.

College performance has been associated with different college outcomes (e.g., dropout, degree completion) and greater emphasis has been placed on degree attainment (Horn et al., 2004). Adelman (1999) stresses that the trend in college grades is one of the strongest indicators for degree completion. Others advocate for the importance of college performance in later semesters as well. Across college career, lack of high GPA was associated with leaving a program (Tumen et al., 2008). Consistent increase in GPA was associated with on-time completion while consistent decline in performance (not necessarily below a certain benchmark) was associated with leaving a program. However, these findings were contradictive to other research that determined that greater gains in GPA were not necessarily associated with better persistence and graduation outcomes (Lord et al., 2013).

Performance is an accessible indicator that has been associated with risk of noncompletion, and many institutions have utilized lower academic performance as a way to identify students who may be at risk academically (Hossler, Ziskin, \& Gross, 2009). Therefore, academic performance may be key to better understanding college student progression and completion. After the first year in college, demographic characteristics, including SES, are only modest contributors to the probability of degree completion (Adelman, 1999). This is indicative of the possibility that any intervention targeted toward improving student performance, especially later 
in college careers, is likely to have an impact on degree completion for all students, regardless of their socio-demographic characteristics.

\section{Remediation in Higher Education}

A remedial course is designed as a full academic term course that provides content at a lower level in comparison to college-level courses (Boylan, Bonham, \& White, 1999). The demand for remediation is high and students from different backgrounds enroll in remediation courses (Adelman, 2006). While many associate the need for remediation with insufficient preparation in high school, students who took college-preparatory courses in high school also participate in remediation. Of college-prep graduates, $73 \%$ needed mathematics remediation, 79\% English remediation, and 76\% reading remediation (Merisotis \& Phipps, 2000). Similarly, Hoyt and Sorensen (2001) determined that more than $50 \%$ of those who took intermediate algebra and geometry in high school had to enroll in remedial mathematics.

Remediation research has focused on the impacts of remedial coursework mainly on student persistence and subsequent achievement in college. The enrollment and completion of remediation may have an impact on student progression in at least two different ways. First, enrollment in remediation may lead to an increase in the number of graduation requirements and an increase in time to degree completion (Bettinger \& Long, 2009). Second, remediation may be a prerequisite for enrolling in upper level and major field academic courses. Any unsuccessful completion of remediation may potentially slow down student progression to degree completion.

The outcomes of studies examining remediation in higher education are often contradictory. Some found that remedial courses had positive benefits in terms of number of credits completed and persistence (Attewell et al., 2006; Bettinger \& Long 2009; Boylan et al., 1999). For example, Calcagno and Long (2008) examined the impact of taking remedial 
coursework on the number of credits students earned compared to those who did not take remedial courses. They found that students who took remedial courses earned more credits but not necessarily toward their degrees and for that reason they concluded that remediation placed students at a disadvantage for degree attainment. Other researchers found that, students in remediation were more likely to persist compared to those with similar background characteristics and admissions test scores (Bettinger \& Long, 2009).

One methodological criticism for remediation research is the comparison approach. Most often, those subject to remediation are compared to those who are not required to complete remediation (e.g., Bettinger \& Long, 2005; Calcagno \& Long, 2008). Calcagno and Long (2008) made an observation that students in credit bearing courses who previously took remedial courses did not perform any better than their peers who had not enrolled in remedial courses. This expectation that students going through remediation would outperform their peers is somewhat ill-founded as Goudas and Boylan (2012) point out. These courses are designed to bring those students up to a level to where they will be successful taking college-level classes and there is no expectation that they will perform better than their peers.

Another aspect that should be considered when examining the effects of remediation is successful completion of that coursework. Often examinations focus on students who are subject to remediation (e.g., Bettingher \& Long, 2009; Calcagno \& Long, 2008). However, if those students passed remedial courses or when they passed may have an impact on their college level outcomes. Bahr (2008) cited this failure to distinguish between successful and unsuccessful remediation in the literature as a major drawback to accurately examine remediation. Further, the significant number of students who do not complete remediation is of concern (Attewell et al., 2006; Bailey, 2009). According to Bailey, Jeong, and Cho (2010) about half of the students 
referred to remediation do not complete the first course of the remediation sequence. It may be more appropriate to examine differences between successful remediation and unsuccessful remediation rather than differences between remediation and no remediation.

Students in remediation possess skills on a continuum and assuming that all students in remediation have the same levels of skill and knowledge deficiencies will be unfounded. The variation of skill levels even within remediation may be a vital factor for remediation success and subsequent progression in college (e.g., Bahr, 2008; Bailey et al., 2010). As Adelman (1999) suggested, remediation may have positive benefits for those who have relatively small gaps in knowledge and skills. This notion is supported by other examinations, which found that within the remediation track, students with higher ACT mathematics scores were more likely to complete a degree than those with lower scores (Bettingher \& Long, 2009). These trends are consistent with those found by Bahr (2008), who examined students in mathematics remediation and determined that "declining math skills progressively foreclose academic opportunity" (p.440).

The type of outcomes relative to remediation are also a concern in the literature. Bahr (2008) calls for examination of long-term outcomes (e.g., degree completion). However, shortterm outcomes are more commonly examined. These include investigation of sequence completion (e.g., Bailey et al., 2010), credit accumulation (e.g., Bettinger \& Long, 2004; Calagno, Crosta, Bailey, \& Jenkins, 2007), performance in college level courses of the same sequence (e.g., Bailey, 2008; Lesik, 2006). Few have looked at successful remediation and longterm college outcomes (e.g., Bahr, 2008; Bettinger \& Long, 2004). For example, Bahr (2009) examined credential attainment and transfers from two-year to four-year institutions and found that remediation completers were more likely to complete associate degrees, transfer with 
credential, and transfer without credential as compared to non-completers. When compared to students who did not require remediation, those successful in remediation are only less likely to complete four year degrees (Bettinger \& Long, 2004). However, more efforts to examine the role of successful remediation for student graduation trajectory are needed.

Mathematics remediation. The importance of examining the role of mathematics remediation relative to college level outcomes is driven by two main areas. First, researchers consistently report the prevalence of mathematics remediation needs in comparison to other types of remediation (Adelman, 2006; Bettinger \& Long, 2005). For example, Bettinger and Long (2009) report about $60 \%$ of students enrolling in community college need mathematics remediation in comparison to $40 \%$ who need English remediation. These numbers are similar to those reported by Bailey, Jeong, and Cho (2010) who found that $59 \%$ of students are referred to mathematics remediation in comparison to $33 \%$ who need remediation in reading. Second, mathematics preparation emerges as a significant element relative to college progression and degree attainment. Adelman (2006) found an association between highest level of mathematics completed and degree attainment while Horn et al. (2001) determined that those who take high quality curriculum in high school are more likely to complete a degree. The high quality curriculum includes at least two extra mathematics courses in high school. Further, those enrolled in mathematics remediation tend to have lower mathematics achievement in high school and lower ACT mathematics scores (Bettinger \& Long, 2005).

While there is a general lack of research on the long-term college outcomes for those subject to remediation, this literature is even scarcer specific to remedial mathematics. Bettinger and Long (2005) are one of the few who looked at the long term outcomes of those in mathematics remediation. They found that in comparison to non-remediation counterparts, those 
in mathematics remediation have poorer outcomes in terms of number of credits completed, stopping out, transferring to four-year institutions, and degree completion (both two-year and four-year degrees). However, Bettinger and Long did not differentiate between those who were successful at mathematics remediation and those who were not, even though they acknowledged that only a portion of students actually complete these types of courses. Bahr (2008) attempted to fill in this gap by exploring differences in remedial completers versus non-completers. He found completers to have better chances of associate degree completion as well as transferring to a four-year institution compared to non-completers.

Other mathematics remediation research explores college retention (e.g., Bettinger \& Long, 2004) and a few studies looked at degree attainment but only on the community college level (e.g., Bahr, 2008; Bettinger \& Long, 2005). Limited number of examinations consider both mathematics remediation and success in remediation (Bahr, 2008; Bettinger \& Long, 2004), and even those are not specific about the point at which that success occurs (e.g., first attempt or later). This may at least partially explain conclusions that remediation is associated with extended time-to-degree (Bettinger \& Long, 2004; Calcagno et al., 2007). Further, most researchers focused on community colleges (e.g., Bailey et al., 2010; Bettinger \& Long, 2004, 2005; Calcagno et. al., 2007), while only a few looked at four-year institutions (e.g., Bettinger \& Long, 2004).

While remediation is more common for community colleges, four-year institutions also offer remedial coursework. Thus, there is a lack of examination of mathematics remediation in four-year institutions. Four-year institutions provide a more direct path to bachelor degree completion, and a potential advantage for students who enter four-year institutions, even if they 
need remediation, is the elimination of the need to transfer to a different institution to complete a four-year degree.

\section{Institution-Centered Examinations in Higher Education}

The world of postsecondary education is becoming more complex to study and navigate. This complexity is driven by the greater diversity of students entering college (e.g., Oblinger, 2003; Reason, 2009), but also the increasing variability in patterns of attendance and progression through college (e.g., Adelman, 1999). A proportion of students shift between part-time and fulltime status (e.g., O'Toole, Stratton, \& Wetzel, 2003), a greater amount of students change institutions at least once during their college career or attend two-year or four-year institutions in a different order (e.g., Cabrera, Burkum, \& La Nasa, 2005), and even change institutions across state borders.

In college remediation focused literature, variation due to differences in institutional remediation placement criteria is a big concern (Bailey, 2009; Bettinger \& Long, 2009). Bettinger and Long (2009) examined this issue through modeling students' probability to be placed in remediation in one type of institution versus another. They acknowledged that when effects of remediation are examined, institutional policies relevant to remediation may introduce another source of variability to be accounted for. Variances may include diverse thresholds for placement in remediation, different placement tests, different durations of remediation sequence (e.g., one course, two course sequence), and different types of course instruction, among others.

It is important to distinguish between persistence and retention. Persistence is a student focused term and refers to student progression through the higher education system, while retention refers to "the ability of an institution to retain a student from admission to the university through graduation" (Berger \& Lyon, 2005, p.7). Thus from an institutional centered 
approach, retention becomes more important. Adelman (1999) points out that degree completion is more important for the student than the institution. Even though he emphasized that institutional graduation rates are less meaningful because of high transfer rates, at the same time he admits that there is "institutional behavior that actually can be changed to improve the odds of attainment" (p.4). A look at existing literature provides evidence that researchers often take an institutional centered approach when examining retention and completion (e.g., Nora \& Cabrera, 1996; Gifford et al., 2006). After all, institutions have the advantage of access to data that can be utilized for monitoring purposes and for designing and targeting interventions that steer students toward degree completion. Institutions possess resources and knowledge about institutional practices relevant to academic advising and academic degree structures. Therefore, institutions may be considered central hubs for research and intervention.

Various examinations in higher education include recommendations for regular and close monitoring of student progression (e.g., Bordes-Edgar et al., 2011). Despite the large volume of existing research on college retention and completion, Seidman (2005) outlined the need for guidelines for institutions interested in creating practices and policies to enhance student success. Perhaps rather than providing specific guidelines as called by Seidman, research can provide tools for institutions to examine their specific population and study their own practices as they relate to student completion. In the end, just like student diversity has been found challenging for those conducting research, the diversity in institutions may pose a hurdle for providing a set of generalizable guidelines across institutions. If this is the case, then institution-centered examinations may be more informative for higher education policy and practice. 


\section{Purpose of the Current Study}

Past examinations have shown a relation between early and subsequent student achievement (Figure 1). This is true for pre-college student performance associations with college performance (e.g., Bean, 1985; Martin et al., 2013; Tumen et al., 2008) and early college performance relations to later performance, but only up to the second year (e.g., Martin et al., 2013). When student degree attainment is studied, examinations have consistently only examined performance in one or two semesters and graduation (e.g., Lord et al., 2013). However, a longitudinal approach may reveal differences in academic performance paths in college careers for students who are on graduation trajectory versus those who are not.

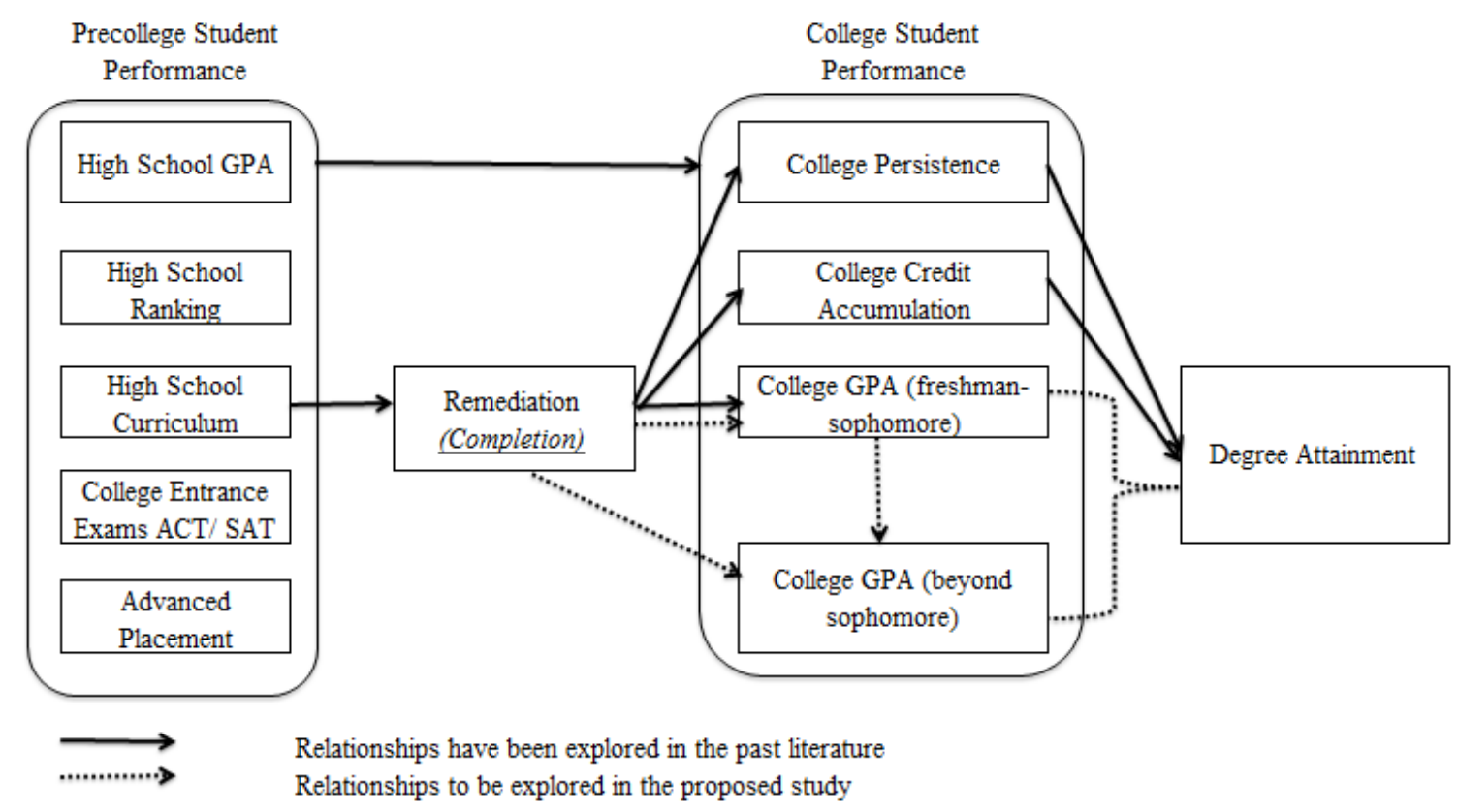

Figure 2.1: Associations across variables examined in the past literature and relations to be investigated in the current study.

As academic momentum theory posits, high academic momentum (usually captured by greater number of credits completed and good academic performance) is associated with greater 
chances for degree completion. Further, students may experience academic performance decline and thus losing academic momentum may have a negative impact on their graduation trajectory. From a practical perspective, if institutions are aware of the existence of such trajectories, faculty and staff may be better prepared to gauge student progress and identify when students are in danger of getting off a trajectory associated with higher chances of degree attainment. Thus, this study adds to the current literature by examining if differential longitudinal trajectories do exist for student who graduated and those who did not. Further, considering the large proportion of students who need remediation in mathematics, the effects of being subject to mathematics remediation and successful completion of such remediation on student trajectories should be examined as mathematics remediation is likely to have an important impact not only on time-todegree completion but also on fluctuations in academic momentum.

This examination contributes to the postsecondary degree completion literature and specifically literature relative to remediation in four-year institutions. It examines mathematics remediation more closely (successful completion versus non-completion versus no remediation) and if mathematics remediation and success in those courses have any differential impact on student trajectories to graduation. Further, it takes on longitudinal perspective of degree attainment through a trajectory framework.

In an attempt to better understand student progression toward degree completion and the role of mathematics remediation, the following questions will be examined in a single four-year institution:

1. What is the average initial level of academic performance and growth trajectory of all students from the first through the eighth semester of enrollment? 
2. Does academic performance growth differ for college students who graduate versus those who do not?

3. Is successful mathematics remediation and graduation status significantly associated with student academic performance growth?

a) Does initial level of academic achievement and performance growth differ for students who were successfully remediated in comparison to those who were not, taking into account if they attained a degree or not?

b) Does initial level of academic achievement and performance growth differ for students who were successfully remediated in comparison to those who did not need remediation, taking into account if they attained a degree or not? 


\section{Chapter 3}

\section{Method}

\section{Participants}

Four cohorts of students who initially enrolled at the institution between Fall 2005 and Fall 2008 semesters were included in the study with data captured in Fall 2014. This participant selection approach provided a minimum of six years to complete a bachelor's degree. The inclusion criteria were: first time freshman students upon first semester enrollment, full time enrollment in the first semester, and undergraduate degree seeking students only. These criteria were chosen in an attempt to select a more homogeneous sample and eliminate variability due to differences in initial pattern of enrollment as they related to academic momentum theory. For example, transfer student may experience higher momentum than first time freshman students because they have been in the higher education system longer. Similarly, part-time students and non-degree seeking students are more likely to have only episodic attendance, which would limit the examination of a longitudinal trajectory.

The total enrollment at the institution between 2005 and 2008 was approximately 2,700 students per year. The institutional student profile indicated that the student body was quite homogeneous: $92 \%$ were white and approximately $58 \%$ of the students were female. Eighty-two percent were of traditional college age and a large proportion self-identified as first-generation college students. Over $40 \%$ of the full time first time freshmen were enrolled in remedial mathematics courses.

Student mathematics ACT and/or SAT scores were considered to determine if students should be referred to remediation. If students scored below a cutoff, they were given a mathematics placement test to determine if they would be placed in the first or the second course 
of the mathematics remediation sequence. The mathematics remedial course (any of the sequence) was taken in the first semester of student enrollment in the institution and was repeated until the student successfully passes the course.

All first time freshmen who started their degrees between Fall 2005 and Fall 2008 were included in the initial sample $(\mathrm{N}=2,595)$. Of those, 1,371 (53\%) had data on four or fewer semesters out of the first eight semesters and were eliminated from the sample. The final sample consisted of 1,224 students, who had data for at least five out of the first eight semesters. It was not a requirement that the five semesters were consecutive. A number of students attended for the first four semesters and returned to the institution after a break of one or more semesters. The specific sample sizes for each cohort for those included and those excluded from the analyses are listed in Table 3.1.

Table 3.1

Sample Sizes for Each Cohort Included in the Analyses

\begin{tabular}{|c|c|c|c|c|}
\hline \multirow[b]{2}{*}{ Cohort } & \multicolumn{2}{|c|}{$\begin{array}{c}\text { Students Included in } \\
\text { Analyses }\end{array}$} & \multicolumn{2}{|c|}{$\begin{array}{l}\text { Students Excluded } \\
\text { from Analyses }\end{array}$} \\
\hline & $N$ & $\begin{array}{l}\text { Percent of } \\
\text { Sample }\end{array}$ & $n$ & $\begin{array}{c}\text { Percent of } \\
\text { Sample }\end{array}$ \\
\hline Cohort 1 2005-2006 & 283 & $11 \%$ & 362 & $14 \%$ \\
\hline Cohort 2 2006-2007 & 286 & $11 \%$ & 317 & $12 \%$ \\
\hline Cohort 3 2007-2008 & 312 & $12 \%$ & 318 & $12 \%$ \\
\hline Cohort 4 2008-2009 & 343 & $13 \%$ & 374 & $14 \%$ \\
\hline Total & 1224 & $47 \%$ & 1371 & $53 \%$ \\
\hline
\end{tabular}

Demographics. The final sample consisted of $76 \%$ who were West Virginia residents and $22 \%$ out-of-state residents. No residency information was available for about $2 \%$ of the participants. For those who were excluded from the analyses, about $70 \%$ were in-state residents. The gender distribution indicated that about $57 \%$ of the sample were females and $43 \%$ were 
males for the subsample included in the analyses. Those who were excluded were evenly distributed between males and females. The ethnic distribution for both included and excluded from the analyses is presented in Table 3.2. The chi-squared indicated that ethnic distribution those included in the analyses was similar to that of those excluded, $\chi^{2}(5)=8.77, p=.123$.

Table 3.2

Ethnic Distribution of the Sample

\begin{tabular}{|c|c|c|c|c|}
\hline \multirow[b]{2}{*}{ Ethnicity } & \multicolumn{2}{|c|}{$\begin{array}{c}\text { Students Included in } \\
\text { Analyses }\end{array}$} & \multicolumn{2}{|c|}{$\begin{array}{l}\text { Students Excluded } \\
\text { from Analyses }\end{array}$} \\
\hline & $n$ & $\begin{array}{l}\text { Percent of } \\
\text { Sample }\end{array}$ & $n$ & $\begin{array}{l}\text { Percent of } \\
\text { Sample }\end{array}$ \\
\hline White & 1121 & $43 \%$ & 1222 & $47.09 \%$ \\
\hline Black & 83 & $3 \%$ & 120 & $5 \%$ \\
\hline Asian & 10 & $0.4 \%$ & 14 & $0.5 \%$ \\
\hline Hispanic/Latino & 9 & $0.3 \%$ & 8 & $0.3 \%$ \\
\hline American Indian/Alaskan & 1 & $0.04 \%$ & 6 & $0.2 \%$ \\
\hline Other & 0 & $0 \%$ & 1 & $0.04 \%$ \\
\hline Total & 1224 & $47 \%$ & 1371 & $53 \%$ \\
\hline
\end{tabular}

A higher proportion of those included in the analyses were PELL Grant recipients $(56.4 \%)$ in comparison to $48.5 \%$ for those excluded, $\chi^{2}(1)=16.04, p<.001$. About $62 \%$ of those included in the analyses received some type of institutional scholarship, which was higher than those excluded in the analyses $(35.4 \%), \chi^{2}(1)=186.05, p<.001$.

Academic Profile. Those who were included in the analyses had higher pre-college academic achievement (Table 3.3). Those included in the analyses had a significantly higher ACT score, $t(2053)=-12.75, p<.0001)$, a significantly higher SAT score, $t(979)=-8.24, p<.0001$, and a significantly higher GPA, $t(2543.281)=-15.03, p<.0001$. 
Table 3.3

Sample Descriptive Statistics for ACT Scores, SAT Scores, and High School GPA

\begin{tabular}{|c|c|c|c|c|c|c|c|c|}
\hline & \multicolumn{4}{|c|}{ Students Included in Analyses } & \multicolumn{4}{|c|}{ Students Excluded from Analyses } \\
\hline & $n$ & Range & Mean & SD & $n$ & Range & Mean & SD \\
\hline ACT Score & 1005 & $11-34$ & 22.10 & 3.88 & 1050 & $8-32$ & 19.97 & 3.70 \\
\hline SAT Score & 486 & $510-1500$ & 995 & 170 & 495 & $410-1560$ & 909 & 157 \\
\hline $\begin{array}{l}\text { High School } \\
\text { GPA }\end{array}$ & 1211 & $1.30-4.00$ & 3.41 & 0.55 & 1337 & $1.10-4.00$ & 3.07 & 0.58 \\
\hline
\end{tabular}

In the sample included in the analyses, about $75 \%$ of the students had graduated with a bachelor degree from the institution. The average number of years to graduation was 4.75 $(\mathrm{SD}=.95)$ and ranged from 3 to 9.

Power analysis was conducted in Optimal Design software. The estimation for a repeated measures design with quadratic change indicated that the recommended sample size is 470 participants for detecting a medium effect size (0.3) with power of 0.9 and 1060 participants for detecting a small effect size (0.2) with power 0.9 .

\section{Measures}

Timeframe. Student performance was examined across eight semesters, including four consecutive fall and spring semesters. Student graduation was captured as of Year 6 for students enrolled in 2008 cohort and Year 9 for 2005 cohort. Past examinations have concluded that students who are continuously enrolled require more than four years to complete a four-year degree (Adelman, 1999; Border-Edgar et al., 2011; Horn et al., 2004). No summer coursework was included in the analyses. The institution operates at a regular fall and spring semester schedule. Summer enrollment was not required and only a small proportion of students enrolled 
in summer courses. Further, financial aid availability impacted students' decisions to take summer courses outside of the regular fall and spring semester.

Student academic performance. Student Performance was measured by the semester college grade point average (on a 4.0 scale). Performance was captured each semester the student was enrolled, regardless if student was part-time or full-time enrolled (all students included in the sample were enrolled full-time during their first semester). Grade point average was calculated based on all credit-bearing courses students completed. Students' grades for any remedial courses were not included in the semester GPA. Semester GPA was assessed each semester and represented a single semester performance and was not cumulative. Table 3.4 presents the college academic performance for those included and those excluded from the analyses. A comparison between those included in the analyses and those excluded indicated that the students in the analyses had a significantly higher number of credits completed by the end of their attendance, $t(2223.04)=-83.78, p<.0001$ and a significantly higher college GPA, $t(2206.16)=-32.23, p<.0001$. 
Table 3.4

Sample Descriptive Statistics for Cumulative College GPA and Cumulative Earned Hours

\begin{tabular}{|c|c|c|c|c|c|c|c|c|}
\hline & \multicolumn{4}{|c|}{ Students Included in Analyses } & \multicolumn{4}{|c|}{ Students Excluded from Analyses } \\
\hline & $n$ & Range & Mean & SD & $n$ & Range & Mean & $\mathrm{SD}$ \\
\hline $\begin{array}{l}\text { Cumulative } \\
\text { College GPA }\end{array}$ & 1224 & $0.24-4.00$ & 2.96 & 0.63 & 1371 & $0.00-4.00$ & 1.82 & 1.12 \\
\hline $\begin{array}{l}\text { Cumulative } \\
\text { Earned } \\
\text { Hours in } \\
\text { College }\end{array}$ & 1224 & $4.00 *-229$ & 128.5 & 35.5 & 1371 & $0.00-225^{* *}$ & 25.05 & 26.07 \\
\hline
\end{tabular}

* One student had only completed 4 cumulative hours but this number does not reflect developmental coursework completed successfully.

** A number of students had accumulated high number of credits but not during their initial attendance across the first four years. These students left the institution after attending two to four semesters and reenrolled two or more years later thus making it unable to capture their performance during the first four years.

Graduation. Student degree attainment was captured as of Fall 2014. For students starting in Fall 2005, graduation was captured as of year 9 after the initial enrollment. For students starting in Fall 2008, graduation was captured as of year 6. Only students who were awarded a bachelor degree from the institution were considered. Table 3.5 presents student GPAs for the first eight semesters for the graduates and non-graduates.

Table 3.5

Cumulative College GPA Mean and Standard Deviation for Non-Graduates and Graduates

\begin{tabular}{lccccccc}
\hline & \multicolumn{3}{c}{ Students Included in Analyses } & & \multicolumn{3}{c}{ Students Excluded from Analyses } \\
\cline { 2 - 4 } \cline { 7 - 8 } & $\mathrm{N}$ & Mean & $\mathrm{SD}$ & & $\mathrm{N}$ & Mean & SD \\
\hline Non-Graduates & 303 & 2.28 & 0.58 & & 1362 & 1.82 & 1.12 \\
Graduates & 921 & 3.18 & 0.47 & & 9 & 2.95 & 0.53 \\
Total & 1224 & 2.96 & 0.63 & & 1371 & 1.82 & 1.12 \\
\hline
\end{tabular}


Mathematics remediation. The institution offered a sequence of two remediation math courses. Students were placed in one of the two courses based on an ACT math score of less than 19 and a Compass placement test. Placement in either math course of the remediation sequence constituted the student being subject to remediation. Student performance in the first course that they took was utilized in the current analyses. Student remediation was represented by a three level categorical variable. Level 1 corresponded to students who did not need remediation, level 2 indicated students who were subject to mathematics remediation and were successful on the first attempt at completing at least the first of the two course mathematics remediation sequence, level 3 indicated students enrolled in mathematics remediation who did not complete the course successfully on the first attempt. A letter grade of D or F, course incomplete, and course withdrawal constituted unsuccessful course completion.

About $64 \%$ of the sample included in the analyses were not subject to remedial mathematics. Of those who took remedial mathematics $(\mathrm{N}=473)$, about $90 \%$ were successful in passing the course on the first attempt. In the group of excluded students, there was an equal split between those who needed remediation $(\mathrm{N}=668,48.7 \%)$ and those who $\operatorname{did}$ not $(\mathrm{N}=703,51.3 \%)$. Of those who needed remediation, about $50 \%$ were successful on the first attempt. Student cumulative GPA descriptive statistics for college ready students, students successful, and students unsuccessful at mathematics remediation are presented in Table 3.6. The data were separated by those who were included in the analyses and those excluded from the analyses. 
Table 3.6

Cumulative College GPA Mean and Standard Deviation for Students Not Successful at Remediation, Successful at Remediation, and College Ready

\begin{tabular}{lcccccc}
\hline & \multicolumn{3}{c}{$\begin{array}{c}\text { Students Included in } \\
\text { Analyses }\end{array}$} & \multicolumn{3}{c}{$\begin{array}{c}\text { Students Excluded from } \\
\text { Analyses }\end{array}$} \\
\cline { 2 - 7 } & $\mathrm{N}$ & Mean & SD & $\mathrm{N}$ & Mean & SD \\
\hline $\begin{array}{l}\text { Not Successful Math } \\
\text { Remediation }\end{array}$ & 44 & 2.23 & 0.64 & 332 & 1.05 & 0.95 \\
$\begin{array}{l}\text { Successful Math } \\
\text { Remediation }\end{array}$ & 393 & 2.70 & 0.60 & 336 & 1.91 & 0.84 \\
No Remediation & 787 & 3.13 & 0.57 & 703 & 2.15 & 1.13 \\
Total & 1224 & 2.96 & 0.63 & 1371 & 1.82 & 1.12 \\
\hline
\end{tabular}

\section{Research Design}

The examination is an institutional case study. A case study is preferred when an examination is exploratory or descriptive in nature and seeks to contribute to the knowledge of organizational phenomena (Yin, 2003). Yin (2003) suggested that one rationale for utilizing case study is when a case is considered "representative or typical" (p. 41). In the current study, the selected institution is a small, public, and less selective university. In the US, the majority of postsecondary institutions are small with enrollment of less than 5000 students and of those a large proportion are considered less selective (National Center for Education Statistics, 2013). Further, only a small proportion of the students entering higher education enroll in highly selective colleges and universities (Reardon, Baker, \& Klasik, 2012). Therefore, the selected case could be identified as representative of one common type of institution.

While the institutional characteristics outlined above are common across US institutions of higher education, there are contextual, economic, and educational peculiarities in which this particular institution exists. They should also be considered. The state has a different educational 
and economic profile in comparison to the national statistics and should be noted given that the majority of students enrolled in the institution are in-state residents (76\%).

The school is situated in West Virginia, the second most rural state in US (U.S. Census, 2012). In addition, 20 out of the 55 counties are considered all rural and rural counties report lower college going rate $(30 \%)$ in comparison to the rest of the counties $(60 \%)$. The proportion of those 25 years or older with a bachelor degree in the state is about $18 \%$, a proportion lower than the national average of $29 \%$ (U.S. Census, 2013). About $50 \%$ of the students included in the analyses come from eight counties surrounding the county of the institution. In those counties, the proportion of adults with a bachelor degree or higher varies from 5.8\% to $17.7 \%$, all lower than the national average (U.S. Census, 2013).

The bordering counties and the state as a whole suffer economically and economic pressure has been associated with a financial burden on students and their families to finance student higher education (Chenoweth \& Galliher, 2004). The institution is in a county where more than $22 \%$ live in poverty in comparison to the $14.5 \%$ reported nationwide (U.S. Census, 2013). The proportion of those living in poverty in the surrounding counties is between $13.3 \%$ and $36.3 \%$. The personal income per capita in all the surrounding West Virginia and Virginia counties and the county of the institution is lower than that of the state of West Virginia $(\$ 22,966)$ and state of Virginia $(\$ 33,493)$ respectively, and nationwide $(\$ 28,155)$ and ranged between $\$ 14,093$ and $\$ 23,485$.

While the current study focuses on a single institution, the unit of analysis is the individual student. The single institution approach bears a limitation that results, implications, and recommendations discussed may be relevant only to institutions sharing a similar profile. 


\section{Procedure}

IRB and data acquisition. Institutional Review Board protocols for non-human subject research were completed at the main institution and at West Virginia University (Appendix A). The study did not involve any interventions and no identifiable information was collected from the students. The study utilized institutional academic records and no additional private data were collected from the participants.

Student level de-identified data was requested from the main institution for all students in the selected cohorts (from Fall 2005 to Fall 2008). Any personal information (e.g., student names, student IDs, addresses, phone numbers) was deleted prior to researcher's access to the data.

\section{Analytical Approach}

Preliminary analyses. Descriptive statistics including means and standard deviations for GPA scores for each semester were reported. In addition, Pearson correlations between GPA scores across the eight semesters were also computed.

Primary analyses. Student academic performance trajectories were estimated through growth curve modeling. Growth models are often utilized when patterns of change over time in specific variables are examined. In the model, latent factors (intercept and slopes) are estimated to indicate patterns of change, i.e., linear, quadratic, or cubic (Hox, 2010). All analyses were conducted in HLM 7 (SSI Scientific Software Int., 1999-2011).

One advantage of utilizing growth modeling to other alternatives to longitudinal change examination (e.g., repeated measured ANOVA) is that these models account for partial data and utilize the information provided by cases with incomplete data to inform the model. In the current examination, this means that data of students who left the institution or were considered 
stop-outs (left the institution for a period of time but later returned and completed more coursework) was included in the model rather than discarded as in traditional analytic approaches.

Data missingness was examined on each of the 8 semesters. The proportion of missing data ranged from $0 \%$ for the first semester to $19 \%$ for semester 8 . Table 3.7 lists the proportion of missing data for each semester. A total of $20 \%$ or less of missing data is considered common in educational studies (Enders, 2003).

Table 3.7

Proportion of Missing Data for Each Semester

\begin{tabular}{lc}
\hline Semester & Proportion Missing Data \\
\hline Semester 1 & $0 \%$ \\
Semester 2 & $0.8 \%$ \\
Semester 3 & $2.2 \%$ \\
Semester 4 & $3.3 \%$ \\
Semester 5 & $2.6 \%$ \\
Semester 6 & $6.5 \%$ \\
Semester 7 & $13.6 \%$ \\
Semester 8 & $19 \%$ \\
\hline
\end{tabular}

The patterns of missing data were also examined. The test for missing completely at random (MCAR) was violated. Missingness in earlier semesters was predictive of missing data in later semester. The assumption for missing completely at random was violated but growth curve modeling is robust to this assumption using the full information maximum likelihood (FIML) approach for parameter estimation (Widaman, 2006).

Kolmogorov-Smirnov test was employed to test for normality of GPA scores for each semester. The tests were significant for each semester (Table 3.8) indicating violation of the assumption for normality. The Q-Q plots indicated a negative skew in the GPA distribution for 
every semester (Appendix B). The skew suggested that a greater number of high achievers were included in the analyses, thus creating a potential difficulty to detect significant effects.

Table 3.8

Test for Normal Distribution of GPA for Each Semester

\begin{tabular}{lccc}
\hline & \multicolumn{3}{c}{ Kolmogorov-Smirnov ${ }^{\mathrm{a}}$} \\
\cline { 2 - 4 } & Statistic & df & $p$ \\
\hline Semester 1 & .092 & 1224 & $<.0001$ \\
Semester 2 & .083 & 1214 & $<.0001$ \\
Semester 3 & .080 & 1197 & $<.0001$ \\
Semester 4 & .093 & 1184 & $<.0001$ \\
Semester 5 & .101 & 1192 & $<.0001$ \\
Semester 6 & .122 & 1144 & $<.0001$ \\
Semester 7 & .126 & 1058 & $<.0001$ \\
Semester 8 & .150 & 992 & $<.0001$ \\
\hline
\end{tabular}

Growth curve modeling utilizes individuals' scores on the variable of interest assessed repeatedly over time to estimate individual growth trajectory. Sample's or subgroups' growth curves are estimated based on the individual trajectories and are defined by mean initial status (the status of the variable at Time 1) and the growth rates (e.g., linear slope, quadratic curvature). Fixed effects indicative of average growth in the sample, including average intercept, linear slope, and quadratic growth were estimated and reported. In addition, random effects, which represent variability, were reported along with significance levels.

Student academic achievement was modeled through a two-level model (Figure 3.1). Time was modeled on level one to capture individual growth and within-subject variability over time. Level two modeled the effects of degree completion and successful remediation. 
Level 1:

$$
Y_{t i}=\pi_{0 i}+\pi_{1 i}\left(\text { time }_{t i}\right)+\pi_{2 i}\left(\text { time }_{t i}\right)^{2}+e_{t i}
$$

Level2:

$$
\begin{aligned}
& \pi_{0 i}=\beta_{00}+\beta_{01}(\text { graduate })+\beta_{02}(\text { remediation })+r_{0 i} \\
& \pi_{1 i}=\beta_{10}+\beta_{11}(\text { graduate })+\beta_{12}(\text { remediation })+r_{1 i} \\
& \pi_{2 i}=\beta_{20}+\beta_{21}(\text { graduate })+\beta_{22}(\text { remediation })+r_{2 i}
\end{aligned}
$$

Initially, unconditional models (growth models without predictors, Level 1 model) were examined to determine if a linear or a quadratic model better fit the data (Singer \& Willett, 2003). The models were compared based on Akaike Information Criterion (AIC) and Bayesian Information Criterion (BIC). Smaller values of AIC and BIC indicated a better fit. Further, as a part of the model fit analyses, the model was tested for a potential cohort effect. Appropriate weighting techniques were employed depending on sample size in each cohort. The sample was almost equally distributed across the four cohorts and as a result unweighted cohort effects were used. In these comparisons, potential differences between each cohort and the overall mean were tested (Cohen, Cohen, West, \& Aiken, 2013). Two models were tested. The first one utilized the first cohort (Fall 2005) as the base group. The second one utilized the second cohort (Fall 2006) as the base group. The second coding scheme remained in all models as it captured all significant cohort effects.

A conditional model was computed subsequently. Two factors were included in the final conditional model: student degree completion from the institution as of fall 2014 (yes/no) and student math remediation. Student gender was not examined as a predictor because of sample size considerations. Degree completion (or graduation) was a dichotomous variable identifying 
those who completed bachelor degrees from the institution versus those who did not.

Remediation was a three level categorical variable as described previously. This variable was appropriately dummy coded into two variables to be included in the models. One variable was coded as being successful at remediation (coded as 1) with not-successful remediation being the reference group (coded as 0 ). The second variable was coded as being successful at remediation (coded as 1) with no remediation being the reference group (coded as 0 ). The two variables were used in two different models. For all models, time was centered around first semester of attendance at the institution. Standardized effect sizes were calculated using the formula $\delta=$ $\frac{\gamma_{01}}{\sqrt{\sigma^{2}}+\tau}$ (Spybrook, 2008).

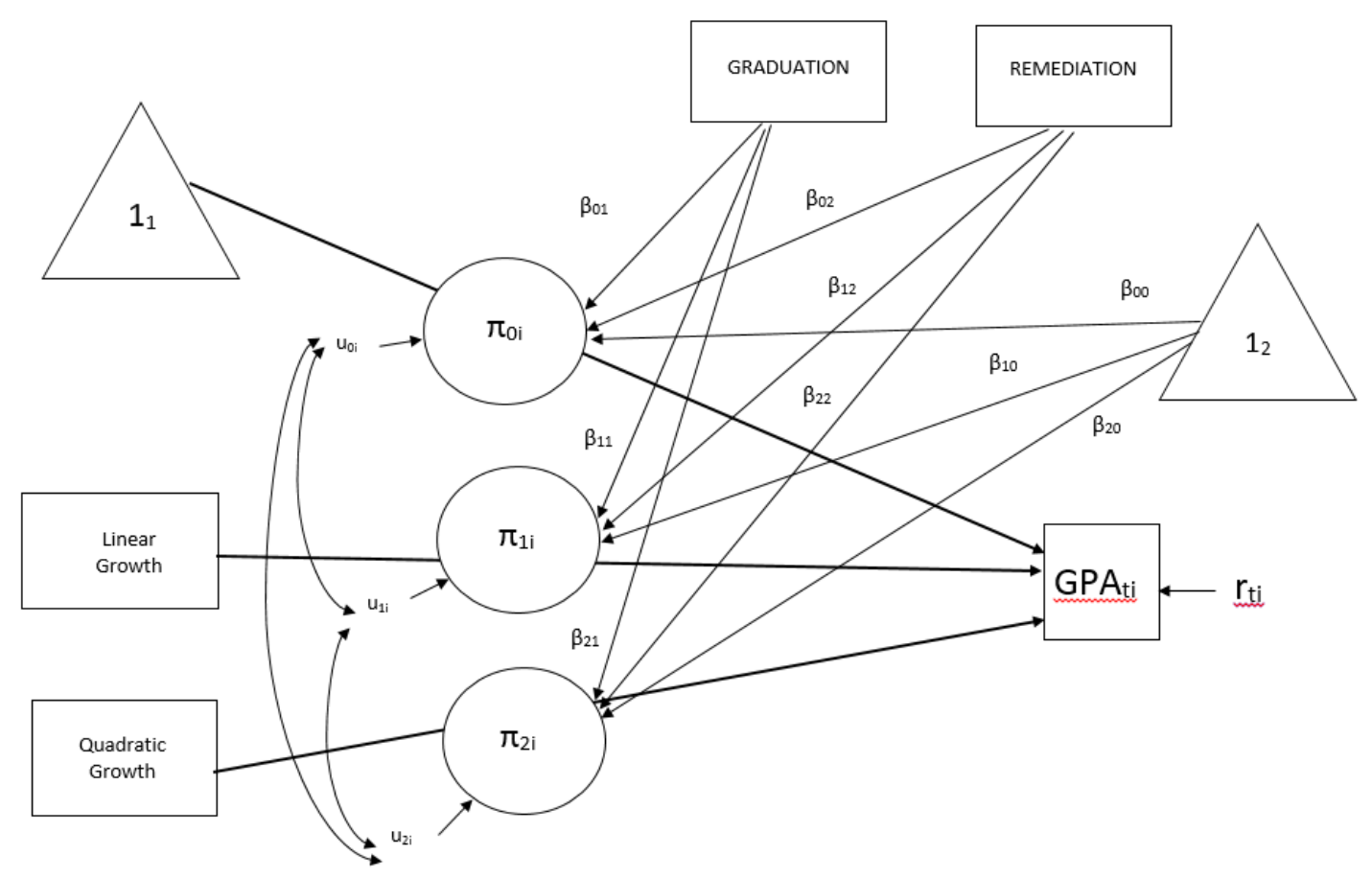

Figure 3.1: Two-level model for student academic achievement with graduation and remediation predictors 
RQ1: What is the average initial level of academic performance and growth trajectory of all students from the first through the eighth semester of enrollment?

The unconditional model with the best data fit (linear, quadratic, or cubic) was examined to answer the first research question. Fixed effects and random effect were reported for the initial intercept and all growth elements. Correlations between intercepts and growth terms were estimated.

RQ2: Does academic performance growth differ for college students who graduate versus those who do not?

The first conditional model examined the growth of student academic performance with one predictor (IV) student graduation status (graduated versus non-graduated). Coefficients, standard errors, and significance levels for each predictor relative to the intercept, linear growth, and quadratic growth were provided. Effect sizes were reported for significant effect on the intercept, linear, and quadratic terms.

RQ3: Is successful mathematics remediation and graduation status significantly associated with student academic performance growth?

a) Does initial level of academic achievement and performance growth differ for students who were successfully remediated in comparison to those who were not, taking into account if they attained a degree or not?

This research question was addressed through two sets of analyses. All students in the original sample $(\mathrm{N}=2,595)$ were included in the analysis. On the first step, a two-level growth model was built examining the effects of graduation and student remediation success. The first predictor was graduation (non-graduates being the reference group). Graduation was coded as 1 
and non-graduation was coded as 0 . The second predictor was successful remediation (notsuccessful remediation being the reference group). Successful remediation was coded as 1 and not-successful remediation was coded as 0 .

Level 1:

$$
Y_{t i}=\pi_{0 i}+\pi_{1 i}\left(\text { time }_{t i}\right)+\pi_{2 i}\left(\text { time }_{t i}\right)^{2}+e_{t i}
$$

Level2:

$$
\begin{aligned}
& \pi_{0 i}=\beta_{00}+\beta_{01}(\text { graduate })+\beta_{02}(\text { successful remediation })+r_{0 i} \\
& \pi_{1 i}=\beta_{10}+\beta_{11}(\text { graduate })+\beta_{12}(\text { succcessful remediation })+r_{1 i} \\
& \pi_{2 i}=\beta_{20}+\beta_{21}(\text { graduate })+\beta_{22}(\text { successful remediation })+r_{2 i}
\end{aligned}
$$

b) Does initial level of academic achievement and performance growth differ for students who were successfully remediated in comparison to those who did not need remediation, taking into account if they attained a degree or not?

A second conditional model was tested to examine the growth of student academic performance across eight semesters with two predictors: graduation status (non-graduation being the reference group) and student successful remediation (no remediation being the reference group). Graduation was coded as 1 and non-graduation was coded as 0 . Successful remediation was coded as 1 and no remediation was coded as 0 . 
Level 1:

$$
Y_{t i}=\pi_{0 i}+\pi_{1 i}\left(\text { time }_{t i}\right)+\pi_{2 i}\left(\text { time }_{t i}\right)^{2}+e_{t i}
$$

Level2:

$$
\begin{aligned}
& \pi_{0 i}=\beta_{00}+\beta_{01}(\text { graduate })+\beta_{02}(\text { successful remediation })+r_{0 i} \\
& \pi_{1 i}=\beta_{10}+\beta_{11}(\text { graduate })+\beta_{12}(\text { succcessful remediation })+r_{1 i} \\
& \pi_{2 i}=\beta_{20}+\beta_{21}(\text { graduate })+\beta_{22}(\text { successful remediation })+r_{2 i}
\end{aligned}
$$

For both models, model indices, coefficients, standard errors, and significance levels for each predictor relative to the intercept, linear growth, and quadratic growth were reported. Effect sizes were reported for significant effect on the intercept, linear, and quadratic terms. 


\section{Chapter 4}

\section{Results}

\section{Descriptive Statistics}

The mean, median, standard deviation, skew and kurtosis were calculated for each semester GPA across the full sample (Table 4.1). The mean initial GPA was 2.99 (SD=.73). On average students performed better in the spring semesters (even numbered semesters) in comparison to the fall semesters in academic year 2 through 4 . The mean GPA for the spring semester in the second academic year (semester 4) was $2.91(\mathrm{SD}=0.80)$ and the average GPA for the fall semester (semester 3) was $2.87, \mathrm{SD}=.80$. Similarly, for third academic year, the spring semester GPA (semester 6) was higher $(M=2.89, \mathrm{SD}=.93)$ than that in the fall semester (semester 5), $M=2.78, \mathrm{SD}=.93$. In spring semester of year 4 , students had the highest GPA, $M=3.01$, $\mathrm{SD}=0.95$ than any other semester. Detailed descriptive statistics are presented in Table 4.1 and means for each semester (semester 1 through semester 8) for those included in the analyses and those excluded are presented on Figure 4.1. 
Table 4.1

Descriptive Statistics, Skew, and Kurtosis for Student GPA for Semesters 1 through 8 for the Overall Sample

\begin{tabular}{lcccccccc}
\hline & & & & & \multicolumn{2}{c}{ Skewness } & \multicolumn{2}{c}{ Kurtosis } \\
\cline { 6 - 9 } & N & Mean & SD & Median & Statistic & SE & Statistic & SE \\
\hline Semester 1 & 1224 & 2.99 & 0.73 & 3.08 & -0.90 & 0.07 & 1.32 & 0.14 \\
Semester 2 & 1214 & 2.98 & 0.74 & 3.06 & -1.09 & 0.07 & 2.16 & 0.14 \\
Semester 3 & 1197 & 2.87 & 0.80 & 3.00 & -0.94 & 0.07 & 1.12 & 0.14 \\
Semester 4 & 1184 & 2.91 & 0.80 & 3.00 & -1.19 & 0.07 & 1.99 & 0.14 \\
Semester 5 & 1192 & 2.78 & 0.93 & 3.00 & -1.03 & 0.07 & 0.89 & 0.14 \\
Semester 6 & 1144 & 2.89 & 0.93 & 3.13 & -1.25 & 0.07 & 1.46 & 0.15 \\
Semester 7 & 1058 & 2.90 & 0.96 & 3.14 & -1.19 & 0.08 & 1.12 & 0.15 \\
Semester 8 & 992 & 3.01 & 0.95 & 3.24 & -1.34 & 0.08 & 1.64 & 0.16 \\
\hline
\end{tabular}

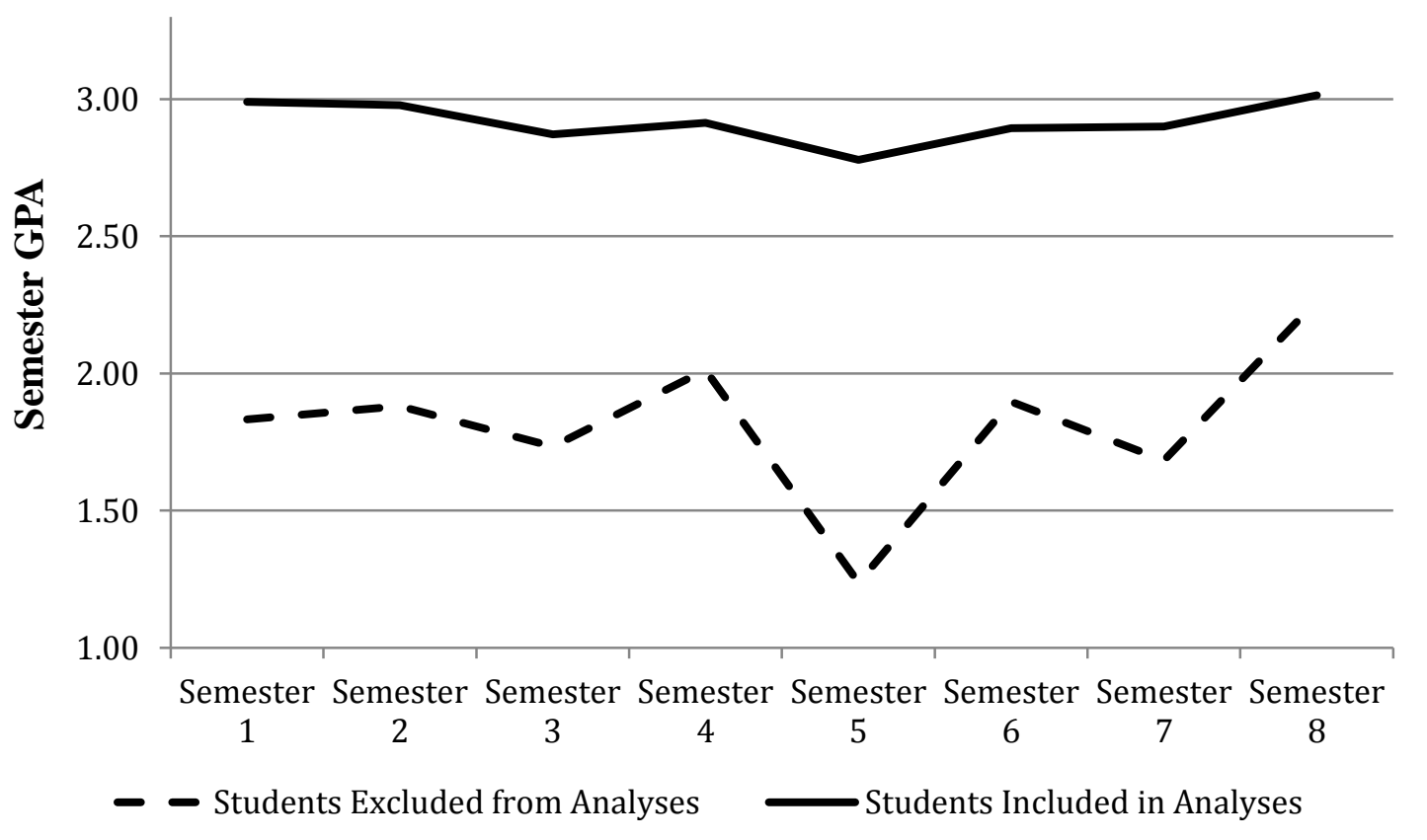

Figure 4.1 Average student academic performance across semesters for students included in the analyses and students excluded in the analyses. 
Descriptive statistics, including the means and standard deviations of student GPAs across eight semesters for non-graduate and graduates are presented in Table 4.2.

Table 4.2

Means and Standard Deviations for Student GPA for Semesters 1 through 8 Based on Graduation Status

\begin{tabular}{|c|c|c|c|c|c|c|}
\hline & \multicolumn{3}{|c|}{ Non-Graduates } & \multicolumn{3}{|c|}{ Graduates } \\
\hline & $\mathrm{N}$ & Mean & SD & $\mathrm{N}$ & Mean & SD \\
\hline Semester 1 & 303 & 2.60 & 0.75 & 921 & 3.12 & 0.67 \\
\hline Semester 2 & 301 & 2.52 & 0.81 & 913 & 3.13 & 0.64 \\
\hline Semester 3 & 294 & 2.29 & 0.88 & 903 & 3.06 & 0.68 \\
\hline Semester 4 & 288 & 2.31 & 0.97 & 896 & 3.11 & 0.63 \\
\hline Semester 5 & 285 & 1.95 & 1.10 & 907 & 3.04 & 0.69 \\
\hline Semester 6 & 236 & 1.95 & 1.11 & 908 & 3.14 & 0.69 \\
\hline Semester 7 & 166 & 1.68 & 1.06 & 892 & 3.13 & 0.74 \\
\hline Semester 8 & 143 & 1.69 & 1.14 & 849 & 3.24 & 0.70 \\
\hline
\end{tabular}

In addition, the mean GPAs for students based on mathematics remediation are presented in Table 4.3. 
Table 4.3

Means and Standard Deviations for Student GPA for Semesters 1 through 8 Based on Mathematics Remediation Status

\begin{tabular}{|c|c|c|c|c|c|c|c|c|c|}
\hline & \multicolumn{3}{|c|}{$\begin{array}{c}\text { Not Successful } \\
\text { Mathematics } \\
\text { Remediation }\end{array}$} & \multicolumn{3}{|c|}{$\begin{array}{c}\text { Successful } \\
\text { Mathematics } \\
\text { Remediation } \\
\end{array}$} & \multicolumn{3}{|c|}{$\begin{array}{c}\text { No Mathematics } \\
\text { Remediation Needed }\end{array}$} \\
\hline & $\mathrm{N}$ & Mean & $\mathrm{SD}$ & $\mathrm{N}$ & Mean & SD & $\mathrm{N}$ & Mean & $\mathrm{SD}$ \\
\hline Semester 1 & 44 & 2.20 & 0.91 & 393 & 2.72 & 0.74 & 787 & 3.17 & 0.64 \\
\hline Semester 2 & 43 & 2.39 & 1.09 & 390 & 2.71 & 0.71 & 781 & 3.14 & 0.67 \\
\hline Semester 3 & 41 & 2.05 & 1.01 & 383 & 2.62 & 0.78 & 773 & 3.04 & 0.74 \\
\hline Semester 4 & 37 & 2.54 & 1.00 & 380 & 2.67 & 0.78 & 767 & 3.05 & 0.77 \\
\hline Semester 5 & 41 & 1.96 & 1.10 & 378 & 2.54 & 0.90 & 773 & 2.94 & 0.89 \\
\hline Semester 6 & 37 & 2.17 & 1.27 & 365 & 2.61 & 0.95 & 742 & 3.07 & 0.84 \\
\hline Semester 7 & 31 & 1.68 & 1.26 & 330 & 2.65 & 0.90 & 697 & 3.07 & 0.90 \\
\hline Semester 8 & 28 & 2.10 & 1.13 & 313 & 2.76 & 0.99 & 651 & 3.18 & 0.87 \\
\hline
\end{tabular}

Correlations across the GPAs across the eight semesters were also calculated.

Correlations reveal the direction and magnitude of the relationship between each pair of semester GPA scores. Semester GPA was significantly and positively correlated for each pair of semesters. The correlation magnitude was moderate and ranged from $r=.37$ to $r=.62$. The lowest correlation was observed between semester 1 and semester $8(r=.37, \mathrm{p}<.001)$ and the highest was detected between semester 4 and semester 5 ( $r=.62, \mathrm{p}<.001)$. All correlations are listed in Table 4.4. 
Table 4.4

Pairwise Correlations across Semester GPA

\begin{tabular}{llccccccc}
\hline & & 1 & 2 & 3 & 4 & 5 & 6 & 7 \\
\hline \multirow{2}{*}{ 1. Semester 1 } & & -- & & & & & & \\
& & & & & & & & \\
2. Semester 2 & Correlation & $.57^{* *}$ & -- & & & & & \\
& $\mathrm{N}$ & 1214 & & & & & & \\
3.Semester 3 & Correlation & $.49^{* *}$ & $.55^{* *}$ & -- & & & & \\
& $\mathrm{N}$ & 1197 & 1190 & & & & & \\
$4.5 e m e s t e r ~ 4$ & Correlation & $.47^{* * *}$ & $.52^{* * *}$ & $.60^{* *}$ & -- & & & \\
& $\mathrm{N}$ & 1184 & 1176 & 1171 & & & & \\
5. Semester 5 & Correlation & $.41^{* * *}$ & $.49^{* *}$ & $.51^{* *}$ & $.62^{* *}$ & -- & & \\
& $\mathrm{N}$ & 1192 & 1182 & 1172 & 1164 & & & \\
6. Semester 6 & Correlation & $.42^{* *}$ & $.45^{* *}$ & $.49^{* *}$ & $.53^{* *}$ & $.61^{* *}$ & -- & \\
& $\mathrm{N}$ & 1144 & 1134 & 1118 & 1109 & 1126 & & \\
7. Semester 7 & Correlation & $.37^{* * *}$ & $.39^{* *}$ & $.51^{* *}$ & $.48^{* *}$ & $.57^{* *}$ & $.63^{* *}$ & -- \\
& $\mathrm{N}$ & 1058 & 1049 & 1033 & 1022 & 1031 & 1033 & \\
8. Semester 8 & Correlation & $.39^{* * *}$ & $.41^{* *}$ & $.49^{* *}$ & $.48^{* * *}$ & $.52^{* *}$ & $.58^{* *}$ & $.67^{* *}$ \\
& $\mathrm{~N}$ & 992 & 985 & 970 & 957 & 966 & 969 & 983 \\
\hline
\end{tabular}

\section{Preliminary Analyses Results}

Growth curve modeling was employed to examine change in student academic

performance over time. This approach allowed for presenting individual changes in academic performance across the eight semesters. Growth models provide an opportunity to study student initial level of achievement as well as rates of growth and any changes of those rates within and between groups (e.g., graduates versus non-graduates, students successful at remediation versus those who did not need remediation). These models provide flexibility relative to comparing groups and changes across time to estimate not only what differences in time trajectories exist but also when those shifts in trajectories appear. The model is often represented as a set of equations (1) that represent a student score across time. 
Level 1:

$$
Y_{t i}=\pi_{0 i}+\pi_{1 i} a_{t i}+\pi_{2 i} a_{t i}^{2}+e_{t i}
$$

Where:

$Y_{t i}$ is the student GPA score in semester $\mathrm{t}$ for student $\mathrm{i}$

$\pi_{0 i}$ is the initial GPA score at time 0 (first semester) for student $\mathrm{i}$

$\pi_{1 i}$ is the linear change over time for student $\mathrm{i}$

$\pi_{2 i}$ is deviation from linear growth over time for student $\mathrm{i}$

$e_{t i}$ is the error for student $i$ from the estimate of $Y_{t i}$

Level 2:

$$
\pi_{p i}=\beta_{p 0}+\sum_{q=1}^{Q p} \beta_{p q} x_{q i}+r_{p i}
$$

Where:

$\pi_{p i}$ is a parameter including initial status, linear change, or non-linear change

$\beta_{p 0}$ is the effect of student characteristics on a parameter $\pi_{p i}$

$r_{p i}$ is error for student i for a parameter estimate $\left(\pi_{p i}\right)$

In those equations, $\pi_{1 i}$ and $\pi_{2 i}$ are interesting in terms of determining changes in the outcome variables (GPA) across time. For example, a positive $\pi_{1 i}$ would be associated with an increasing trend in the outcome variable while a negative $\pi_{1 i}$ would indicate a decrease in GPA. Further, $\pi_{2 i}$ indicates how fast or how slow changes in GPA occur and is often interpreted in conjunction with $\pi_{1 i}$. For instance, a positive linear slope with a positive quadratic term indicates that there is growth in the outcome variable and this growth accelerates across time. If the linear slope is negative but the quadratic term is positive, this is an indication that the decline in the outcome variable slows down over time. If such a deceleration is large enough, it is possible for the decline to taper off and even turn into a positive growth. 


\section{RQ1: What is the average initial level of academic performance and growth trajectory of all students from the first through the eighth semester of enrollment?}

Two initial models were examined to determine which one presents a better fit for the data. These models were unconditional and no predictors were included in estimating the intercept or the growth parameters. The goodness of fit indices AIC and BIC indicated that the quadratic model was a better fit for the data in comparison to the linear model (Table 4.5). The trajectories based on the linear and quadratic growth are shown on Figure 4.2.

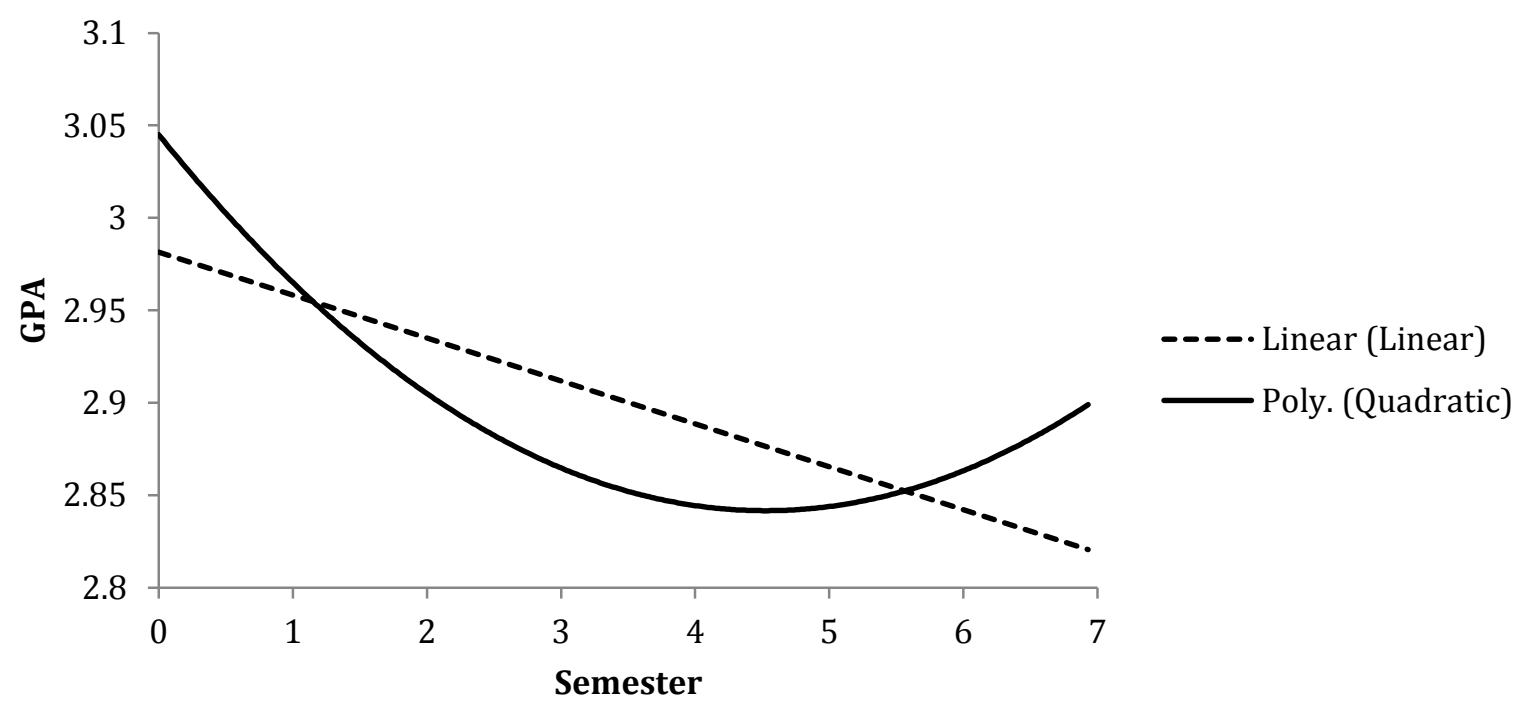

Figure 4.2 Depiction of linear and nonlinear trajectories across eight semesters

Fixed effects for the quadratic model revealed the average intercept was 3.06, the average linear slope was -0.09 , and the average quadratic growth was 0.01 , all significant at $\mathrm{p}<.001$ level. The model implied trajectory indicates that there is an initial rapid decline up until semester 4 or semester 5 , followed by a recovery and growth between semester 4 and semester 8 . There was also observed significant individual variability for the intercept ( $\left.\tau_{00}=0.2617\right)$, linear slope $\left(\tau_{11}=0.0290\right)$ and quadratic curvature $\left(\tau_{22}=0.0004\right)$, all significant at $\mathrm{p}<.001$ level. The correlations among the intercept and the individual growth terms were calculated. 
Table 4.5

Parameter Estimate for Two-Level Growth Curve Models of College GPA

\begin{tabular}{|c|c|c|c|c|c|c|}
\hline \multirow[b]{2}{*}{ Parameter } & \multicolumn{2}{|c|}{ Linear model } & \multicolumn{4}{|c|}{ Quadratic model } \\
\hline & Coefficient (SE) & $95 \% \mathrm{CI}$ & & Coefficient (SE) & $95 \% \mathrm{CI}$ & \\
\hline \multicolumn{7}{|l|}{ Fixed Effects } \\
\hline Intercept $\left(\beta_{00}\right)$ & $2.982 *(0.018)$ & {$[2.95,3.02]$} & & $3.045^{*}(0.020)$ & {$[3.00,3.08]$} & \\
\hline Time: Linear $\left(\beta_{10}\right)$ & $-0.023 *(0.005)$ & {$[-0.03,-0.01]$} & & $-0.090 *(0.010)$ & {$[-0.110,-0.070]$} & \\
\hline Time $^{2}$ : Quadratic $\left(\beta_{20}\right)$ & -- & -- & & $0.010 *(0.001)$ & {$[0.008,0.012]$} & \\
\hline Random Effects & Variance & $\chi^{2}$ & $\mathrm{df}$ & Variance & $\chi^{2}$ & df \\
\hline Level one $\left(\sigma^{2}\right)$ & 0.285 & & & 0.2728 & & \\
\hline Intercept $\left(\tau_{00}\right)$ & $0.266^{*}$ & 3616.50 & 1179 & $0.2617 *$ & 2769.99 & 1179 \\
\hline Linear $\left(\tau_{11}\right)$ & $0.012^{*}$ & 3007.26 & 1179 & $0.0290 *$ & 1531.20 & 1179 \\
\hline \multirow[t]{2}{*}{ Quadratic $\left(\tau_{22}\right)$} & -- & -- & & $0.0004 *$ & 1614.97 & 1179 \\
\hline & Covariance & & & & & \\
\hline Intercept, Linear $\left(\tau_{10}\right)$ & 0.001 & & & -0.0012 & & \\
\hline Intercept, Quadratic $\left(\tau_{20}\right)$ & -- & -- & & 0.0004 & & \\
\hline \multirow[t]{2}{*}{ Linear, Quadratic $\left(\tau_{21}\right)$} & -- & -- & & -0.0028 & & \\
\hline & $\mathrm{AIC}$ & $\mathrm{BIC}$ & & $\mathrm{AIC}$ & $\mathrm{BIC}$ & \\
\hline Fit Indices & 17846.54 & 17895.42 & & 17779.06 & 17814.83 & \\
\hline
\end{tabular}

Note: Time is measured in semesters and is centered on the first time point so that zero corresponds to the first semester in college; standard errors (SE) follow parameter estimates in parentheses; for variance estimates $\tau_{00}, \tau_{11}$, and $\tau_{22}$ are residual variances, while $\tau_{10}, \tau_{20}$, and $\tau_{21}$ are residual covariances; $* p<.001$ 
Higher intercepts were associated with slower linear growth $(r=-0.01)$ and higher quadratic growth $(r=0.03)$. In addition, there was a large negative correlation between the linear and quadratic growth terms $(r=-.78)$. This was indicative of the fact that greater linear change was counterbalanced by greater curvature over time.

The students from four cohorts were included in the analyses. Even though differences across cohorts were not the focus on the current investigation, cohort effects were examined as a part of the preliminary analyses. Figures 4.3 through 4.6 display the means for each semester across cohorts and Table 4.6 lists the means and standard deviations for each semester and each cohort.

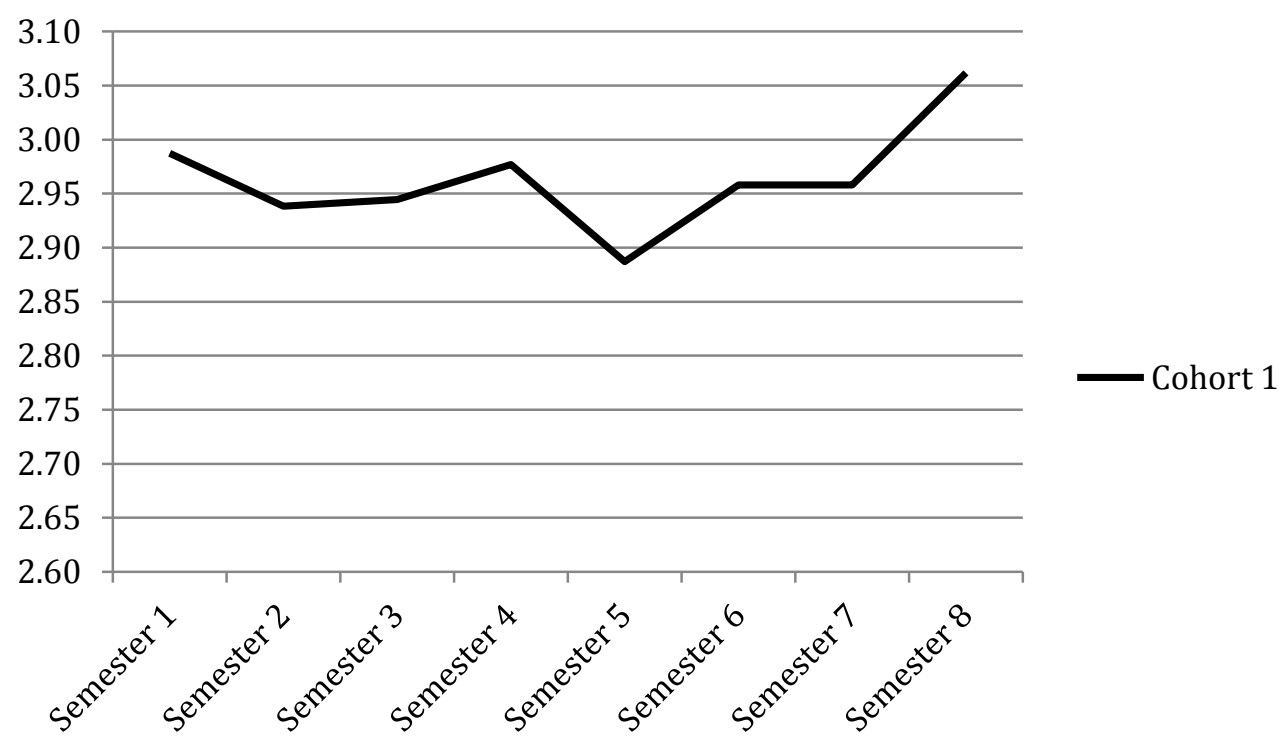

Figure 4.3 Mean GPA for each semester from semester 1 through semester 8 for Cohort 1 


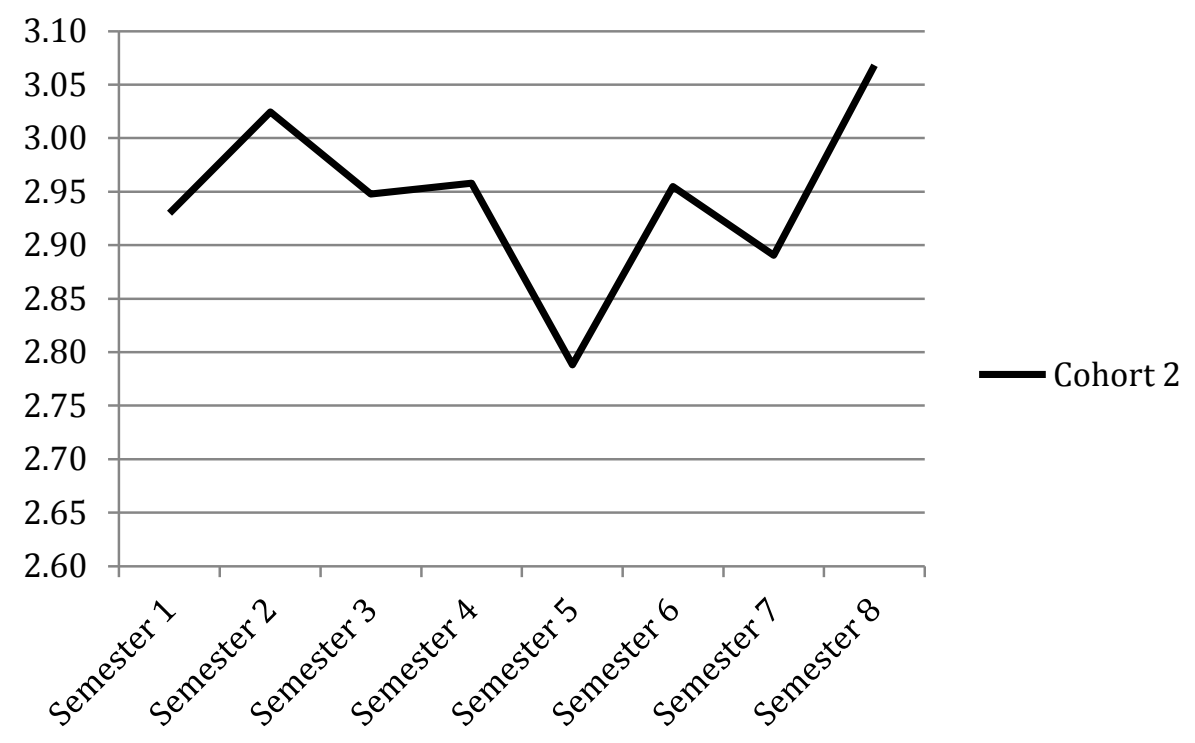

Figure 4.4 Mean GPA for each semester from semester 1 through semester 8 for Cohort 2

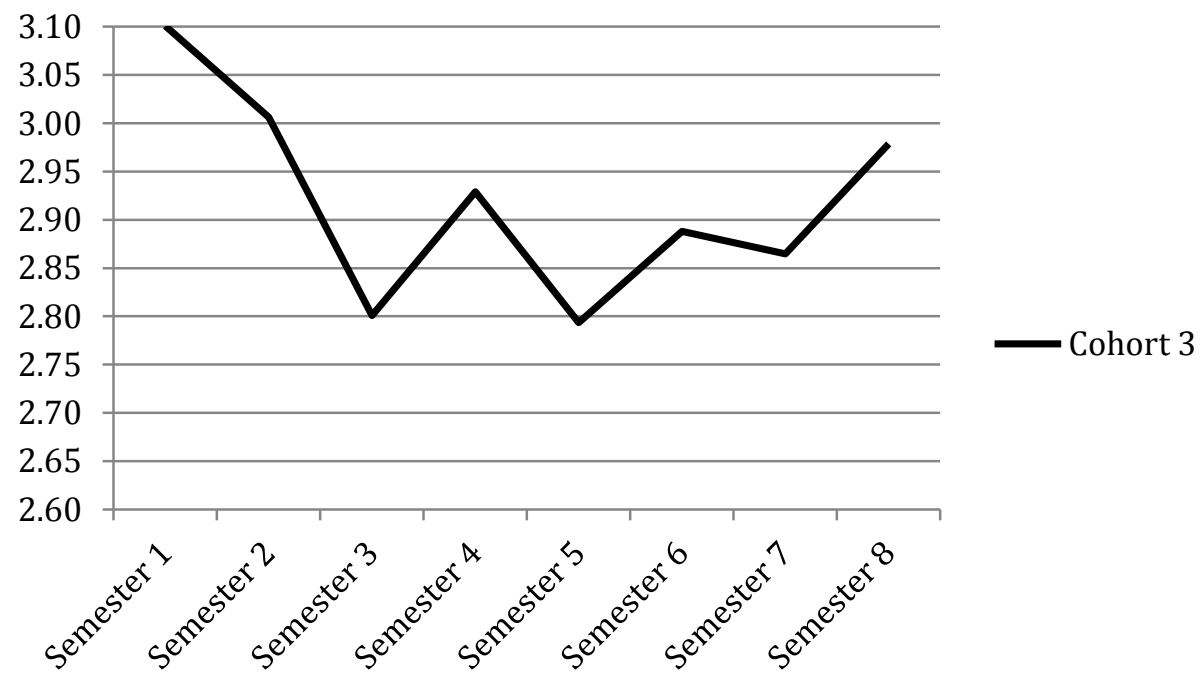

Figure 4.5 Mean GPA for each semester from semester 1 through semester 8 for Cohort 3 


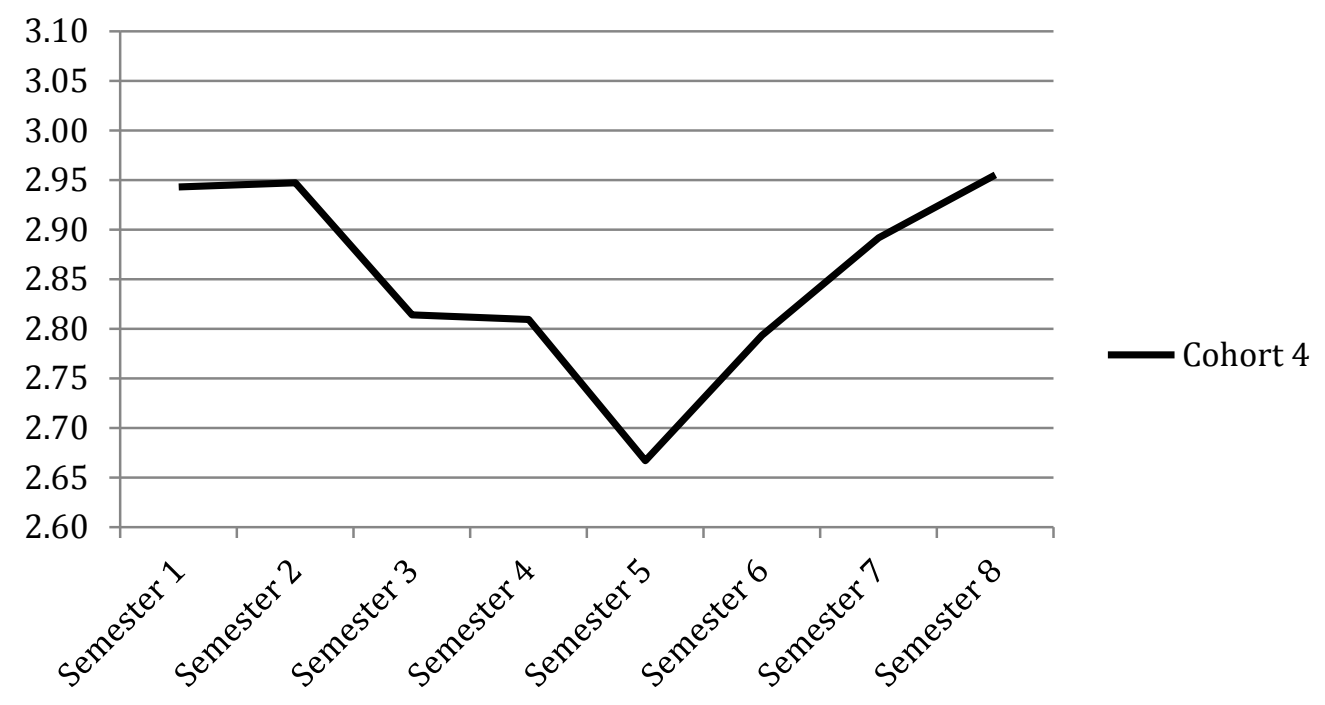

Figure 4.6 Mean GPA for each semester from semester 1 through semester 8 for Cohort 4 Table 4.6

GPA Means and Standard Deviations for Each Semester across the Four Cohorts

\begin{tabular}{ccccccccc}
\hline & Sem 1 & Sem 2 & Sem 3 & Sem 4 & Sem 5 & Sem 6 & Sem 7 & Sem 8 \\
& $M$ & $M$ & $M$ & $M$ & $M$ & $M$ & $M$ & $M$ \\
& $(\mathrm{SD})$ & $(\mathrm{SD})$ & $(\mathrm{SD})$ & $(\mathrm{SD})$ & $(\mathrm{SD})$ & $(\mathrm{SD})$ & $(\mathrm{SD})$ & $(\mathrm{SD})$ \\
\hline Cohort 1 & 2.99 & 2.94 & 2.94 & 2.98 & 2.89 & 2.96 & 2.96 & 3.06 \\
& $(0.74)$ & $(0.75)$ & $(0.73)$ & $(0.70)$ & $(0.84)$ & $(0.90)$ & $(0.95)$ & $(0.95)$ \\
Cohort 2 & 2.93 & 3.02 & 2.95 & 2.96 & 2.79 & 2.95 & 2.89 & 3.07 \\
& $(0.76)$ & $(0.71)$ & $(0.72)$ & $(0.85)$ & $(0.94)$ & $(0.82)$ & $(0.95)$ & $(0.90)$ \\
Cohort 3 & 3.1 & 3.01 & 2.8 & 2.93 & 2.79 & 2.89 & 2.86 & 2.98 \\
& $(0.62)$ & $(0.74)$ & $(0.89)$ & $(0.82)$ & $(0.88)$ & $(0.94)$ & $(0.95)$ & $(0.97)$ \\
Cohort 4 & 2.94 & 2.95 & 2.81 & 2.81 & 2.67 & 2.79 & 2.89 & 2.95 \\
& $(0.78)$ & $(0.74)$ & $(0.84)$ & $(0.83)$ & $(1.02)$ & $(1.02)$ & $(0.99)$ & $(0.98)$ \\
\hline
\end{tabular}

To determine if cohort effects existed, each separate cohort was tested whether it differed from the overall (sample) mean and growth terms (linear and quadratic). Given the approximately equal sample size across cohorts $\left(\mathrm{n}_{1}=283, \mathrm{n}_{2}=286, \mathrm{n}_{3}=312, \mathrm{n}_{4}=343\right)$, unweighted effects coding was utilized (Cohen et al., 2013). In the first part of the analyses, Cohort 1 was used as a reference group and Cohort $2(\mathrm{C} 1)$, Cohort $3(\mathrm{C} 2)$, and Cohort $4(\mathrm{C} 4)$ were entered in model. This model tested if any of Cohort 2 , Cohort 3 , and Cohort 4 are significantly difference 
than the overall mean. This coding approach does not allow to test for differences between the reference group (Cohort 1) and the overall mean, thus a second model was built to examine differences for Cohort 1 . The results revealed that Cohort 3 (C2) had a significantly different intercept $\left(\beta_{01}=0.076, p=0.027\right)$ and a significantly different linear slope $\left(\beta_{01}=-0.039, p=0.026\right)$ (Table 4.7 and Table 4.8). 
Table 4.7

Fixed Effects for the Hierarchical Model with Cohort Effects

\begin{tabular}{|c|c|c|c|}
\hline Fixed effects & Coefficient (SE) & $t(d f)$ & $P$ \\
\hline \multicolumn{4}{|c|}{ Model for intercept of college GPA $\left(\pi_{0 i}\right)$} \\
\hline \multicolumn{4}{|c|}{ Intercept } \\
\hline \multicolumn{4}{|l|}{ Cohort 2 (C1) } \\
\hline Intercept $\left(\beta_{01)}\right.$ & $-0.013(0.036)$ & $-0.366(1220)$ & 0.714 \\
\hline \multicolumn{4}{|l|}{ Cohort 3 (C2) } \\
\hline Intercept $\left(\beta_{02}\right)$ & $0.076(0.034)$ & $2.216(1220)$ & 0.027 \\
\hline \multicolumn{4}{|l|}{ Cohort 4 (C3) } \\
\hline Intercept $\left(\beta_{03}\right)$ & $-0.032(0.033)$ & $-0.971(1220)$ & 0.332 \\
\hline \multicolumn{4}{|c|}{ Model for linear growth effect $\left(\pi_{1 i}\right)$} \\
\hline \multicolumn{4}{|c|}{ Intercept } \\
\hline Intercept $\left(\beta_{10}\right)$ & $-0.083(0.010)$ & $-8.055(1220)$ & $<0.001$ \\
\hline \multicolumn{4}{|l|}{ Cohort $2(\mathrm{C} 1)$} \\
\hline Intercept $\left(\beta_{11)}\right.$ & $0.018(0.018)$ & $0.997(1220)$ & 0.319 \\
\hline \multicolumn{4}{|l|}{ Cohort $3(\mathrm{C} 2)$} \\
\hline Intercept $\left(\beta_{12}\right)$ & $-0.039(0.018)$ & $-2.230(1220)$ & 0.026 \\
\hline \multicolumn{4}{|l|}{ Cohort 4 (C3) } \\
\hline Intercept $\left(\beta_{13}\right)$ & $-0.027(0.017)$ & $-1.548(1220)$ & 0.122 \\
\hline \multicolumn{4}{|c|}{ Model for quadratic growth effect $\left(\pi_{2 i}\right)$} \\
\hline \multicolumn{4}{|c|}{ Intercept } \\
\hline Intercept $\left(\beta_{20}\right)$ & $0.009(0.001)$ & $6.131(1220)$ & $<0.001$ \\
\hline \multicolumn{4}{|l|}{ Cohort 2 (C1) } \\
\hline Intercept $\left(\beta_{21}\right)$ & $-0.001(0.002)$ & $-0.416(1220)$ & 0.678 \\
\hline \multicolumn{4}{|l|}{ Cohort 3 (C2) } \\
\hline Intercept $\left(\beta_{22}\right)$ & $0.004(0.002)$ & $1.497(1220)$ & 0.135 \\
\hline \multicolumn{4}{|l|}{ Cohort 4 (C3) } \\
\hline Intercept $\left(\beta_{23}\right)$ & $0.002(0.002)$ & $0.935(1220)$ & 0.350 \\
\hline
\end{tabular}

Note: Time is measured in semesters and is centered so that zero corresponds to the first semester in college; Cohort 2, Cohort 3, and Cohort 4 are unweighted cohort effects with Cohort 1 as the reference group; 
Table 4.8

Random Effects for the Hierarchical Model with Cohort Effects

\begin{tabular}{lcccc}
\hline & $\begin{array}{c}\text { Variance } \\
\text { component }\end{array}$ & df & $\chi^{2}$ & $p$ \\
\hline $\begin{array}{c}\text { Level I (within students) } \\
\text { Temporal variation, } e_{t i}\end{array}$ & 0.286 & & & \\
$\begin{array}{c}\text { Level II (between students) } \\
\text { Individual initial } \\
\text { status, } r_{0 i} \\
\quad \begin{array}{l}\text { Individual linear } \\
\text { growth rate, } r_{1 i} \\
\text { Individual quadratic }\end{array}\end{array}$ & 0.286 & 1220 & 2928.10 & $<0.001$ \\
growth rate, $r_{2 i}$ & 0.032 & 1220 & 1579.44 & $<0.001$ \\
\hline
\end{tabular}

In order to determine if the Cohort 1 was different than the overall mean, a second model was tested with Cohort 2 being the base group and Cohort 1 (D1), Cohort 3 (D2), and Cohort4 (D4) included in the model. The results showed that in addition to Cohort 3 differences, Cohort 1 has a significantly different linear growth $\left(\beta_{11}=0.048, p=0.009\right)$ (Table 4.9 and Table 4.10). 
Table 4.9

Fixed Effects for the Hierarchical Model with Cohort Effects

\begin{tabular}{|c|c|c|c|}
\hline Fixed effects & Coefficient (SE) & $t(d f)$ & $p$ \\
\hline \multicolumn{4}{|c|}{ Model for intercept of college GPA $\left(\pi_{0 i}\right)$} \\
\hline $\begin{array}{l}\text { Intercept } \\
\text { Intercept }\left(\beta_{00}\right)\end{array}$ & \multicolumn{2}{|c|}{ Intercept } & $<0.001$ \\
\hline \multicolumn{4}{|l|}{ Cohort 1 (D1) } \\
\hline Intercept $\left(\beta_{01)}\right.$ & $-0.031(0.036)$ & $-0.868(1220)$ & 0.386 \\
\hline \multicolumn{4}{|l|}{ Cohort 3 (D2) } \\
\hline Intercept $\left(\beta_{02}\right)$ & $0.076(0.034)$ & $2.216(1220)$ & 0.027 \\
\hline \multicolumn{4}{|l|}{ Cohort 4 (D3) } \\
\hline Intercept $\left(\beta_{03}\right)$ & $-0.032(0.033)$ & $-0.971(1220)$ & 0.332 \\
\hline \multicolumn{4}{|c|}{ Model for linear growth effect $\left(\pi_{1 i}\right)$} \\
\hline \multicolumn{4}{|c|}{ Intercept } \\
\hline Intercept $\left(\beta_{10}\right)$ & $-0.083(0.010)$ & $-8.055(1220)$ & $<0.001$ \\
\hline \multicolumn{4}{|l|}{ Cohort 1 (D1) } \\
\hline Intercept $\left(\beta_{11)}\right.$ & $0.048(0.018)$ & $2.622(1220)$ & 0.009 \\
\hline \multicolumn{4}{|l|}{ Cohort 3 (D2) } \\
\hline Intercept $\left(\beta_{12)}\right.$ & $-0.039(0.018)$ & $-2.230(1220)$ & 0.026 \\
\hline \multicolumn{4}{|l|}{ Cohort 4 (D3) } \\
\hline Intercept $\left(\beta_{13)}\right.$ & $-0.027(0.017)$ & $-1.548(1220)$ & 0.122 \\
\hline \multicolumn{4}{|c|}{ Model for quadratic growth effect $\left(\pi_{2 i}\right)$} \\
\hline \multicolumn{4}{|l|}{ Intercept } \\
\hline Intercept $\left(\beta_{20}\right)$ & $0.009(0.001)$ & $6.131(1220)$ & $<0.001$ \\
\hline \multicolumn{4}{|l|}{ Cohort 1} \\
\hline Intercept $\left(\beta_{21)}\right.$ & $-0.005(0.003)$ & $-1.917(1220)$ & 0.055 \\
\hline \multicolumn{4}{|l|}{ Cohort 3} \\
\hline Intercept $\left(\beta_{22)}\right.$ & $0.004(0.002)$ & $1.497(1220)$ & 0.135 \\
\hline \multicolumn{4}{|l|}{ Cohort 4} \\
\hline Intercept $\left(\beta_{23}\right)$ & $0.002(0.002)$ & $0.935(1220)$ & 0.350 \\
\hline
\end{tabular}

Note: Time is measured in semesters and is centered so that zero corresponds to the first semester in college; Cohort 1, Cohort 3, and Cohort 4 are unweighted cohort effects with Cohort 2 as the reference group; 
Table 4.10

Random Effects for the Hierarchical Model with Cohort Effects

\begin{tabular}{lcccc}
\hline & $\begin{array}{c}\text { Variance } \\
\text { component }\end{array}$ & df & $\chi^{2}$ & $p$ \\
\hline $\begin{array}{c}\text { Level I (within students) } \\
\text { Temporal variation, } e_{t i}\end{array}$ & 0.286 & & & \\
$\begin{array}{c}\text { Level II (between students) } \\
\text { Individual initial }\end{array}$ & 0.286 & 1220 & 2928.10 & $<0.001$ \\
$\begin{array}{c}\text { status, } r_{0 i} \\
\text { Individual linear } \\
\text { growth rate, } r_{1 i} \\
\text { Individual quadratic }\end{array}$ & 0.032 & 1220 & 1579.44 & $<0.001$ \\
growth rate, $r_{2 i}$ & 0.0005 & 1220 & 1657.44 & $<0.001$ \\
\hline
\end{tabular}

Specific cohort effects were detected as indicated above and as a result the second coding of the cohort effects remained in all models to account for cohort differences. The second coding scheme was selected as it captured all significant cohort effects. The effects were unweighted and Cohort 1 (D1), Cohort 3(D2), and Cohort (D4) were coded with Cohort 2 being the reference group.

\section{RQ2: Does academic performance growth differ for college students who graduate versus those who do not?}

A model for college performance with graduation as a predictor was estimated to examine differences in trajectories for graduates versus non-graduates. Non-graduates were the reference group in this model and were coded as 0 while graduates were coded as 1 . Equation 1 presents the Level 1 and Level 2 equations for the conditional model. 
Level 1:

$$
G P A_{t i}=\pi_{0 i}+\pi_{1 i}\left(\text { time }_{t i}\right)+\pi_{2 i}\left(\text { time }_{t i}\right)^{2}+e_{t i}
$$

Level2:

$$
\begin{aligned}
& \pi_{0 i}=\beta_{00}+\beta_{01}(\text { graduate })+\beta_{02}(D 1)+\beta_{03}(D 2)+\beta_{04}(D 3)+r_{0 i} \\
& \pi_{1 i}=\beta_{10}+\beta_{11}(\text { graduate })+\beta_{12}(D 1)+\beta_{13}(D 2)+\beta_{14}(D 3)+r_{1 i} \\
& \pi_{2 i}=\beta_{20}+\beta_{21}(\text { graduate })+\beta_{22}(D 1)+\beta_{23}(D 2)+\beta_{24}(D 3)+r_{2 i}
\end{aligned}
$$

The parameters estimated for the growth model with graduation as a predictor are presented in Table 4.11 and Table 4.12. The first semester GPA of those who did not graduate was 2.65 . Those who eventually graduated started about 0.50 GPA points higher for an average first semester GPA of 3.15. The between-student variance in the predicted initial GPA was statistically significant $(p<.001)$ indicating that there are differences in initial student achievement after accounting for graduation status and cohort effects. The effect size of graduation was very large $(\delta=.72)$.

Students who did not graduate experienced decline $\left(\beta_{10}=-0.139\right)$ and the lack of curvature $\left(\beta_{20}=-0.003\right)$ indicated that the rate of this decline remained relatively consistent over time. For example, the predicted GPA for the first semester was 2.65 , while that during the second semester was 2.51 , a decline of 0.14 GPA points. By semester four, a student's predicted GPA was 2.05 and that in semester five was 1.88 , which indicated a difference of 0.17 GPA points and a semester decline greater than that in the first semesters.

Those who graduated experienced a different change in performance. First, their overall instantaneous initial growth was smaller with a cumulative effect of $-0.061\left(\beta_{10}=-0.139\right.$, $\left.\beta_{11}=0.078,-0.139+0.078=-0.061\right)$ and the significant positive quadratic term $\left(\beta_{21}=0.014, p<\right.$ $.001)$ indicated that this declined slowed down over time and eventually turned into growth in 
GPA. For instance, the predicted GPA for the first semester for those who graduated was 3.16, while that during the second semester was 3.11, a decline of 0.05 GPA points. By semester four, a student's predicted GPA was 3.09 and that in semester five was 3.13, which indicated a gain of 0.04 GPA points. The effect size of graduation was small for the linear growth $(\delta=.14)$ and very small for the quadratic growth $(\delta=.03)$.

The between-student variances for the linear and quadratic growth were statistically significant $(p<.001)$ indicating that there were between student differences in linear and quadratic change after accounting for graduation status and cohort effects. 
Table 4.11

Fixed Effects for the Hierarchical Model Based on Student Graduation

\begin{tabular}{|c|c|c|c|}
\hline Fixed effects & Coefficient (SE) & $t(d f)$ & $p$ \\
\hline \multicolumn{4}{|c|}{ Model for intercept of college GPA $\left(\pi_{0 i}\right)$} \\
\hline \multicolumn{4}{|c|}{ Intercept } \\
\hline Intercept $\left(\beta_{00}\right)$ & $2.653(0.040)$ & $66.975(1175)$ & $<0.001$ \\
\hline \multicolumn{4}{|l|}{ Graduation status } \\
\hline Intercept $\left(\beta_{01)}\right.$ & $0.503(0.045)$ & $11.178(1175)$ & $<0.001$ \\
\hline \multicolumn{4}{|l|}{ Cohort 1 (D1) } \\
\hline Intercept $\left(\beta_{02}\right)$ & $-0.040(0.033)$ & $-1.197(1175)$ & 0.231 \\
\hline \multicolumn{4}{|l|}{ Cohort 3 (D2) } \\
\hline Intercept $\left(\beta_{03}\right)$ & $0.082(0.032)$ & $2.534(1175)$ & 0.011 \\
\hline \multicolumn{4}{|l|}{ Cohort 4 (D3) } \\
\hline Intercept $\left(\beta_{04)}\right.$ & $-0.011(0.031)$ & $-0.341(1175)$ & 0.734 \\
\hline \multicolumn{4}{|c|}{ Model for linear growth effect $\left(\pi_{1 i}\right)$} \\
\hline \multicolumn{4}{|c|}{ Intercept } \\
\hline Intercept $\left(\beta_{10}\right)$ & $-0.139(0.022)$ & $-6.221(1175)$ & $<0.001$ \\
\hline \multicolumn{4}{|l|}{ Graduation status } \\
\hline Intercept $\left(\beta_{11)}\right.$ & $0.078(0.025)$ & $3.140(1175)$ & 0.002 \\
\hline \multicolumn{4}{|l|}{ Cohort 1 (D1) } \\
\hline Intercept $\left(\beta_{12}\right)$ & $0.042(0.018)$ & $2.351(1775)$ & 0.019 \\
\hline \multicolumn{4}{|l|}{ Cohort 3 (D2) } \\
\hline Intercept $\left(\beta_{13}\right)$ & $-0.033(0.017)$ & $-1.885(1775)$ & 0.06 \\
\hline \multicolumn{4}{|l|}{ Cohort 4 (D3) } \\
\hline Intercept $\left(\beta_{14)}\right.$ & $-0.014(0.017)$ & $-0.809(1175)$ & 0.418 \\
\hline \multicolumn{4}{|c|}{ Model for quadratic growth effect $\left(\pi_{2 i}\right)$} \\
\hline \multicolumn{4}{|c|}{ Intercept } \\
\hline Intercept $\left(\beta_{20}\right)$ & $-0.003(0.003)$ & $-0.973(1175)$ & 0.331 \\
\hline \multicolumn{4}{|l|}{ Graduation status } \\
\hline Intercept $\left(\beta_{21}\right)$ & $0.014(0.004)$ & $3.727(1175)$ & $<0.001$ \\
\hline \multicolumn{4}{|l|}{ Cohort 1 (D1) } \\
\hline Intercept $\left(\beta_{22}\right)$ & $-0.005(0.002)$ & $-2.132(1175)$ & 0.033 \\
\hline \multicolumn{4}{|l|}{ Cohort 3 (D2) } \\
\hline Intercept $\left(\beta_{23}\right)$ & $0.003(0.002)$ & $1.423(1175)$ & 0.155 \\
\hline \multicolumn{4}{|l|}{ Cohort 4 (D3) } \\
\hline Intercept $\left(\beta_{24}\right)$ & $0.002(0.002)$ & $0.916(1175)$ & 0.36 \\
\hline
\end{tabular}

Note: Time is measured in semesters and is centered so that zero corresponds to the first semester in college; Cohort 1 , Cohort 3, and Cohort 4 are unweighted cohort effects with Cohort 2 as the reference group; 
Table 4.12

Random Effects for the Hierarchical Model Based on Student Graduation

\begin{tabular}{lcccc}
\hline & $\begin{array}{c}\text { Variance } \\
\text { component }\end{array}$ & df & $\chi^{2}$ & $p$ \\
\hline $\begin{array}{c}\text { Level I (within students) } \\
\text { Temporal variation, } e_{t i}\end{array}$ & 0.272 & & & \\
$\begin{array}{c}\text { Level II (between students) } \\
\text { Individual initial }\end{array}$ & 0.220 & 1175 & 2480.83 & $<0.001$ \\
$\begin{array}{c}\text { status, } r_{0 i} \\
\text { Individual linear } \\
\text { growth rate, } r_{1 i} \\
\text { Individual quadratic } \\
\text { growth rate, } r_{2 i}\end{array}$ & 0.028 & 1175 & 1524.32 & $<0.001$ \\
\hline
\end{tabular}

The trajectories of the graduates and non-graduates are presented on Figure 4.7. Those who did not graduate (solid line) started with lower GPA and experienced a continuous decline across the eight semesters. In contrast, those who graduated (dotted line) started higher and even though they experience slight initial decline until semesters 4 or 5 , they managed to recover and showed an increase in performance during the second half of the period (semesters 5 through 8 ).

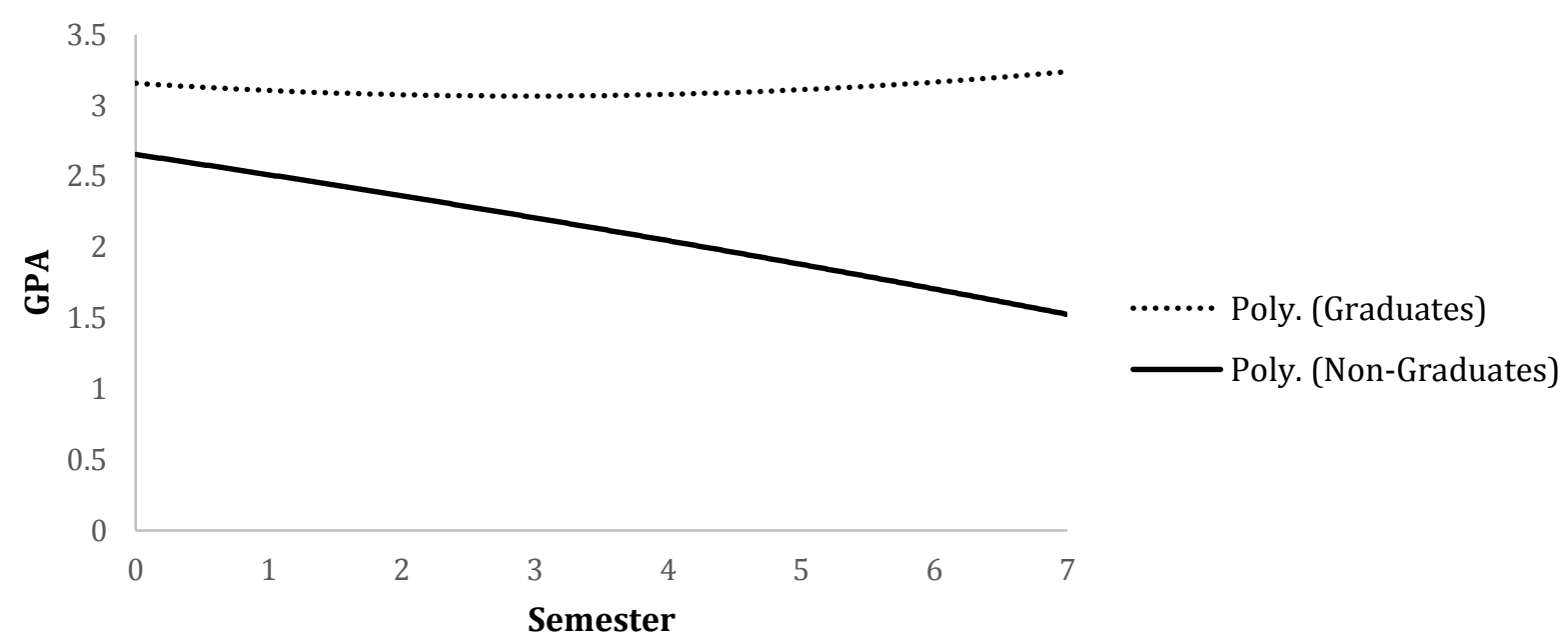

Figure 4.7. Model of GPA growth for graduates and non-graduates between semester 1 and semester 8 of enrollment 
RQ3: Is successful mathematics remediation and graduation status significantly associated with student academic performance growth?

a) Does initial level of academic achievement and performance growth differ for students who were successfully remediated in comparison to those who were not, taking into account if they attained a degree or not?

In the next set of analyses, the effect of mathematics remediation was examined along with the effect of graduation. This examination was approached through a two-step analysis.

First, a model was built to examine changes in GPA during the first four semesters for those who were not successful at remediation (reference group and coded as 0) in comparison to those who were successful at remediation. The cohort effects were still included in the model. The model was tested on all students who were subject to remediation in the original sample $(\mathrm{N}=1105)$. Descriptive statistics, including means and standard deviations for each subgroup across the first four semesters are presented in Table 4.13. 
Table 4.13

Means and Standard Deviations of Student GPAs from Semester 1 through Semester 4 Based on Successful Mathematics Remediation and Graduation Status

\begin{tabular}{|c|c|c|c|c|c|c|c|c|}
\hline & \multicolumn{8}{|c|}{ Semester } \\
\hline & \multicolumn{2}{|r|}{1} & \multicolumn{2}{|r|}{2} & \multicolumn{2}{|c|}{3} & \multicolumn{2}{|r|}{4} \\
\hline & $\mathrm{N}$ & $\begin{array}{l}\text { Mean } \\
(\mathrm{SD})\end{array}$ & $\mathrm{N}$ & $\begin{array}{c}\text { Mean } \\
(\mathrm{SD})\end{array}$ & $\mathrm{N}$ & $\begin{array}{l}\text { Mean } \\
(\mathrm{SD})\end{array}$ & $\mathrm{N}$ & $\begin{array}{c}\text { Mean } \\
(\mathrm{SD})\end{array}$ \\
\hline \multicolumn{9}{|l|}{ Non-Graduates } \\
\hline $\begin{array}{l}\text { Not-Successful Math } \\
\text { Remediation }\end{array}$ & 361 & $\begin{array}{l}1.17 \\
(1.08)\end{array}$ & 233 & $\begin{array}{c}1.32 \\
(1.14)\end{array}$ & 103 & $\begin{array}{l}1.24 \\
(1.10)\end{array}$ & 59 & $\begin{array}{c}1.79 \\
(1.18)\end{array}$ \\
\hline $\begin{array}{l}\text { Successful Math } \\
\text { Remediation }\end{array}$ & 475 & $\begin{array}{l}2.08 \\
(0.96)\end{array}$ & 415 & $\begin{array}{c}2.07 \\
(0.97)\end{array}$ & 265 & $\begin{array}{l}1.93 \\
(1.07)\end{array}$ & 205 & $\begin{array}{c}2.12 \\
(1.04)\end{array}$ \\
\hline Total & 836 & $\begin{array}{l}1.69 \\
(1.11)\end{array}$ & 648 & $\begin{array}{c}1.80 \\
(1.10)\end{array}$ & 368 & $\begin{array}{l}1.74 \\
(1.12)\end{array}$ & 264 & $\begin{array}{c}2.04 \\
(1.08)\end{array}$ \\
\hline \multicolumn{9}{|l|}{ Graduates } \\
\hline $\begin{array}{l}\text { Not-Successful Math } \\
\text { Remediation }\end{array}$ & 15 & $\begin{array}{c}2.13 \\
(1.12)\end{array}$ & 13 & $\begin{array}{c}2.61 \\
(1.14)\end{array}$ & 11 & $\begin{array}{c}2.34 \\
(1.10)\end{array}$ & 10 & $\begin{array}{c}3.11 \\
(0.57)\end{array}$ \\
\hline $\begin{array}{l}\text { Successful Math } \\
\text { Remediation }\end{array}$ & 254 & $\begin{array}{c}2.87 \\
(0.66)\end{array}$ & 251 & $\begin{array}{c}2.84 \\
(0.65)\end{array}$ & 247 & $\begin{array}{c}2.81 \\
(0.67)\end{array}$ & 245 & $\begin{array}{c}2.84 \\
(0.67)\end{array}$ \\
\hline Total & 269 & $\begin{array}{c}2.83 \\
(0.71)\end{array}$ & 264 & $\begin{array}{c}2.83 \\
(0.68)\end{array}$ & 258 & $\begin{array}{c}2.79 \\
(0.70)\end{array}$ & 255 & $\begin{array}{c}2.85 \\
(0.67)\end{array}$ \\
\hline
\end{tabular}

Equation 2 represents Level 1 and Level 2 equations of the fully conditional model.

Level 1:

$$
G P A_{t i}=\pi_{0 i}+\pi_{1 i}\left(\text { time }_{t i}\right)+\pi_{2 i}\left(\text { time }_{t i}\right)^{2}+e_{t i}
$$

Level2:

$$
\begin{aligned}
& \pi_{0 i}=\beta_{00}+\beta_{01}(\text { graduate })+\beta_{02}(D 1)+\beta_{03}(D 2)+\beta_{04}(D 3)+\beta_{05}(\text { successful_rem })+r_{0 i} \\
& \pi_{1 i}=\beta_{10}+\beta_{11}(\text { graduate })+\beta_{12}(D 1)+\beta_{13}(D 2)+\beta_{14}(D 3)+\beta_{15}(\text { successful_rem })+r_{1 i} \\
& \pi_{2 i}=\beta_{20}+\beta_{21}(\text { graduate })+\beta_{22}(D 1)+\beta_{23}(D 2)+\beta_{24}(D 3)+\beta_{25}(\text { successful_rem })+r_{2 i}
\end{aligned}
$$


The results indicated that those who were successful at remediation $\left(\beta_{01}=0.909, p<\right.$ $.001)$ and graduated $\left(\beta_{05}=0.810, p<.001\right)$ started at almost two GPA points higher than those who were not successful and did not graduate (Table 4.14). The effect on initial status was the only significant effect. The effect size for successful remediation was very large $(\delta=0.97)$ as well as for graduation $(\delta=0.87)$. For this subset of the sample, the effect of successful remediation and graduation were not significant for the linear $\left(\beta_{15}=0.025, p=.795 ; \beta_{11}=\right.$ $0.067, p=.447)$ or quadratic $\left(\beta_{25}=-0.027, p=.427 ; \beta_{21}=0.007, p=.815\right)$ growth in the model. Figure 4.4 represents the model graphically. The differences in the initial GPA were evident with those who were successful at remediation and graduated starting with the highest GPA from all the groups. One interesting trend was that those who were not successful at remediation but eventually graduated (dotted line) started slightly lower than those who were successful at remediation but did not graduate (dashed line). However, by the second semester those who were unsuccessful at remediation seemed to surpass those who were initially successful at remediation but eventually did not graduate. The random effects of the model are presented in Table 4.15 . 
Table 4.14

Fixed Effects for the Hierarchical Model Based on Student Graduation and Successful Remediation in Comparison to Unsuccessful Remediation

\begin{tabular}{|c|c|c|c|}
\hline Fixed effects & Coefficient (SE) & $t(d f)$ & $p$ \\
\hline \multicolumn{4}{|c|}{ Model for intercept of college GPA $\left(\pi_{0 i}\right)$} \\
\hline \multicolumn{3}{|c|}{ Intercept } & $<0.001$ \\
\hline \multicolumn{4}{|l|}{ Graduation status } \\
\hline Intercept $\left(\beta_{01}\right)$ & $0.810(0.069)$ & 11.685 (1099) & $<0.001$ \\
\hline \multicolumn{4}{|l|}{ Cohort 1 (D1) } \\
\hline Intercept $\left(\beta_{02}\right)$ & $-0.227(0.048)$ & $-4.761(1099)$ & $<0.001$ \\
\hline \multicolumn{4}{|l|}{ Cohort 3 (D2) } \\
\hline Intercept $\left(\beta_{03}\right)$ & $0.272(0.051)$ & $5.316(1099)$ & $<0.001$ \\
\hline \multicolumn{4}{|l|}{ Cohort 4 (D3) } \\
\hline Intercept $\left(\beta_{04}\right)$ & $0.069(0.047)$ & $1.456(1099)$ & $<0.001$ \\
\hline \multicolumn{4}{|l|}{ Remediation Status } \\
\hline Successful Remediation $\left(\beta_{05}\right)$ & $0.909(0.063)$ & $14.447(1099)$ & $<0.001$ \\
\hline \multicolumn{4}{|l|}{ Model for linear growth effect $\left(\pi_{1 i}\right)$} \\
\hline \multicolumn{4}{|l|}{ Intercept } \\
\hline Intercept $\left(\beta_{10}\right)$ & $-0.163(0.079)$ & $-2.076(1099)$ & 0.038 \\
\hline \multicolumn{4}{|l|}{ Graduation status } \\
\hline Intercept $\left(\beta_{11}\right)$ & $0.067(0.088)$ & $0.761(1099)$ & 0.447 \\
\hline \multicolumn{4}{|l|}{ Cohort 1 (D1) } \\
\hline Intercept $\left(\beta_{12}\right)$ & $0.035(0.066)$ & $0.530(1099)$ & 0.596 \\
\hline \multicolumn{4}{|l|}{ Cohort 3 (D2) } \\
\hline Intercept $\left(\beta_{13}\right)$ & $-0.270(0.070)$ & $-3.857(1099)$ & $<0.001$ \\
\hline \multicolumn{4}{|l|}{ Cohort 4 (D3) } \\
\hline Intercept $\left(\beta_{14}\right)$ & $0.166(0.065)$ & $2.57(1099)$ & 0.010 \\
\hline \multicolumn{4}{|l|}{ Remediation status } \\
\hline Successful Remediation $\left(\beta_{15}\right)$ & $0.025(0.095)$ & $0.259(1099)$ & 0.795 \\
\hline
\end{tabular}


Table 4.14 Continued

\begin{tabular}{|c|c|c|c|}
\hline Fixed effects & Coefficient (SE) & $t(d f)$ & $p$ \\
\hline \multicolumn{4}{|c|}{ Model for quadratic growth effect $\left(\pi_{2 i}\right)$} \\
\hline \multicolumn{4}{|c|}{ Intercept } \\
\hline Intercept $\left(\beta_{20}\right)$ & $0.038(0.029)$ & $1.323(1099)$ & 0.186 \\
\hline \multicolumn{4}{|l|}{ Graduation status } \\
\hline Intercept $\left(\beta_{21}\right)$ & $0.007(0.028)$ & $0.234(1099)$ & 0.815 \\
\hline \multicolumn{4}{|l|}{ Cohort 1 (D1) } \\
\hline Intercept $\left(\beta_{22}\right)$ & $0.009(0.022)$ & $0.404(1099)$ & 0.686 \\
\hline \multicolumn{4}{|l|}{ Cohort 3 (D2) } \\
\hline Intercept $\left(\beta_{23}\right)$ & $0.073(0.023)$ & 3.178 (1099) & 0.002 \\
\hline \multicolumn{4}{|l|}{ Cohort 4 (D3) } \\
\hline Intercept $\left(\beta_{24)}\right.$ & $-0.762(0.021)$ & $-3.570(1099)$ & $<0.001$ \\
\hline \multicolumn{4}{|l|}{ Remediation status } \\
\hline Successful Remediation $\left(\beta_{25}\right)$ & $-0.027(0.033)$ & $-0.794(1099)$ & 0.427 \\
\hline
\end{tabular}

Note: Time is measured in semesters and is centered so that zero corresponds to the first semester in college; Cohort 1, Cohort 3, and Cohort 4 are unweighted cohort effects with Cohort 2 as the reference group

Table 4.15

Random Effects for the Hierarchical Model Based on Student Graduation and Successful Remediation in Comparison to Unsuccessful Remediation

\begin{tabular}{lcccc}
\hline & $\begin{array}{c}\text { Variance } \\
\text { component }\end{array}$ & df & $\chi^{2}$ & $P$ \\
\hline $\begin{array}{c}\text { Level I (within students) } \\
\text { Temporal variation, } e_{t i}\end{array}$ & 0.455 & & & \\
$\begin{array}{c}\text { Level II (between students) } \\
\text { Individual initial }\end{array}$ & 0.421 & 632 & 1127.51 & $<0.001$ \\
$\begin{array}{c}\text { status, } r_{0 i} \\
\text { Individual linear } \\
\text { growth rate, } r_{1 i} \\
\text { Individual quadratic }\end{array}$ & 0.091 & 632 & 607.90 & $>0.500$ \\
growth rate, $r_{2 i}$ & 0.003 & 632 & 616.39 & $>0.500$ \\
\hline
\end{tabular}




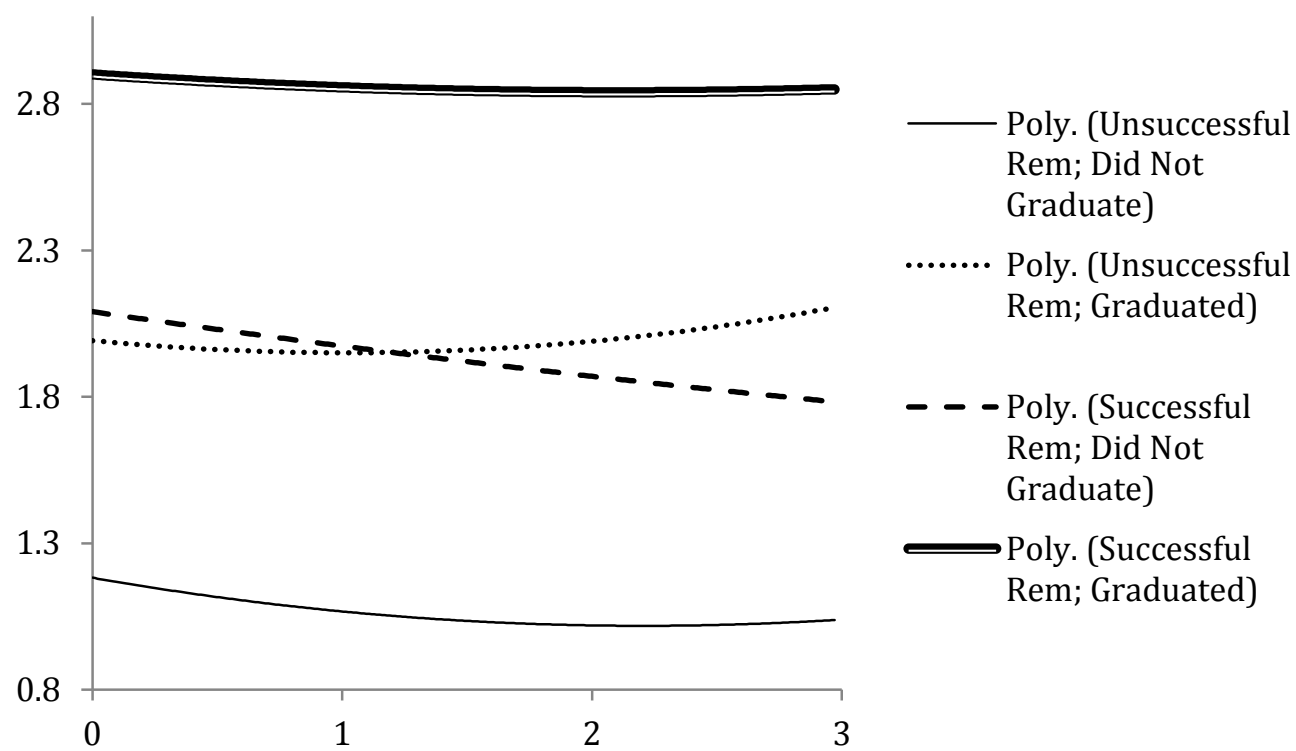

Figure 4.8. Model of GPA growth for graduates and non-graduates and those successful at remediation and those who were not successful between semester 1 and semester 4

RQ3: Is successful mathematics remediation and graduation status significantly associated with student academic performance growth?

b) Does initial level of academic achievement and performance growth differ for students who were successfully remediated in comparison to those who did not need remediation, taking into account if they attained a degree or not?

On the second step of the remediation examination, the trajectories of those who were successful at remediation were compared to those who did not require remediation (reference group) with taking into account the student graduation (non-graduation being the reference group). This model was tested with the main sample $(\mathrm{N}=1124)$, where students had data on at least 5 out of the 8 data points. The means and standard deviations of student GPAs for semesters 1 through 8 are displayed in Table 4.16. 
Table 4.16

Means and Standard Deviations of Student GPAs from Semester 1 through Semester 8 Based on Successful Mathematics Remediation and No Remediation and Graduation Status

\begin{tabular}{llrrrrrrrr}
\hline & & \multicolumn{8}{c}{ Semester } \\
& & \multicolumn{1}{c}{1} & \multicolumn{1}{c}{2} & 3 & 4 & \multicolumn{1}{c}{5} & 6 & 7 & \multicolumn{1}{c}{8} \\
\hline \multirow{2}{*}{ Non-Graduate } & & & & & & & & & \\
Successful & $\mathrm{N}$ & 140 & 139 & 136 & 135 & 133 & 117 & 80 & 66 \\
Math & Mean & 2.45 & 2.49 & 2.25 & 2.35 & 2.01 & 1.87 & 1.83 & 1.57 \\
Remediation & SD & 0.79 & 0.75 & 0.85 & 0.86 & 1.04 & 1.05 & 0.97 & 1.05 \\
& $\mathrm{~N}$ & 132 & 131 & 128 & 126 & 122 & 94 & 67 & 61 \\
No Math & Mean & 2.83 & 2.61 & 2.42 & 2.26 & 1.96 & 2.10 & 1.63 & 1.82 \\
Remediation & SD & 0.63 & 0.80 & 0.87 & 1.07 & 1.17 & 1.11 & 1.11 & 1.22 \\
& $\mathrm{~N}$ & 272 & 270 & 264 & 261 & 255 & 211 & 147 & 127 \\
Total & Mean & 2.63 & 2.55 & 2.33 & 2.31 & 1.99 & 1.97 & 1.74 & 1.69 \\
& SD & 0.74 & 0.77 & 0.86 & 0.97 & 1.10 & 1.08 & 1.04 & 1.14 \\
& & & & & & & & & \\
Graduate & & & & & & & & & \\
Successful & $\mathrm{N}$ & 253 & 251 & 247 & 245 & 245 & 248 & 250 & 247 \\
Math & Mean & 2.87 & 2.84 & 2.81 & 2.84 & 2.83 & 2.96 & 2.92 & 3.08 \\
Remediation & SD & 0.66 & 0.65 & 0.67 & 0.67 & 0.65 & 0.66 & 0.70 & 0.69 \\
& $\mathrm{~N}$ & 655 & 650 & 645 & 641 & 651 & 648 & 630 & 590 \\
No Math & Mean & 3.24 & 3.25 & 3.17 & 3.21 & 3.12 & 3.21 & 3.22 & 3.32 \\
Remediation & SD & 0.62 & 0.58 & 0.64 & 0.58 & 0.68 & 0.69 & 0.73 & 0.69 \\
& $\mathrm{~N}$ & 908 & 901 & 892 & 886 & 896 & 896 & 880 & 837 \\
Total & Mean & 3.14 & 3.14 & 3.07 & 3.11 & 3.04 & 3.14 & 3.14 & 3.25 \\
& SD & 0.65 & 0.63 & 0.67 & 0.63 & 0.69 & 0.69 & 0.73 & 0.70 \\
\hline
\end{tabular}

The equation for this model was identical to Equation 2 with the only difference that the reference group for remediation was no remediation required. The results for this model are presented in Table 4.17 and Table 4.18. 
Table 4.17

Fixed Effects for the Hierarchical Model Based on Student Graduation and Successful Remediation in Comparison to No Remediation

\begin{tabular}{|c|c|c|c|}
\hline Fixed effects & Coefficient (SE) & $t(d f)$ & $p$ \\
\hline \multicolumn{4}{|c|}{ Model for intercept of college GPA $\left(\pi_{0 i}\right)$} \\
\hline \multicolumn{4}{|c|}{ Intercept } \\
\hline \multicolumn{4}{|l|}{ Graduation status } \\
\hline Intercept $\left(\beta_{01}\right)$ & $0.411(0.044)$ & $9.271(1174)$ & $<0.001$ \\
\hline \multicolumn{4}{|l|}{ Cohort 1 (D1) } \\
\hline Intercept $\left(\beta_{02}\right)$ & $-0.027(0.032)$ & $-0.832(1174)$ & 0.406 \\
\hline \multicolumn{4}{|l|}{ Cohort 3 (D2) } \\
\hline Intercept $\left(\beta_{03}\right)$ & $0.062(0.031)$ & $1.987(1174)$ & 0.047 \\
\hline \multicolumn{4}{|l|}{ Cohort 4 (D3) } \\
\hline Intercept $\left(\beta_{04}\right)$ & $-0.021(0.030)$ & $-0.683(1174)$ & 0.495 \\
\hline \multicolumn{4}{|l|}{ Remediation Status } \\
\hline Successful Remediation $\left(\beta_{05}\right)$ & $-0.374(0.039)$ & $-9.479(1174)$ & $<0.001$ \\
\hline \multicolumn{4}{|l|}{ Model for linear growth effect $\left(\pi_{1 i}\right)$} \\
\hline \multicolumn{4}{|l|}{ Intercept } \\
\hline Intercept $\left(\beta_{10}\right)$ & $-0.165(0.025)$ & $-6.591(1174)$ & $<0.001$ \\
\hline \multicolumn{4}{|l|}{ Graduation status } \\
\hline Intercept $\left(\beta_{11}\right)$ & $0.091(0.025)$ & $3.556(1174)$ & $<0.001$ \\
\hline \multicolumn{4}{|l|}{ Cohort 1 (D1) } \\
\hline Intercept $\left(\beta_{12}\right)$ & $0.040(0.018)$ & $2.246(1174)$ & 0.025 \\
\hline \multicolumn{4}{|l|}{ Cohort 3 (D2) } \\
\hline Intercept $\left(\beta_{13}\right)$ & $-0.030(0.017)$ & $-1.730(1174)$ & 0.084 \\
\hline \multicolumn{4}{|l|}{ Cohort 4 (D3) } \\
\hline Intercept $\left(\beta_{14}\right)$ & $-0.012(0.017)$ & $-0.714(1174)$ & 0.476 \\
\hline \multicolumn{4}{|l|}{ Remediation status } \\
\hline Successful Remediation $\left(\beta_{15}\right)$ & $0.051(0.022)$ & $2.311(1174)$ & 0.021 \\
\hline
\end{tabular}


Table 4.17 continued

\begin{tabular}{|c|c|c|c|}
\hline Fixed effects & Coefficient (SE) & $t(d f)$ & $p$ \\
\hline \multicolumn{4}{|c|}{ Model for quadratic growth effect $\left(\pi_{2 i}\right)$} \\
\hline \multicolumn{4}{|c|}{ Intercept } \\
\hline Intercept $\left(\beta_{20}\right)$ & $-0.0009(0.004)$ & $-0.243(1174)$ & 0.808 \\
\hline \multicolumn{4}{|l|}{ Graduation status } \\
\hline Intercept $\left(\beta_{21)}\right.$ & $0.012(0.004)$ & $3.364(1174)$ & $<0.001$ \\
\hline \multicolumn{4}{|l|}{ Cohort 1 (D1) } \\
\hline Intercept $\left(\beta_{22}\right)$ & $-0.005(0.002)$ & $-2.059(1174)$ & 0.040 \\
\hline \multicolumn{4}{|l|}{ Cohort 3 (D2) } \\
\hline Intercept $\left(\beta_{23}\right)$ & $0.003(0.002)$ & $1.324(1174)$ & 0.186 \\
\hline \multicolumn{4}{|l|}{ Cohort 4 (D3) } \\
\hline Intercept $\left(\beta_{24)}\right.$ & $0.002(0.002)$ & $0.842(1174)$ & 0.400 \\
\hline \multicolumn{4}{|l|}{ Remediation status } \\
\hline Successful Remediation $\left(\beta_{25}\right)$ & $-0.004(0.003)$ & $-1.447(1174)$ & 0.148 \\
\hline \multicolumn{4}{|c|}{$\begin{array}{l}\text { Note: Time is measured in semesters and is centered so that zero corresponds to the first } \\
\text { semester in college; Cohort } 1 \text {, Cohort } 3 \text {, and Cohort } 4 \text { are unweighted cohort effects with } \\
\text { Cohort } 2 \text { as the reference group; }\end{array}$} \\
\hline
\end{tabular}

Table 4.18

Random Effects for the Hierarchical Model Based on Student Graduation and Successful Remediation in Comparison to No Remediation

\begin{tabular}{lcccc} 
& $\begin{array}{c}\text { Variance } \\
\text { component }\end{array}$ & df & $\chi^{2}$ & $p$ \\
\hline $\begin{array}{c}\text { Level I (within students) } \\
\text { Temporal variation, } e_{t i}\end{array}$ & 0.272 & & & \\
$\begin{array}{c}\text { Level II (between students) } \\
\text { Individual initial }\end{array}$ & 0.191 & 1174 & 2301.01 & $<0.001$ \\
$\begin{array}{c}\text { status, } r_{0 i} \\
\text { Individual linear } \\
\text { growth rate, } r_{1 i} \\
\text { Individual quadratic } \\
\text { growth rate, } r_{2 i}\end{array}$ & 0.027 & 1174 & 1516.87 & $<0.001$ \\
\hline
\end{tabular}


The parameter estimates for the fully conditional growth model with graduation and remediation as a predictor are presented in Table 4.8. The first semester GPA of those who did not graduate and did not require remediation was 2.85 . Those who eventually graduated (and did not require remediation) started about 0.41 GPA points higher for an average first semester GPA of 3.26 while those who graduated and successfully completed remediation started at 2.89 . The between-student variance in the predicted initial GPA was statistically significant $(p<.001)$ indicating that there are differences in initial student achievement after accounting for graduation status, remediation, and cohort effects. The effect size of graduation was medium $(\delta=.61)$ as well as the effect size of remediation $(\delta=.55)$.

Students who did not graduate and did not require remediation experienced decline $\left(\beta_{10}=-0.165\right)$ and the lack of curvature $\left(\beta_{20}=-0.0009\right)$ indicated that the rate of this decline remained relatively consistent over time. For those who graduated and did not require remediation experienced a smaller decline $-0.074\left(\beta_{10}=-0.165, \beta_{11}=0.091,-0.165+0.091=\right.$ -0.074) and the significant positive quadratic term $\left(\beta_{21}=0.012, p<.001\right)$ indicated that this decline slowed down over time and eventually turned into growth in GPA. For instance, the predicted GPA for the first semester for those who graduated was 3.26, while that during the second semester was 3.20, a decline of 0.06 GPA points. By semester four, a student's predicted GPA was 3.16 and that in semester five was 3.19, which indicated a gain of 0.03 GPA points. The effect size of graduation was small for the linear growth $(\delta=.17)$ and very small for the quadratic growth $(\delta=.02)$. The effect size of remediation on the linear growth was small as well $(\delta=.09)$.

Students who graduated and successfully completed remediation had the smallest decline of all, $0.023\left(\beta_{10}=-0.165, \beta_{11}=0.091, \beta_{15}=0.051,-0.165+0.091+0.051=-0.023\right)$ and still had a 
positive quadratic growth. Even though the remediation effect was not associated with significant negative quadratic growth $\left(\beta_{25}=-0.004, p=<.001\right)$, the cumulative effect was positive, $0.007\left(\beta_{10}=-0.0009, \beta_{11}=0.012, \beta_{15}=-0.004,-0.009+0.012-0.004=0.007\right)$ indicating that this decline slowed down over time and eventually turned into growth in GPA. For instance, the predicted GPA for the first semester for those who graduated and remediated successfully was 2.89 , while that during the second semester was 2.87 , a decline of 0.02 GPA points. By the fourth semester, a student's predicted GPA was 2.91 and that in the fifth semester was 2.95, which indicated a semester gain of 0.04 GPA points.

The between-student variances for the linear and quadratic growth were statistically significant $(p<.001)$ indicating that there were between student differences in linear and quadratic change after accounting for graduation and remediation status and cohort effects.

The graphical representation of the model is displayed on Figure 4.9. In addition to the differences in the initial GPA, differences in patterns of change across time were also evident. Those who were on graduation trajectory (solid thick line and dotted line) experienced initial decline in performance but recovered from that decline and in fact performed even better than initially in their first semester. Interestingly, those who were successful at remediation experienced smaller decline than those who did not need remediation. While those who did not need remediation started to recover about semester 4 or 5 , those who were remediated regained momentum sooner, around semester three. Those who did not graduate, regardless of remediation, experienced consistent decline in performance. 


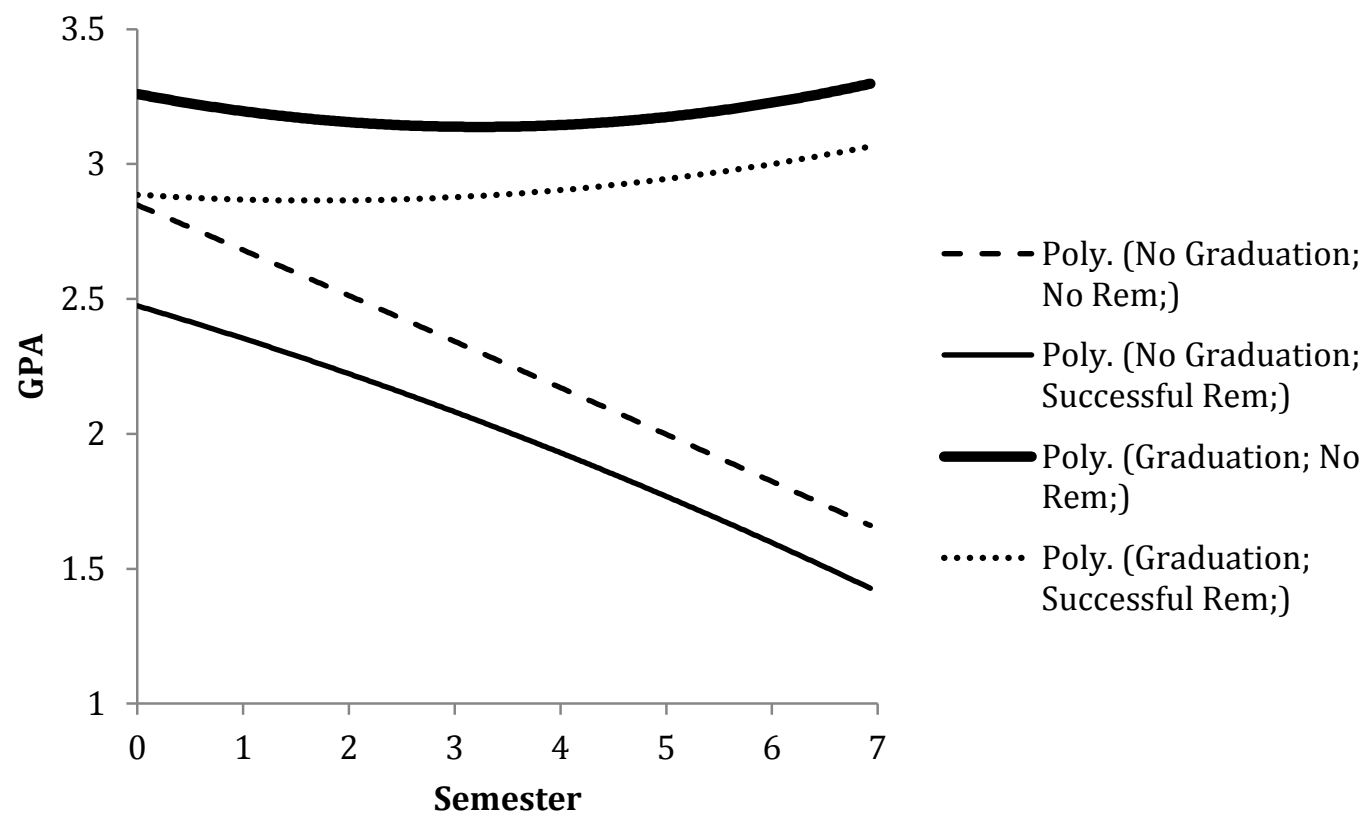

Figure 4.9. Model of GPA growth for graduates and non-graduates and those successful at remediation and those who did not require remediation between semester 1 and semester 8 


\section{Chapter 5}

\section{Discussion}

Several major findings emerged. First, student performance did not follow a linear trend but a quadratic growth with initial decline, followed by a recovery period. Second, the second and third year in college emerged as a period during which the decline slows down and turns into a recovery. Further, the trajectory of students who graduated was significantly different than that of students who did not graduate. Those differences were evident not only in the initial levels of academic achievement but also in the rates of growth of that achievement across time. Lastly, mathematics remediation had a significant effect on academic performance during the first semester in college but did not show a significant effect on the trends of change across time. The trajectory of graduates who were successfully remediated mimicked that of their college ready peers who graduates.

\section{Initial Level and Changes in Academic Performance}

The overall model, prior to taking graduation and remediation into account, indicated that students' first semester GPA was on average close to 3.0. This level of performances is similar to what others have reported in the literature as first semester performance (Grove \& Wasserman, 2004) or end of first year performance (Geiser \& Santelices, 2007). Further, earning a GPA of at least 3.0 at the beginning of one's college career has been associated with good long term academic outcomes (Chen \& Carrol, 2005) and persistence (Kahn \& Nauta, 2001; Nora \& Cabrera, 1996). Because of these associations, this level of performance could be considered an indicator of high academic momentum.

While the students performed relatively well during their first semester, the performance growth curve showed that students experienced a decline in performance during the next few 
semesters before recovering from this initial setback and going into a performance improving trend. The decline in GPA was observed starting with the first semester and lasted till the fourth or fifth semester into student enrollment. These results were somewhat different than others documented in the literature. For example, Grove and Wasserman (2004) examined student GPA across eight semesters in a private university and reported a "check-mark pattern" where student grades declined only in the second semester but improved thereafter. They reported a decline of 0.10 GPA points and a very slight drop during the senior year. They also provided an overview of another examination at a different private university where no GPA decline was observed whatsoever. Likewise, continuous improvement across four years with no decrease in performance was found by others (Geiser \& Santelices, 2007). It is evident that students at different institutions exhibit different patterns of performance across time and it would be valuable to examine the factors that play a role in the decline reported here as well as the relatively longer duration academic momentum loss.

Even though there was an initial decline in student performance, this trend slowed down and eventually students entered into a period of recovery, which indicated a regaining of momentum. Such initial drop in performance and subsequent improvement in college has been documented in the literature for students who transfer from a community college to a bachelor degree granting institution (Diaz, 1992). Although Diaz did focus on students who entered a new institution, in his meta-analysis he indicated that the majority of studies reported a "transfer shock" in terms of decreased performance and subsequent recovery. The "transfer shock" reported by Diaz could be comparable to the transition that students in general experience during the first years in college. 


\section{Beyond the First Year in College}

The timing of the performance drop and recovery observed here was also interesting. Those shifts occurred during the second and third year of student enrollment. While the first year still was considered a transitional period and critical for college success (Pascarella \& Terenzini, 2005; Tinto, 1996, 1999;), the second year in college emerged as a focus of a number of examinations (e.g., Coghlan, Fowler, \& Messel, 2009; Gahagan \& Hunter, 2006; Graunke \& Woosley, 2005). Some define the second year as more important than the first one (Adelman, 2006) and as distinctly different than the first year and a "more challenging period" (Gahagan \& Hunter, 2006 p.17). Sophomores were often referred to in the literature as the college population who was "forgotten", “overlooked", "invisible” (Gahagan \& Hunter, 2006; Schreiner \& Pattengale, 2000), or "the academy's middle child" (Coghlan et al., 2009 p.193). Institutions have very comprehensive efforts relative to support for their freshman students but rarely continue those in the second year (Flanagan, 1991). Until recently sophomore focused retention efforts were only sporadic. It is possible that institutions provided less support because they felt that they have been successful at retaining students after their first year (Pattengale \& Schreiner, 2000).

One aspect of the second year challenge is the notion of the "sophomore slump." Freedman (1956) was credited with popularizing this concept even though he noted that the occurrence of sophomore slump was more likely to happen at the end of the first year in college. Gahagan and Hunter (2006) referred to the slump as the phenomenon when students "flounder academically" (p. 18). Kennedy and Upshir (2010) redefined the sophomore slump as a multidimensional phenomenon and one of those dimensions was "academic deficiencies." Similarly, Graunke and Woosley (2005) considered academic performance and academic success 
during the second year in college as a distinct aspect of the sophomore slump. Others have pointed out that students may experience academic disengagement and as a result their grades were impacted adversely (Pattengale \& Schreiner, 2000). While a single definition of the "sophomore slump" does not appear in the literature, those who examine this phenomenon consistently report changes in academic performance associated with it.

Performance during the sophomore year has been associated with factors like academic major selection and coursework related to the specific field of choice. Major selection is pivotal for student college careers and it usually takes place during the second year (Freedman, 1956; Gahagan \& Hunter, 2006; Gardner, Pattengale, Tobolowsky, \& Hunter, 2010). Graunke and Woosley (2005) noticed that some students performed better during their second year than others. When they examined this phenomenon closely, they found that sophomores who had a higher certainty of their chosen major performed better. Similarly, others have examined the link between major selection and long-term student academic outcomes. For example, Gardner et al. (2010) suggested that students without a major were at greater risk of non-completion. Thus, major selection and confidence in that selection are important factors for both academic performance and long-term outcomes like degree completion.

Another factor associated with student performance is academic self-efficacy. Academic self-efficacy is related to student perceptions of their own abilities to be successful academically (Chemers, Hu, \& Garcia, 2001; Robbins et al., 2004). Robbins et al. (2004) found that academic self-efficacy was the best predictor of GPA. Similarly, Chemers et al. (2001) determined that academic self-efficacy had both direct effect on academic performance and indirect effect through expectations and coping perceptions during the first year in college. While the relationship between academic self-efficacy and performance has been documented in a number 
of studies, Gore (2006) found that the strength of this relationship was dependent on whether academic self-efficacy was measured early on or later in college careers. He determined that academic self-efficacy had poor predictive powers relative to earlier performance, which could be related to the student transition from high school and changes in the academic environment. However, academic self-efficacy predictive powers in relations to performance improved in later semesters. Thus, if the decline in grades observed here was associated with lower academic selfefficacy, then potential reasons for that were lower performance than expected during the freshman year or not being accepted into a certain major.

Changes in performance during the second year, whether related to major selection, academic self-efficacy, or other factors, may be an indicator of how well students cope with the "sophomore slump." In the past, those who were considered to be coping well with the challenges of the second year maintained or improved their GPA and those who were not dealing well with the challenges experienced a decline (Wilder, 1993). Likewise, different levels of coping with academic challenges during the second year could explain variability in individual performance.

The challenges associated with the sophomore year are being recognized as more institutions implement sophomore success programs (Ellis, 2010; Heier, 2012; Schaller, 2010). Many programs share a similar focus as reported by the 2008 National Survey of SophomoreYear Initiatives. A large proportion of these program facilitate student major selection and provide academic assistance. The fact that the majority of the programs incorporate elements relative to academic major selection and academic support is indicative that these issues are key for second year success (Ellis, 2010; National Resource Center for The First-Year Experience and Students in Transition, 2008). 
The results here indicate that there are certain shifts taking place during the second year. However, these changes spill over into the third year as well. This is indicative that third year of enrollment is also impactful on overall student trajectories. In addition, performance in the third year may be more indicative of how well students will do in their later college career. This notion was reinforced by the correlations across semester GPA scores. Correlations grew weaker between semesters which were further apart. For example, first semester GPA had the strongest correlations with second and third semester GPA scores and smallest relation with scores in semester seven and eight. Later college performance (e.g., performance in the third year) may be a more accurate indicator of student academic success (e.g., Allen, Robbins, Casillas, \& Oh, 2008; Lord et al., 2013; Robbins et al., 2004).

Students spend less time in general education and are introduced to major related courses during their sophomore year (Gardner et al., 2010). During their junior year, they are expected to be fully engaged in upper level coursework. Transitioning into upper level coursework has been considered a second transition in postsecondary education (Lord et al., 2013). Harackiewicz, Barron, Tauer, and Elliot (2002) suggest that courses in the final years in college may be different in terms of level and required quality of work. Approaches to studying and learning which had yielded success before may be insufficient or inadequate for this type of coursework. Some students may be prepared to meet those expectations while others may struggle. Carlan and Byxbe (2000) reported a drop in GPA for a majority of students when they entered their third year of studies and attributed that to the more challenging upper level courses. If the lower levels of performance are indeed associated with the more challenging coursework, then different types of interventions targeting specific difficulties associated with upper level coursework should be in place. Some have already adopted such initiatives. Lord et al. (2013) 
reported on potential the positive impact of academic support programs in upper level coursework. These impacts included both immediate effects (e.g., student performance) as well as long term ones (e.g., student degree attainment).

The trajectories outlined by the data reveal that even though the students in the sample performed relatively well during their first semester, they tended to perform worse going into their second and third year thus losing some academic momentum. The growth curve indicated that students went through a recovery and eventually experienced growth in their performance but this growth was not initiated until their third year of studies. A question remains as to whether all students experience the same trajectory in terms of academic achievement across time.

\section{Differences in Growth Trajectories Based on Graduation}

The patterns of performance investigated here indicate some distinct differences between those who were on graduation trajectory versus those who were not. The students included in the current examination did remain enrolled for the majority of the eight semesters (at least 5 out of the 8 semesters) but a portion of those students did not graduate. Even though past examinations suggest that students who did not maintain continuous enrollment had lower chances of degree completion (Cabrera, Burkum, \& La Nasa, 2005), the results here supported the notion that continuous enrollment was not the only ingredient for success. This is consistent with previous examinations, which found that even though retention efforts were successful at keeping students enrolled, longer attendance did not automatically result in degree attainment (Nora et al., 2005; Radford et al., 2010). From the academic momentum theory perspective, these students experienced one element of high momentum (continuous enrollment) but still fail to graduate. 
In all models student initial performance as captured by the first semester GPA was significantly higher for those who eventually graduated in comparison to those who did not. The importance of student initial performance has been examined before and was consistent with the observations here that those who were on graduation trajectories performed on average better initially. For example, Chen and Carroll (2005) pointed that first year academic performance was strongly related to long-term degree completion. Similarly, McCormick and Carroll (1999) determined that those who achieved a higher GPA during the first year in college were more likely to receive a bachelor degree, while Chen and Carrol (2005) found that completion of 30 credits or earning at least a 3.0 GPA during the freshman year was associated with higher likelihood of earning a degree.

In addition to differences in initial achievement, differences in patterns of performance for graduates and non-graduates were observed. In the current sample, students experienced an initial decline in their academic performance during the first semesters of their college career. This decline happened a lot faster for non-graduates than graduates. For example, non-graduates were predicted to drop by 0.28 GPA points by the middle of their second year (semester 3 ) in comparison to the graduates who were predicted to drop only by 0.10 GPA. Further, students who eventually graduated showed recovery after this initial decline and an increase in their GPA. Based on the academic momentum theory (Adelman, 1999, 2006; Attewell et al., 2012), both groups lost some momentum, the non-graduates to a much greater extent than the graduates, but the graduates regained momentum and by the time they completed their degrees, their semester GPA tended to be higher than their academic achievement during the first few semesters.

The examinations discussed above, however, did not study differences in performance for students who graduated versus those who did not. In the current analyses, the divergence 
between the graduate and non-graduate trajectories was very clear by the end of the second year and the beginning of the third. By this point, there were not only differences in rates of change but differences in direction of that change. The non-graduates were likely to experience consistent decline while those on a "graduation" trajectory never really experienced much of a drop in their performance and even started to perform better. These findings were similar to the academic performance gap identified by Adelman (2006). He found that by the end of the second year there was a consistent difference in terms of academic performance and credit accumulation between those who eventually graduated and those who did not. Adelman identified the second year as an opportunity to "recapture any lack of momentum of the first" (p.53). Such a change in momentum could be associated with more positive academic outcomes for students. Thus, examining student performance during the second or third year of enrollment in relation to their prior college achievement provided a better distinction between those who graduated versus those who did not. This notion of looking at student progress later in their college career to gauge their academic success has been researched in the past. Allen et al. (2008) suggested that the third year provided a more accurate picture of student success.

Another interesting aspect of the changes in GPA observed here were the reported gains in performance for those who graduated. Past examinations have focused specifically on the gains in GPA in relation to persistence and graduation (Cabrera, Burkum, \& La Nasa, 2005; Lord et al., 2013; Offenstein, Moore, Shulock, 2010). Cabrera et al. (2005) reported that increases in GPA were associated with improved chances of degree attainment for all students. The observed trends in this study also supports one of the hypotheses by Bean (1985) that grades would show an increase later in student careers. That was true only for the graduates in the current analyses and was a distinct difference between graduates and non-graduates, even though it was not clear 
if this increase was due to a greater student commitment as a result of a longer stay in school as Bean hypothesized.

Higher education research associated with student performance and degree attainment has historically looked at the first year in college as critical for student success. However, more researchers are exploring the factors associated with the second and third year in college as a way to study impact on student progression. Further, tracking retention rates may not be sufficient for better understanding progression to graduation. Rather, monitoring specific academic indicators longitudinally and tracking important milestones may prove critical for ensuring students are on graduation trajectory (Offenstein et al, 2010).

\section{Differences in Growth Trajectories Based on Graduation and Remediation}

Remediation has been examined through its effects on chances for obtaining a degree. Taking remedial coursework has been found to have a statically significant negative effect on students' chances of degree completion for students at four-year institutions (Attewell et al., 2006). Those who were successful at remediation were more likely to complete a bachelor's degree than those were not successful (Bettinger \& Long, 2004). Success at mathematics remediation was related to higher chances for graduation, suggesting that successful remediation had some potential positive consequences. For this reason, the current study examined the effects of successful remediation in comparison to both unsuccessful and no remediation.

In the comparison between successful and unsuccessful remediation in mathematics, the only significant effect was found for initial achievement. Those who successfully completed the mathematics remediation on the first attempt had a significantly higher first semester GPA than those who did not. These observations supported the idea that those who were remediated successfully experienced higher initial academic momentum. Even though they were considered 
underprepared in mathematics and referred to remediation, they performed relatively well in their other coursework. This is indicative of the notion that students possess different strengths in different areas (Attelwell et al., 2006). They may be academically underprepared in math but have solid preparation in writing. Those who were not successfully remediated, however, experienced a relatively lower momentum (lower GPA in the first semester). This potentially indicate that students have lower level skills in areas other than mathematics, which results in lower performance in other courses as well.

From an academic momentum perspective students who were successful at remediation also experienced higher momentum associated with credit accumulation. Even though remediation credits did not count toward graduation requirements, it was possible that success in remediation had a momentum boosting effect in terms of both credit accumulation and persistence. Calcagno and Long (2008) found that students who were in remedial courses earned more credits. Successful remediation was associated with higher persistence rates (Bettinger \& Long, 2009).

Further, the trajectories of those who graduated and were successfully remediated were compared to graduates who did not require remediation. Not surprisingly those who were remediated started significantly lower than their "college ready" peers in the first semester. Others have found similar differences in initial performance (Hoyt, 1999; Kreysa, 2006). However, during the initial period of GPA decline between the first semester and the fourth or fifth semesters, those in remediation experienced a slower and shorter relative decline and eventually improved their performance. This pattern was similar to what Kreysa (2006) reported. He found that remedial students improved academically by their later semesters even though he did not distinguish between those who graduated and those who did not. 
Even though the performance of the remedial students who graduated was overall lower than the non-remedial students, the relative changes in the trajectories across time mimicked those of the non-remedial graduates. In fact, the remedial students experienced a somewhat slower decline and earlier recovery than their non-remedial counterparts, which may be indicative of a positive impact of successful remediation on overall student performance (Bettinger \& Long, 2004). A positive effect was observed for non-graduates as well. Those who were successful at remediation experienced a smaller decline in GPA during the first part of their college careers than their non-remediation counterparts.

In conclusion, the effects of successful remediation were somewhat differential on the various aspects of academic momentum. While those who were successful startede lower than those who were not remediated, their long-term academic trajectories were very similar within the graduate and non-graduate subgroups. This supports previous research that those who were successful at remediation had similar long-term outcomes to their college ready counterparts (Offenstein et al., 2010). If anything, a small positive effect was detected in terms of initial slower decline in performance for non-graduates and shorter and less severe drop in GPA for those on graduation trajectory.

The current study contributes to the existing postsecondary completion literature in two major aspects. First, the results revealed a differential longitudinal trajectories for graduates versus non-graduates. While these exact patterns may not be observed at other institutions, the examination here supported the value of looking at the patterns of academic performance change as a pathway to further understand student progression and provide appropriate academic support. Mathematics remediation is the second area, where this study expands the college student success research. The current study addresses two major methodological concerns in the 
remediation literature. These include the examination of long-term student outcomes relative to remediation and the investigation of successful remediation completion rather than studying the impact of being a subject to remediation.

\section{Limitations}

A number of limitations exist in the current study and should be considered in the review of the examination. Some of these emerge from the nature of the data used in the study while others were related to the employed methodology and theoretical model application.

\section{Data and Methodological Considerations}

The data were collected at a single institution and as a result the representativeness of the findings is limited. The findings and discussed considerations should be interpreted in the context of the specific institutional advising practices and degree or curriculum requirement policies. A closer examination of those practices and policies may reveal the specific mechanisms related to the changes in student performance revealed here.

The student sample from the particular institution was very homogeneous. It lacked diversity in terms of socio-demographic characteristics. Previous examinations of the academic momentum theory claimed that the socio-demographic effects were not impactful of the overall projection of student degree attainment. However, a limited number of empirical examinations of this theory and an additional strength of the study would have been an inclusion of these factors within the context of the current institution. Because the current sample was very homogeneous the examination of these effects was not appropriate.

Cohort effects were detected in the preliminary analyses and included in subsequent statistical models. However, these were not addressed specifically here as the examination did 
not focus on cohort differences. These should be examined in the future to study if there were certain institutional policy or practice changes that may account for these effects.

Two of the assumptions relative to growth curve modeling were violated. First, the distribution of student performance for each wave of data was not normally distributed. The data were negatively skewed for each semester. While these models are robust to this assumption by itself, homoscedasticity indicated that there was a very small number of large residuals. These large residuals may be associated with a less accurate overall model but they did not invalidate it (Appendix C). In addition, the assumption for data missing completely at random (MCAR) was violated. The violation could be a result of students graduating early or discontinuing their studies at the institution, which could be linked to missingness. If missingness is associated with group membership (e.g., graduates versus non-graduates), data missingness could be associated with less model accuracy. Models based on less missing data are more accurate than models based on mode missing data.

Graduation was captured only as of graduation from the current institution and did not account for any degrees received from a different institution. This is a definite limitation given the recent trend that students often transfer to a different institution to complete a degree. It is possible that students who were considered non-completers at this institution, completed degree elsewhere.

Further, student graduation was captured as of year 6 for the last cohort in the study. Student graduation was captured as of Fall 2014 for those who started in Fall 2008. Even though the probability for students to return and complete a degree past the sixth year is small, it is possible that students return to the institution and complete their degree at a later date. Their 
degree completion past the sixth year of their initial enrollment was not accounted for in the current study.

\section{Academic Momentum Theory Considerations}

The academic momentum theory posits that high academic momentum is associated with continuous enrollment, credit accumulation, academic performance, and additional academic activities participation like enrollment in summer coursework. In the current study, continuous enrollment was kept at a relative constant with only students who took courses in at least five out of the first eight semesters being included in the analyses. This approach ensured that students continuous attendance, one of the aspects of high momentum, was kept at a relative constant for all students. Student performance was the focus of the examination but other elements of the academic momentum theory, including credit accumulation and summer coursework, were not considered. Those aspects should be studied in the future to gauge potential interconnections across those elements. For example, it may be important to consider if students who take fewer credits but perform better have superior long-term outcomes in comparison to students who enroll in more credits per semester but perform at lower levels overall. Further, relative to the credit accumulation aspect of the theory, the examination of earned versus attempted number of credits, and maintaining full-time versus part-time enrollment across the semesters, can reveal another level of complexity to student academic momentum. These were not addressed in the current study. 


\section{Conclusions}

In the current study, the focus was on differential patterns of change in college performance between students who graduated and those who did not. While such patterns were observed, these analyses did not address the reasons why those shifts happened. Are these differences really associated with enrolling in major courses and the higher demands in those classes? What aspects of the "sophomore slump," if any, are related to changes in performance during the second and third year in college? Nora et al. (2005) called attention to the need for institutions to "gather and examine data on their individual students" (p. 145). Such data should be examined and utilized by institutional teams, including student retention administrators, academic advisors, and faculty. Trends evident in the data may inform institutional policies and practices to target further facilitation of student success and progression to degree completion.

If changes are really associated with students entering their major courses and the shifts in requirements and expectations in that coursework, then additional academic assistance for students focused exclusively on specific academic fields may be appropriate as suggested by Lord et al. (2013). This may be a key to shifting student trajectories and increasing student performance. However, the question still remains if the same factors associated with better academic performance result in degree completion (Nora et al., 2005).

Further examinations focused on sophomore and junior years and student success during that period has been recommended in the past (Kenedy \& Upshaft, 2010; Shaller, 2010). The current examination is a step in this direction and additional investigations need to be conducted. There were certain changes in student performance, but as Heier (2012) emphasizes there is a need for more empirical research focused on this period. For example, literature suggests that students without a major are at greater risk of non-completion (Gardner et al., 2010). The aspects 
of major selection and particular fields of study were not examined here. However, future examinations need to study whether these changes are associated with selecting a major.

The longitudinal perspective reveals some of the trends in student performance and points to the importance of monitoring student progression semester by semester. In the past, others have suggested going beyond tracking retention and implementing practices to monitor important milestones and benchmarks in student academics (Shulock \& Jenkins, 2011; Offenstein et al., 2010). Such monitoring systems provide detailed information regarding whether students are on track so that relevant interventions can be implemented in a timely manner. There are already such milestones suggested by researchers, including successful completion of remediation (Shulock \& Jenkins, 2011; Offenstein et al., 2010), completion of college level mathematics course (Shulock \& Jenkins, 2011; Offenstein et al., 2010), and credit accumulation during each year (Chen \& Carrol, 2005). The current study adds change over time and rate of change in student performance as an indicator to intuitional monitoring systems.

The theory of academic momentum holds great potential for better understanding and further facilitating student degree attainment. The current study examined only two aspects of academic momentum: continuous enrollment and academic performance. However, other aspects of this momentum including credit accumulation and specific activities such as summer term enrollment will be beneficial. It may be important to investigate which aspects of the academic momentum have the greatest impact on student graduation. Such examination would be valuable for institutions that have limited resources and seek to invest those in the most optimal manner. Bound, Loverheim, and Turner (2010) point out that unfortunate trends in degree completion may be associated with declining student resources. Students in non-selective institutions may require the greatest amount of academic support for success but non-selective institutions also 
usually have the fewest resources. Because of that, those who need the resources the most may have the least access to them. Institutions must decide how to best utilize these limited resources to maximize impact for increasing student persistence and graduation. 


\section{References}

Adelman, C. (1999). Answers in the tool box: Academic intensity, attendance patterns, and bachelor's degree attainment. Washington, DC: U.S. Department of Education.

Adelman, C. (2006). The toolbox revisited: Paths to degree completion from high school through college. Washington, DC: U.S. Department of Education.

Alexander, F. K. (2000). The changing face of accountability: Monitoring and assessing institutional performance in higher education. Journal of Higher Education, 411-431.

Allen, J., Robbins, S. B., Casillas, A., \& Oh, I. S. (2008). Third-year college retention and transfer: Effects of academic performance, motivation, and social connectedness. Research in Higher Education, 49(7), 647-664.

Attewell, P. A., Lavin, D. E., Domina, T., \& Levey, T. (2006). New evidence on college remediation. The Journal of Higher Education, 77(5), 886-924.

Attewell, P., Heil, S., \& Reisel, L. (2012). What is academic momentum? And does it matter? Educational Evaluation and Policy Analysis, 34(1), 27-44.

Bahr, P. R. (2008). Does mathematics remediation work? A comparative analysis of academic attainment among community college students. Research in Higher Education, 49(5), 420-450.

Bailey, T. (2009). Challenge and opportunity: Rethinking the role and function of developmental education in community college. New Directions for Community Colleges, 2009(145), $11-30$.

Bailey, T., Jeong, D. W., \& Cho, S. W. (2010). Referral, enrollment, and completion in developmental education sequences in community colleges. Economics of Education Review, 29(2), 255-270. 
Baker, G. A., Dudziak, J., \& Tyler, P. (1994). A handbook on the community college in America: Its history, mission, and management. Westport, Conn: Greenwood Press.

Barton, P.E. (2002). The closing of the education frontier? Princeton, NJ: Educational Testing Service, Policy Information Center.

Bastedo, M. N., \& Gumport, P. J. (2003). Access to what? Mission differentiation and academic stratification in US public higher education. Higher Education, 46(3), 341-359.

Bean, J. P. (1980). Dropouts and turnover: The synthesis and test of a causal model of student attrition. Research in Higher Education, 12(2), 155-187.

Bean, J. P. (1985). Interaction effects based on class level in an explanatory model of college student dropout syndrome. American Educational Research Journal, 22(1), 35-64.

Berger, J. B., \& Lyon, S.C. (2005). Past to present: A historical look at retention. In A. Seidman (Ed.), College student retention: Formula for student success (pp. 1-29). Greenwood Publishing Group.

Bettinger, E. (2004). How financial aid affects persistence. In C. Hoxby (Ed.), College choices: The economics of where to go, when to go, and how to pay for it (pp. 207-238). University of Chicago Press.

Bettinger, E. P., \& Long, B. T. (2004). Shape up or ship out: The effects of remediation on students at four-year colleges (No. w10369). National Bureau of Economic Research. Retrieved from http://time.dufe.edu.cn/wencong/laboreconomics/longbettinger.pdf

Bettinger, E. P., \& Long, B. T. (2005). Remediation at the community college: Student participation and outcomes. New Directions for Community Colleges, 2005(129), 17-26. 
Bettinger, E. P., \& Long, B. T. (2009). Addressing the needs of underprepared students in higher education: Does college remediation work? Journal of Human Resources, 44(3), 736771.

Boivin, M., Fountain, G. A., \& Baylis, B. (2000). Meeting the challenges of the sophomore year. In L.A. Schreiner \& J. Pattengale (Eds). Visible solutions for invisible students: Helping sophomores succeed (pp. 118-128). National Resource Center for the First Year Experience and Students in Transition, University of South Carolina, Columbia, SC.

Bordes-Edgar, V., Arredondo, P., Kurpius, S. R., \& Rund, J. (2011). A longitudinal analysis of Latina/o students' academic persistence. Journal of Hispanic Higher Education, 10(4), $358-368$.

Bottoms, C. (2002). Improving schools are trying new approaches to raise achievement of struggling students. In Opening doors to the future: Preparing low-achieving middle grades students to succeed in high school, 41-56. Atlanta: Southern Regional Education Board.

Boylan, H. R., Bonham, B. S., \& White, S. R. (1999). Developmental and remedial education in postsecondary education. New Directions for Higher Education, 1999(108), 87-101.

Cabrera, A. F., Nora, A., \& Castaneda, M. B. (1992). The role of finances in the persistence process: A structural model. Research in Higher Education, 33(5), 571-593.

Cabrera, A., Burkum, K., \& La Nasa, S. (2005). Pathways to four-year degree: Determinants of transfer and degree completion. In A. Seidman (Ed.), College student retention: Formula for student success (pp. 155-214). Westport, CT: Praeger Publishers. 
Calcagno, J. C., Crosta, P., Bailey, T., \& Jenkins, D. (2007). Stepping stones to a degree: The impact of enrollment pathways and milestones on community college student outcomes. Research in Higher Education, 48(7), 775-801.

Calcagno, J. C., \& Long, B. T. (2008). The impact of postsecondary remediation using a regression discontinuity approach: Addressing endogenous sorting and noncompliance (No. w14194). National Bureau of Economic Research.

Carlan, P. E., \& Byxbe, F. R. (2000). Community colleges under the microscope: An analysis of performance predictors for native and transfer students. Community College Review, 28(2), 27-42.

Cauley, K. M., \& Jovanovich, D. (2006). Developing an effective transition program for students entering middle school or high school. The Clearing House: A Journal of Educational Strategies, Issues and Ideas, 80(1), 15-25.

Chemers, M. M., Hu, L. T., \& Garcia, B. F. (2001). Academic self-efficacy and first year college student performance and adjustment. Journal of Educational Psychology, 93(1), 55-64.

Chen, X. (2007). Part-time undergraduates in post-secondary education: 2003-2004 (NCES 2007-165). Washington, DC: National Center for Educational Statistics.

Chen, X., \& Carroll, C. D. (2005). First-generation students in postsecondary education: A look at their college transcripts. Postsecondary education descriptive analysis report. NCES 2005-171. National Center for Education Statistics.

Cheng, W., Ickes, W., \& Verhofstadt, L. (2012). How is family support related to students' GPA scores? A longitudinal study. Higher Education, 64(3), 399-420.

Chenoweth, E., \& Galliher, R. V. (2004). Factors influencing college aspirations of rural West Virginia high school students. Journal of research in rural education, 19(2), 1-14. 
Commission on the Future of the Advanced Placement Program. (2001). Access to excellence: A report of the commission on the future of the Advanced Placement program. New York: College Entrance Examination Board.

DeBerard, M. S., Spielmans, G., \& Julka, D. (2004). Predictors of academic achievement and retention among college freshmen: A longitudinal study. College Student Journal, 38(1), 66-80.

DesJardins, S. L., Ahlburg, D. A., \& McCall, B. P. (2002). A temporal investigation of factors related to timely degree completion. Journal of Higher Education, 555-581.

Diaz, P. E. (1992). Effects of transfer on academic performance of community college students at the four-year institution. Community/Junior College Quarterly of Research and Practice, 16(3), 279-291.

Dougherty, C., Mellor, L., \& Jian, S. (2006). The relationship between Advanced Placement and college graduation. 2005 AP Study Series, Report 1. National Center for Educational Accountability.

Ellis, J. L. (2010). Continuing the support: Programs for second-year college students. Journal of Student Affairs, 19, 51-56.

Enders, C. K. (2003). Using the expectation maximization algorithm to estimate coefficient alpha for scales with item-level missing data. Psychological methods, 8(3), 322-337.

Ewell, P. T. (2008). Assessment and accountability in America today: Background and context. New Directions for Institutional Research, 2008(S1), 7-17.

Fain, P. (2012). How to end remediation. Inside Higher Ed. Retrieved from http://www.insidehighered.com/news/2012/04/04/connecticut-legislature-mullselimination-remedial-courses. 
Flanagan, W. J. (1991). Sophomore retention: The missing strategy in small college retention efforts (Doctoral dissertation). Retrieved from ProQuest. (Order No. 9111372)

Fletcher, J. M., \& Tienda, M. (2009). High school classmates and college success. Sociology of Education, 82(4), 287-314.

Friedel, J. N., Thornton, Z. M., D’Amico, M. M., \& Katsinas, S. G. (2013). Performance-based funding: The national landscape. Retrieved from http://uaedpolicy.ua.edu/uploads/2/1/3/2/21326282/pbf_9-17_web.pdf

Geiser, S., \& Santelices, M. V. (2004). The role of advanced placement and honors courses in college admissions. In P. Gandara, G. Orfield, \& C. Horn (Eds.) Expanding opportunity in higher education: Leveraging promise (pp. 75-113). State University of New York Press: Albany.

Geiser, S., \& Santelices, M. V. (2007). Validity of high-school grades in predicting student success beyond the freshman year: High-school record vs. standardized tests as indicators of four-year college outcomes. Research \& Occasional Paper Series: CSHE. 6.07. Center for Studies in Higher Education.

Gifford, D. D., Briceno-Perriott, J., \& Mianzo, F. (2006). Locus of control: Academic achievement and retention in a sample of university first-year students. Journal of College Admission, 191, 18-25.

Goodman, K., \& Pascarella, E. (2006). First-year seminars increase persistence and retention. Peer Review, 8(3), 26-28.

Goudas, A. M, \& Boylan, H. R. (2012). Addressing flawed research in developmental education. Journal of Developmental Education, 36(1), 2-13. 
Grove, W. A., \& Wasserman, T. (2004). The life-cycle pattern of collegiate GPA: Longitudinal cohort analysis and grade inflation. The Journal of Economic Education, 35(2), 162-174.

Harackiewicz, J. M., Barron, K. E., Tauer, J. M., \& Elliot, A. J. (2002). Predicting success in college: A longitudinal study of achievement goals and ability measures as predictors of interest and performance from freshman year through graduation. Journal of Educational Psychology, 94(3), 562-575.

Heier, M. (2012). Understanding the sophomore year experience. Retrieved from: http://depts.washington.edu/stdntlfe/wpcontent/uploads/2012/02/SYE_SummaryReport_FINAL_12.18.12.pdf

Higher Education Policy Commission. (2009). West Virginia Chancellor's Diversity Initiative. Retrieved from https://www.wvhepc.org/resources/diversity/chancellor_diversity_initiative.pdf

Horn, L., Berger, R., \& Carroll, C. D. (2004). College persistence on the rise? Changes in 5-year degree completion and postsecondary persistence rates between 1994 and 2000: Postsecondary education descriptive analysis reports. NCES 2005-156. National Center for Education Statistics. Washington, DC: U.S. Government Printing Office.

Horn, L., \& Carroll, C. D. (1998). Stopouts or stayouts?: Undergraduates who leave college in their first year. DIANE Publishing.

Horn, L., Kojaku, L. K., \& Carroll, C. D. (2001). High school academic curriculum and the persistence path through college. National Center for Education Statistics.

Hossler, D., Ziskin, M., \& Gross, J. P. (2009). Getting serious about institutional performance in student retention: Research-based lessons on effective policies and practices. About Campus, 13(6), 2-11. 
Hox, J. (2010). Multilevel analysis: Techniques and applications. New York, NY: Routledge.

Hoyle, R. H. (Ed.). (2012). Handbook of structural equation modeling. Guilford Press.

Hoyt, J. E. (1999). Remedial education and student attrition. Community college review, 27(2), $51-72$

Hoyt, J. E., \& Sorensen, C. T. (2001). High school preparation, placement testing, and college remediation. Journal of Developmental Education, 25(2), 26-34.

Ishitani, T. T. (2003). A longitudinal approach to assessing attrition behavior among firstgeneration students: Time-varying effects of pre-college characteristics. Research in Higher Education, 44(4), 433-449.

Kahn, J. H., \& Nauta, M. M. (2001). Social-cognitive predictors of first-year college persistence: The importance of proximal assessment. Research in Higher Education, 42(6), 633-652.

Klopfenstein, K., \& Thomas, M. K. (2009). The link between advanced placement experience and early college success. Southern Economic Journal, 75(3), 873-891.

Kreysa, P. G. (2006). The impact of remediation on persistence of under-prepared college students. Journal of College Student Retention: Research, Theory and Practice, 8(2), 251-270.

Kuh, G. D., Cruce, T. M., Shoup, R., Kinzie, J., \& Gonyea, R. M. (2008). Unmasking the effects of student engagement on first-year college grades and persistence. The Journal of Higher Education, 79(5), 540-563.

Lesik, S. A. (2006). Applying the regression-discontinuity design to infer causality with nonrandom assignment. The Review of Higher Education, 30(1), 1-19. 
Lord, V. B., Bjerregaard, B., \& Hartman, J. L. (2013). Evaluating the graduation gap:

Interventions designed to enhance upper-level student success and commitment. Journal of Criminal Justice Education, 24(2), 153.

Martin, A. J., Wilson, R., Liem, G., \& Ginns, P. (2013). Academic momentum at university/college: Exploring the roles of prior learning, life experience, and ongoing performance in academic achievement across time. The Journal of Higher Education, 84(5), 640-674.

McCormick, A. C., \& Carroll, C. D. (1999). Credit production and progress toward the bachelor's degree: An analysis of postsecondary transcripts for beginning students at 4year institutions. DIANE Publishing.

McKenzie, K., \& Gow, K. (2004). Exploring the first year academic achievement of school leavers and mature-age students through structural equation modelling. Learning and Individual Differences, 14(2), 107-123.

Merisotis, J. P., \& Phipps, R. A. (2000). Remedial education in colleges and universities: What's really going on? The Review of Higher Education, 24(1), 67-85.

Mortenson, T. G. (2005). Measuring persistence. In A. Seidman (Ed.), College student retention: Formula for student success (pp. 31-60). Westport, CT: Praeger Publishers.

Murtaugh, P. A., Burns, L. D., \& Schuster, J. (1999). Predicting the retention of university students. Research in Higher Education, 40(3), 355-371.

National Center for Education Statistics. (2012). Digest of Education Statistics. Retrieved from: http://www.nces.ed.gov/programs/digest/

National Center for Education Statistics. (2013). IPED Data Center. Retrieved from http://nces.ed.gov/ipeds/datacenter/. 
National Resource Center for the First-Year Experience and Students in Transition. (2008). 2008 National survey of sophomore-year initiatives. Columbia: University of South Carolina.

Noble, J., \& Sawyer, R. (2002). Predicting different levels of academic success in college using high school GPA and ACT composite score. ACT Research Report Series.

Nora, A., Barlow, E., \& Crisp, G. (2005). Student persistent and degree attainment beyond the first year in college: The need for research. In A. Seidman (Ed.), College student retention: Formula for student success (pp. 129-153). Westport, CT: Praeger Publishers.

Nora, A., \& Cabrera, A. F. (1996). The role of perceptions of prejudice and discrimination on the adjustment of minority students to college. The Journal of Higher Education, 67(2), 119148.

Oblinger, D. (2003). Boomers, gen-xers, and millennials: Understanding the "new students." EDUCASE Review, 38(4), 36-40, 42, 44-45.

O'Connell, A. A., \& McCoach, D. B. (2008). Multilevel modeling of educational data. Information Age Publishing.

Offenstein, J., Moore, C., \& Shulock, N. (2010). Advancing by degrees: A Framework for increasing college completion. Institute for Higher Education Leadership \& Policy.

O'Toole, D. M., Stratton, L. S., \& Wetzel, J. N. (2003). A longitudinal analysis of the frequency of part-time enrollment and the persistence of students who enroll part time. Research in Higher Education, 44(5), 519-537.

Parsad, B., \& Lewis, L. (2003). Remedial Education at Degree-Granting Postsecondary Institutions in Fall 2000. Statistical Analysis Report. National Center for Education Statistics. 
Pascarella, E.T, \& Terenzini, P.T. (2005). A third decade of research. Vol 2 of how college affects students. San Francisco: Jossey-Bass.

Radford, A.W., Berkner, L., Wheeless, S.C., \& Shepherd, B. (2010). Persistence and Attainment of 2003-04 Beginning Postsecondary Students: After six Years (NCES 2011-151). U.S. Department of Education. Washington, DC: National Center for Education Statistics. Retrieved [8/22/2014] from http://nces.ed.gov/pubsearch

Reardon, S., Baker, R., \& Klasik, D. (2012). Race, income, and enrollment patterns in highly selective colleges, 1982-2004. Center for Education Policy Analysis, Stanford University. Retrieved from http://cepa.stanford.edu/content/race-income-and-enrollmentpatternshighly-selective-colleges-1982-2004.

Reason, R. (2009). Student variables that predict retention: Recent research and new developments. NASPA Journal, 46(3), 482-501.

Ross, T., Kena, G., Rathbun, A., KewalRamani, A., Zhang, J., Kristapovich, P., \& Manning, E. (2012). Higher education: Gaps in access and persistence study (NCES 2012-046). U.S. Department of Education, National Center for Education Statistics. Washington, DC: Government Printing Office.

Sadler, P. M., \& Tai, R. H. (2007). Advanced placement exam scores as a predictor of performance in introductory college biology, chemistry and physics courses. Science Educator, 16(2), 1-19.

Satisfactory Academic Progress Policy, 34 C.F.R. § 668.34 (2009).

Seidman, A. (Ed.). (2005). College student retention: Formula for student success. Greenwood Publishing Group. 
Singer, J. D., \& Willett, J. B. (2003). Applied longitudinal data analysis: Modeling change and event occurrence. Oxford university press.

Spann, M. G., \& McCrimmon, S. (1993). Remedial/developmental education: Past, present, and future. In G. A. Baker, J. Dudziak, \& P. Tyler (Eds.), A handbook on the community college in America (pp-pp). Westport: Greenwood Press.

Spybrook, J. (2008). Power, sample size, and design. In A. A. O’Connell and D.B. McCoach (Eds.), Multilevel modeling of educational data (pp. 273-311). Information Age Publishing.

Stillwell, R., \& Sable, J. (2013). Public School Graduates and Dropouts from the Common Core of Data: School Year 2009-10: First Look (Provisional Data)(NCES2013-309rev). U. S. Department of Education. Washington, DC: National Center for Education Statistics. Retrieved from http://nces.ed.gov/pubsearch

Stinebrickner, T. R., \& Stinebrickner, R. (2009). Learning about academic ability and the college drop-out decision (No. w14810). National Bureau of Economic Research.

Tinto, V. (1975). Dropout from higher education: A theoretical synthesis of recent research. Review of Educational Research, 45(1), 89-125.

Tinto, V. (1996). Reconstructing the first year of college. Planning for Higher Education, 25(1), $1-6$.

Tinto, V. (1999). Taking retention seriously: Rethinking the first year of college. NACADA Journal, 19(2), 5-9.

Tumen, S., Shulruf, B., \& Hattie, J. (2008). Student pathways at the university: Patterns and predictors of completion. Studies in Higher Education, 33(3), 233-252. 
U. S. Department of Education (2009). Obama Administration announces streamlined college aid application. Improvements aimed at increasing college access for low- and middleincome students [Press release]. Retrieved from http://www.ed.gov/news/pressreleases/obama-administration-announces-streamlined-college-aid-application.

U.S. Census Bureau. (2012). Educational attainment. Available at: http://www.census.gov/hhes/socdemo/education/

U.S. Census Bureau. (2013). State \& county quick facts. Retrieved from: http://quickfacts.census.gov/qfd/states/

U.S. Department of Education, National Center for Education Statistics. (2014). The condition of education 2014 (NCES 2014-083), Immediate Transition to College. Retrieved from: http://nces.ed.gov/pubs2014/2014083.pdf

Widaman, K. F. (2006). III. Missing data: What to do with or without them. Monographs of the Society for Research in Child Development, 71(3), 42-64.

Wintre, M., \& Bowers, C. (2007). Predictors of persistence to graduation: Extending a model and data on the transition to university model. Canadian Journal of Behavioural Science, $39(3), 220-234$.

Yin, R. K. (2003). Case study research: Design and methods (3rd ed.). Thousand Oaks, CA: Sage Publications.

Zwick, R., \& Sklar, J. C. (2005). Predicting college grades and degree completion using high school grades and SAT scores: The role of student ethnicity and first language. American Educational Research Journal, 42(3), 439-464. 


\section{Appendix A \\ IRB Letters of Approval}

\section{Concord University \\ Human Subjects Review Board Non-Human Subject Research Letter \& Checklist}

To: Zornitsa Georgieva

(principal investigator)

(additional investigators)

Project Title: Using Growth Curve Modeling to Describe Differential Patterns of Change in College Level Student Achievement across Five Years Based on Degree Attainment and Mathematics Remediation

Project Number: $\underline{\mathrm{S} 15-18}$

Your proposed activity is being returned because it was determined that it is not "human subject research" by DHHS and FDA Regulatory definition and, therefore, does not need to be evaluated by the Human Subjects Review Board.

You may wish to review the definitions below that were used in making this determination. Your proposed activity does not meet the criterion indicated below:

A. Research means a systematic investigation designed to develop or contribute to generalizable knowledge. Most case reports and most oral histories are not generalizable and, therefore, not research. Many classroom projects, if not intended to be published, are also not considered research. Many quality improvement or program evaluation studies are not research.

B. Human Subjects. According to federal definitions, a human subject is a living individual. If the research does not include living individuals, the project is not human subject research and should not be submitted for evaluation.

$\underline{\mathbf{X}}$ C. In order to be considered human subject research, individually identifiable private information must be obtained or used in the research. If there is no individually identifiable private information involved, the project is not human subject research and does not require being submitted to the Human Subjects Review Board. Private information must be individually identifiable (i.e., the identity of the subject is or may be readily ascertained by the investigator or someone else associated with the information) in order to constitute research involving human subjects.

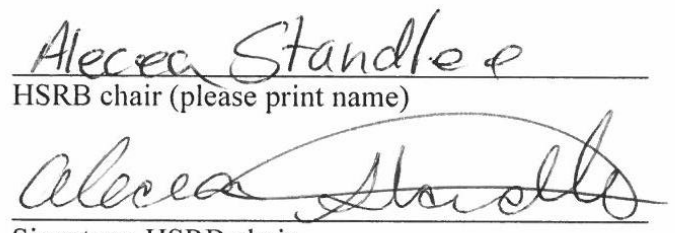

Signature, HSRB chair

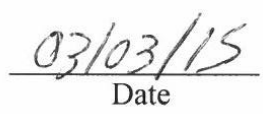


Id: 206337

From: admin

Recipients: recurtis , zgeorgie

Channel: KC Notification Chann

Type: FYI

Priority: Normal

Send Date: 2015-03-24T11:07:54.000-04:00

Removal Date: none

Title: IRB Protocol Notice: Review Not Required for Protocol 1503628697

Content:

IRB protocol number: 1503628697

Title: Using Growth Curve Modeling to Describe Differential Patterns of Change in College Level Student Academic Achievement across Four Years Based on Degree Attainment and

Mathematics Remediation

PI: Reagan Curtis

The West Virginia University Institutional Review Board reviewed the above-referenced protocol on 24-Mar-2015 and determined that it does not meet the definition of human subject research. To access this protocol, click on the protocol number link provided. Your approval letter can be found in the History subsection of the Summary a History section located on the Protocol Actions page. For more information, see the Viewing Correspondence quick reference guide. Any future protocol action requests can be completed through the WVU+kc

Questions related to NHSR protocols should be directed to Lilo Ast at 304.293.7555 or lilo.ast@mail.wvu.edu. 
Appendix B

Examination of the Normality Assumption: Normal Q-Q Plots. Figure illustrates the patters in the distributions of GPA for semesters 1 through 8
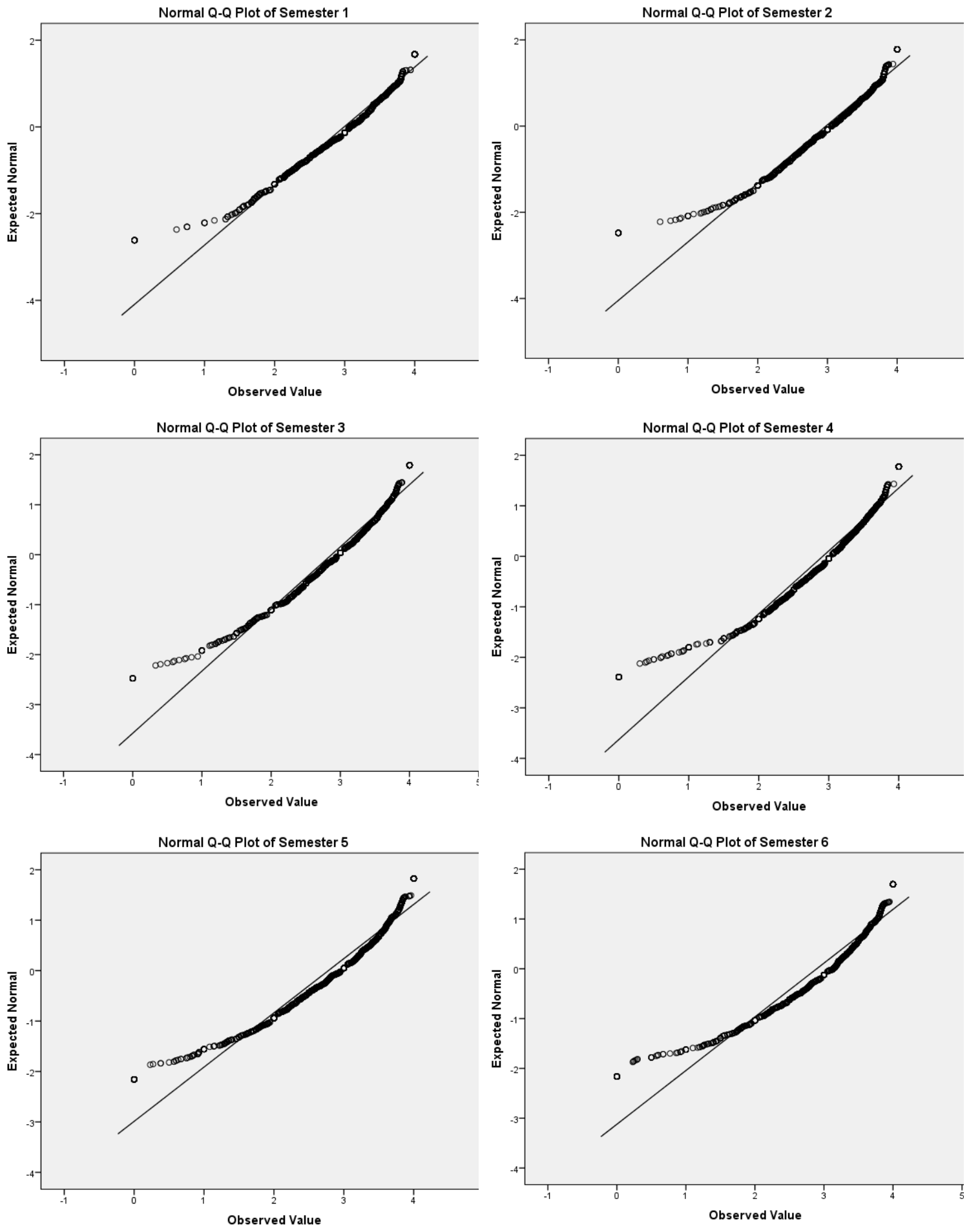
121
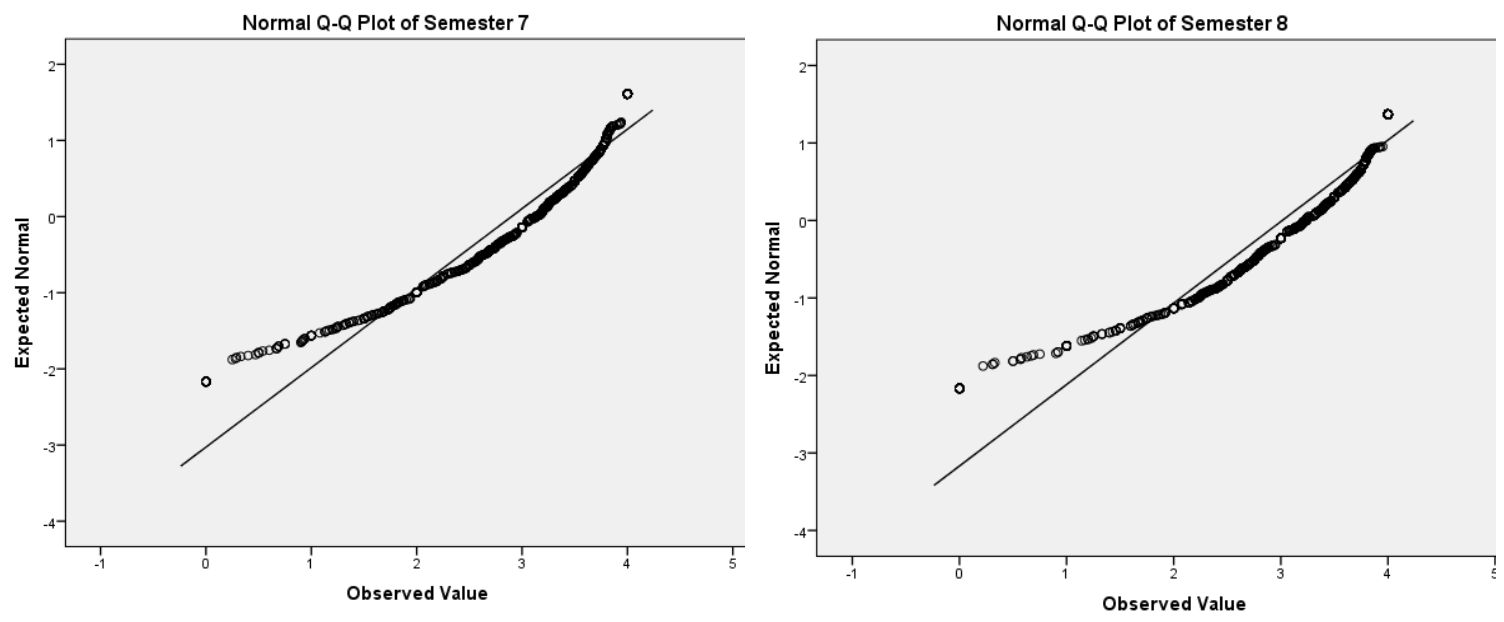


\section{Appendix C}

Examination of the Homoscedasticity Assumption: Standardizes Residuals versus Standardized Fit Values Plots. Figure illustrates the patters in homoscedasticity for semesters 1 through 8
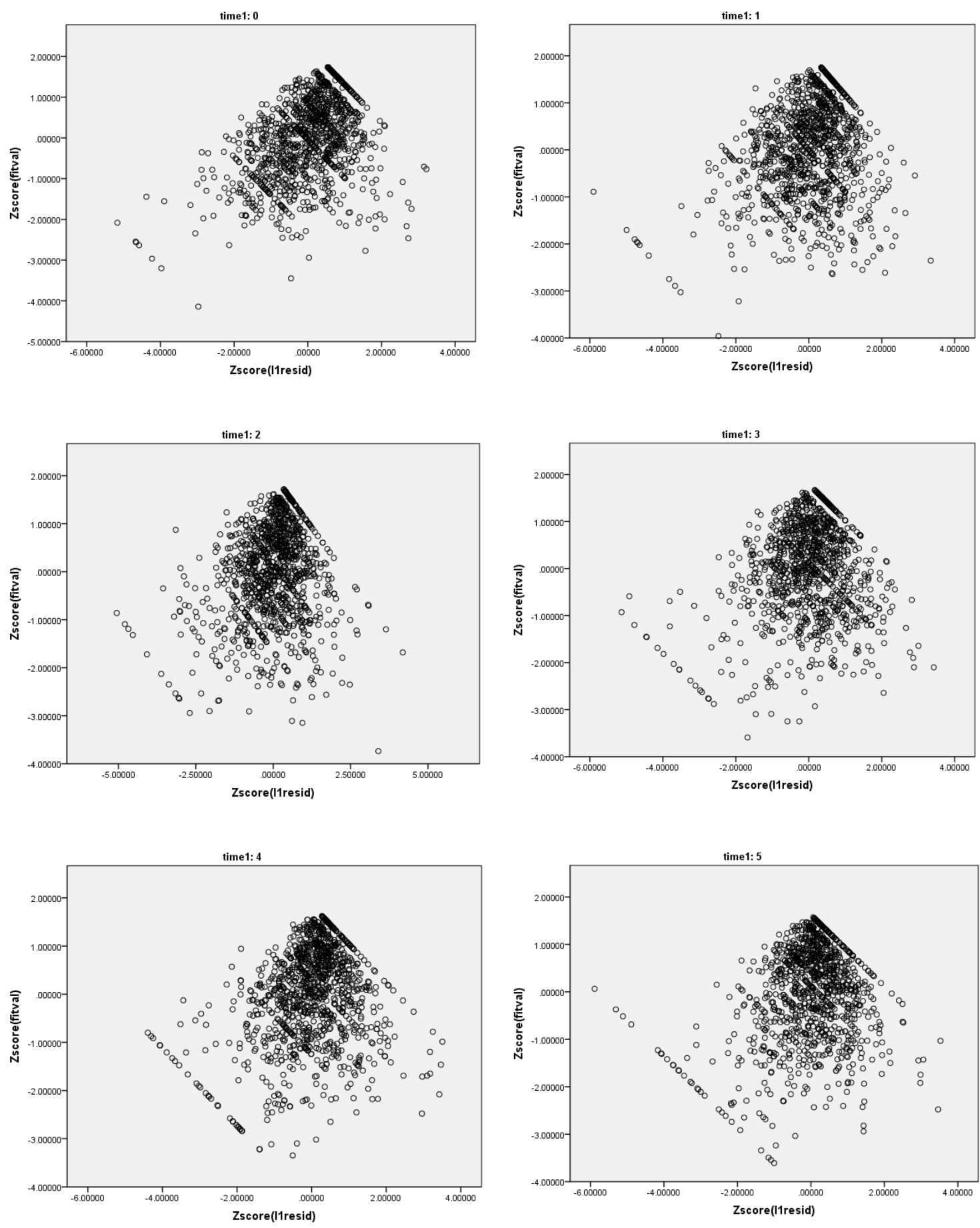

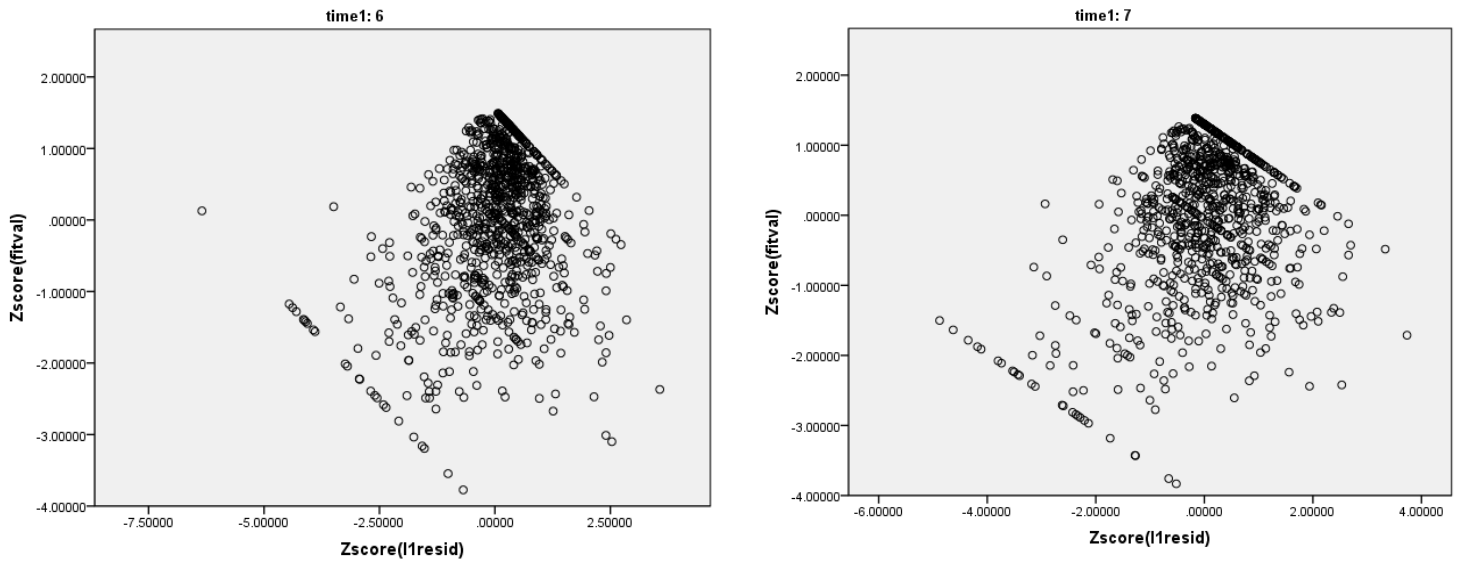